BNWL-1261 UC-25

3 .

3.70

\title{
MARK I \\ PROTOTYPIC FTR FUEL ELEMENT \\ SUBASSEMBLY SODIUM FLOW TEST
}

March 1970

\section{AEC RESEARCH \& DEVELOPMENT REPORT}

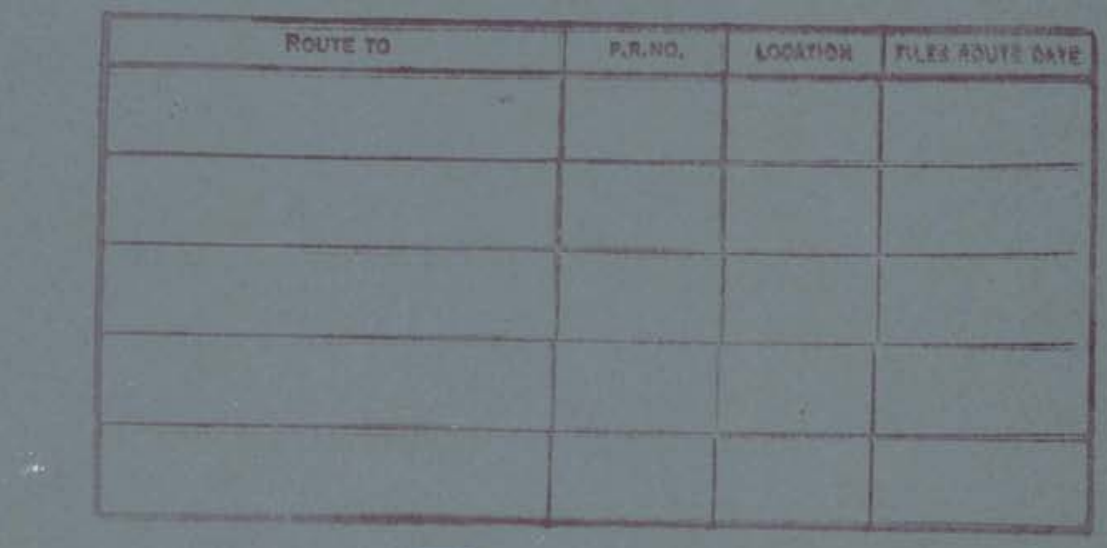

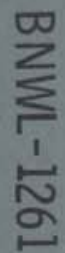




\section{LEGAL NOTICE}

This report was prepared as an occount of Government sponsored work. Neither the United States, nor the Commission, nor any person acting on behalf of the Commission:

A. Makes any warranty or representation, expressed or implied, with respect to the accuracy, completeness, or usefulness of the information contained in this report, or that the use of any information, apparatus, method, or process disclosed in this report may not infringe privately owned rights; or

B. Assumes any liabilities with respect to the use of, or for damages resulting from the use of any information, apparatus, method, or process disclosed in this report.

As used in the above, "person acting on behalf of the Cammission" includes any employee or contractor of the Commission, or employee of such contractor, to the extent that such employee or conrractor of the Commission, or employee of such contractor prepares, disseminates, or provides access to, any information pursuant to his employment or controct with the Commission, or his employment with such contractor.

\section{PACIFIC NORTHWEST LABORATORY}

RICHLAND, WASHINGTON

operated by

BATTELLE MEMORIAL INSTITUTE

for the

UNITED STATES ATOMIC ENERGY COMMISSION UNDER CONTRACT AT(45-1)-1830 
UC- 25 , Meta1s, Ceramics, and Materials

\section{MARK I \\ PROTOTYPIC FTR FUEL ELEMENT \\ SUBASSEMBLY SODIUM FLOW TEST}

by

M. K. Millhollen, T. J. Bennett

and R. L. Myers

FFTF Fuels Division

FFTF Project

March 1970

70

BATTELLE MEMORIAL INSTITUTE

PACIFIC NORTHWEST LABORATORIES

RICHLAND，WASHINGTON 99352 
BNWL -1261

Printed in the United States of America Available from

Clearinghouse for Federal Scientific and Technical Information National Bureau of Standards, U.S. Department of Commerce Springfield, Virginia 22151

Price: Printed Copy $\$ 3.00 ;$ Microfiche $\$ 0.65$ 


\author{
MARK I \\ PROTOTYPIC FTR FUEL ELEMENT \\ SUBASSEMBLY SODIUM FLOW TEST \\ M. K. Millhollen, T. J. Bennett \\ and R. L. Myers
}

\title{
ABSTRACT
}

A Mark I prototypic FTR fuel element subassembly was tested in flowing $1060^{\circ} \mathrm{F}$ sodium in the Core Components Test Loop (CCTL) at Argonne National Laboratory. The subassembly comprised 217, 0.250-in. diameter by 71-in. long fuel pins, assembled into a hexagonal array on a bottom grid arrangement and contained within a hexagonal flow duct. The flow duct shape changed from hexagonal to round above the fuel section of the pins. Individual pins were wire wrapped on a 12-in. pitch with $0.030-i n$. diameter wire, which provided constant pin spacing in the bundle. Cladding, wire wrap and flow duct were fabricated from Type 304 SS.

The subassembly was under flow test in the CCTL for $5067 \mathrm{hr}, 3687$ of which were at full sodium flow (400 gal/min) and isothermal temperature $\left(1060^{\circ} \mathrm{F}\right)$ conditions. Sodium chemistry was checked frequently to ensure that the oxygen content of the coolant did not exceed $10 \mathrm{ppm}$ and that the carbon content did not exceed $20 \mathrm{ppm}$. When the subassembly was finally removed from the test 100 , it was immersed in Dowanol-EB and then in alcohol to remove residual sodium.

No significant surface corrosion was observed on the wire wrap, cladding or flow duct. Dimensions of the fuel pins did not change appreciably, but all wire wraps loosened, some as much as 0.006 inch. There was no evidence of vibration-induced damage to neighboring cladding by the loose wire wrap, but there was slight flattening (up to 0.002 in.) of wires in the rows adjacent to the flow duct. 


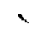




\section{CONTENTS}

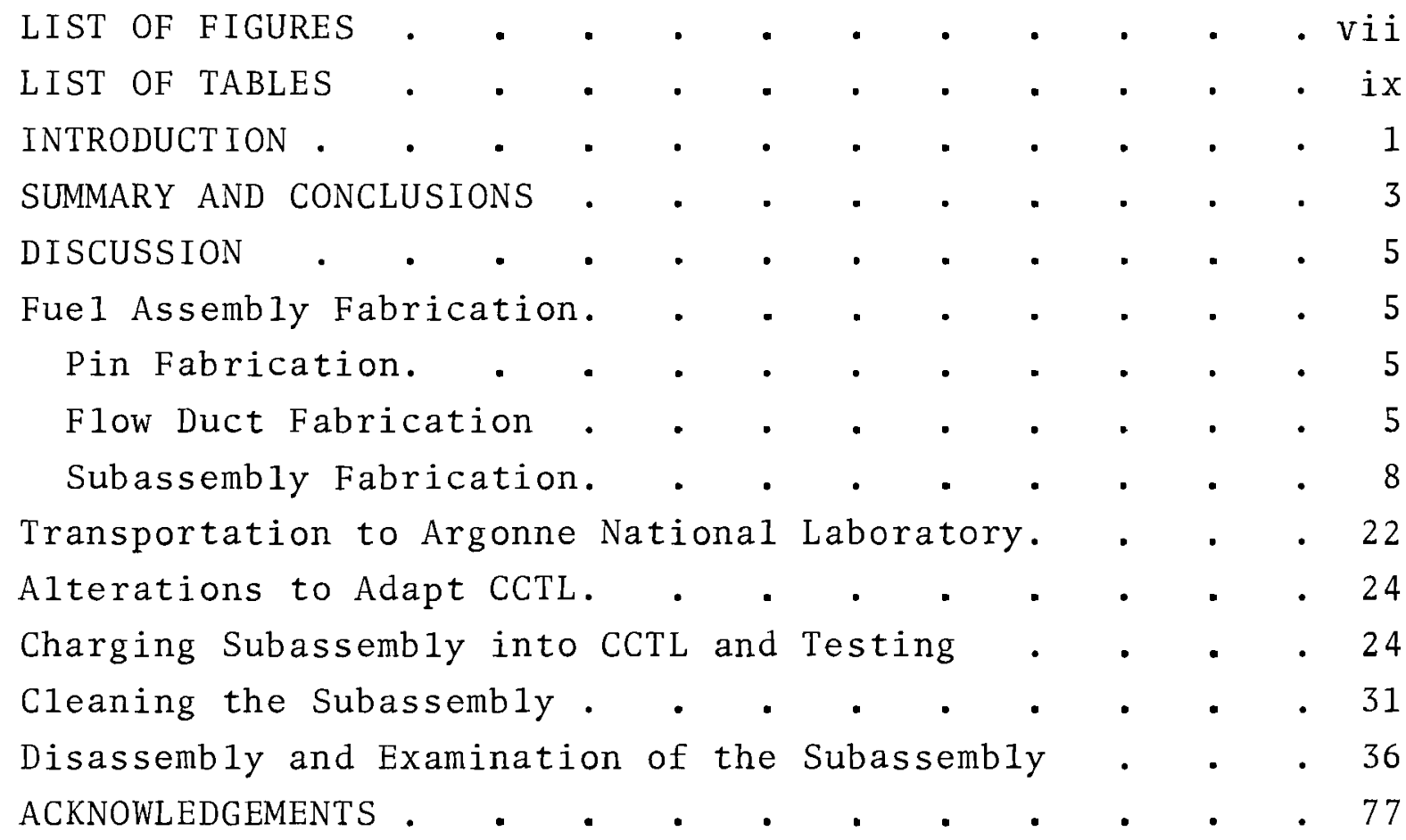


$+$ 


\section{FIGURES}

1 Pinning Fuel Pins to Grid Strip 9

2 Welding Grid Strip Pins to Fue1 Pin End Caps 10

3 Welding Grid Strip to Grid Plate 11

4 Pin Bundle Partially Assembled 12

5 Details of Strip Layers and Grid Strips Partially Assembled Cluster

6 Bottom of Assembly Before Last Strip Layer Was Welded In

7 Top Spacer Fitting in Place 15

8 Flow Duct in Place and Welded to Pin Bundle 16

9 Reflector Pin Bundle 19

10 Reflector Bundle Welded in Bottom End of F1ow Duct 20

11 Mark I Subassembly in Inner Shipping Container 23

12 FFTF Mark I Subassembly Prior to Installation in the CCTL 25

13 Startup Pressure Loss Versus CCTL Sodium F1ow Rate 27

14 Removal of FFTF Mark I Subassembly from the CCTL 30

15 Sodium Buildup on Guide Ring 32

16 Mark I Subassembly During Transfer from CCTL to Deep Pit 33

17 Mark I Subassembly Being Lowered into Deep Pit for Cleaning

18 Mark I Subassembly After Interior Cleaning 35

19 Lower Guide Ring Section of Duct After Exterior Cleaning 37

20 Pin Bundle and Duct Interior After Cleaning 38

21 Reflector Bundle and Duct Interior After Cleaning 39

22 Sodium Exposed Support Cable After Tension Test of $100 \mathrm{lb} \quad 40$

23 Crated Subassembly Prior to Shipment 41

24 Reflector Pin Bundle After Test 42

25 We1ds Ground Away to Remove Locking Bars 44

26 Tested Pin Bundle with Flow Duct Removed 45

27 Flow Duct Interior After Test 46

28 Flow Duct Showing Location of Cut-Out Section 51 
BNWL -1261

29 One Flat from Cut-Out Section of Duct Showing Internal Surface

30 Section of Hexagonal Duct with One Flat Removed 52

31 Top Grid Plate After Removal from Pin Bundle 54

32 Bottom View of Top Grid Plate After Removal from Pin Bundle

33 Bottom Locking Grid After Test 56

34 Pin Bundle with First Strip Layer Removed 57

35 First Pin Layer Removed - Bottom End Cap Region 58

36 First Pin Layer Removed - Central Region 59

37 First Pin Layer Removed - Top End Cap Region 60

38 Bundle Cross Section Showing Pin Numbers 62

39 Wire Wrap Slack 63

40 Curve for Wire Wrap Looseness Versus Gap 64

41 Section of Type 304 SS Tubing Archive Sample 67

42 Enlarged Section at OD of Type 304 SS Tubing Archive Sample

43 Section of 0.030 Diameter, Type 304 SS Wire Archive Sample

44 Type 304 SS Wire Wrap Archive Sample Enlarged 68

45 Higher Magnification of Type 304 SS Wire Wrap Archive Sample

46 Transverse Tubing Section from Plenum Region of Fue 1 Pin 9

47 Enlargement at $O D$ of Tube Section from Pin 9 Plenum Region

48 Transverse Tubing Section from Fueled Region of Fue 1 Pin 9

49 Enlargement at Tube OD from Fueled Region of Pin $9 \quad 70$

50 Transverse Section of Type 304 SS Wire Wrap After Test

51 Enlargement of Section of Type 304 SS Wire Wrap After Test

52 Transverse Tubing Section from Pin 51 Fuel Region 72

53 Enlargement of Tube Section from Pin 51 Fue1 Region 72

54 Transverse Tubing Section from Pin 51 Plenum Region 73

55 Enlargement of Tube Section from Pin 51 Plenum Region 73 
56 Transverse Tubing Section from Pin 110 Fue1 Region

57 Enlargement of Tubing Section from Pin 110 Fue 1 Region

58 Burst Specimen of Mark I FTR Fuel Pin Cladding 75

\section{TABLES}

1 Cold Trap Data 28

2 Duct Diametral Measurements - Hex End 48

3 Duct Diametral Measurements - Round End 49

4 Wa11 Thickness at Each End of Duct 49

5 Bow, Drop, and Twist in Duct 50

6 Bundle Cross-Flat Measurements 53

7 Pin Diameters 61

8 Wire Wrap Looseness 65

9 Pin Bow 65

10 Wire Wrap Tensile Test 66 
BNWL-1261

MARK I PROTOTYPIC FTR FUEL ELEMENT SUBASSEMBLY SODIUM FLOW TEST INTRODUCTION

The purpose of this test was to evaluate the exposure of a prototypic FFTF fuel pin subassembly to high velocity, high temperature sodium for a period of time approaching a normal in-reactor life span of a fuel subassembly. Specifically, it was decided to look for corrosion, erosion, and vibration damage to fuel pin, wire wrap, and flow duct surfaces. An added purpose was to evaluate a proposed method for removing trapped sodium from the subassembly after discharge from the loop.

During initial FFTF fuel element subassembly development, it became apparent that it would be advantageous to the design staff to conduct a long-term sodium flow test on a "near prototype" design. At that time (CY-1967), the candidate design selected for the split-core reactor concept was a 217-pin assembly of 0.250 in. diameter fue 1 pins, spaced by $0.030 \mathrm{in}$. diameter wire wrapped on a $12 \mathrm{in.} \mathrm{pitch.} \mathrm{The} \mathrm{fue} 1$ pins had an overall length of 71 in., and Type 304 SS was chosen as the cladding and wire wrap material. A Type 304 SS flow duct was used to house the hexagonal array of 217 pins. The flow duct was hexagonal in shape along the fuel bearing portion of the pin assembly and circular in the fue 1 pin plenum section.

No sodium flow test facility approaching the required size was either available or under construction at BattelleNorthwest (BNW). A canvass of vacant existing facilities in the country showed that no desirable flow loop was immediately available. The most likely candidate was a partially completed facility at Argonne National Laboratory, the Core Component Test Loop (CCTL). This loop was sufficiently large, both in physical dimensions and pump capacity, to test an FFTF element, and only a relatively minor amount of work was needed to complete it. After negotiations with AEC/DRDT 
and ANL, work was restarted to complete the facility. Concurrently, modifications were included to allow the FFTF fue 1 element subassembly to be installed at a slight angle to vertical, a feature of the split-core FTR concept. Work on the facility was completed during the first half of CY-1968. The completed fuel element subassembly was then installed. The subassembly was hot sodium flow tested in the CCTL intermittently for a total period of $5067 \mathrm{hr}, 3687$ of which were at full flow ( $400 \mathrm{gal} / \mathrm{min})$ and maximum temperature $\left(1060^{\circ} \mathrm{F}\right)$. Pressure drop across the subassembly at ful1 flow and maximum temperature conditions was 45 psi. 


\section{SUMMARY AND CONCLUSIONS}

A careful, visual post-test examination of the disassembled fuel pin bundle and the flow duct showed insignificant surface erosion or corrosion. It showed no evidence of significant change in fuel pin dimensions, and only extremely minor changes were observed in flow duct dimensions. Visible "rub" marks on fuel pins produced by movement of pins against adjacent wires, and on flow duct surfaces produced by movement of wire wrapped pins against the surfaces, were so slight as to be unmeasurable.

The major change found was that the 0.030 in. diameter wire, wrapped on the pins under a tension of approximately $10,000 \mathrm{psi}$, had relaxed appreciably and all wires were loose. There was no evidence, however, that wire looseness caused any wear or fretting or, in any other way, affected the normal behavior of the subassembly. It is, of course, impossible to ascertain when, during the period of the test, the wires became loose. There was evidence that wires contacting the sides of the flow duct were flattened as much as 0.002 in. at the points of contact, but no wires were broken.

The cleaning technique, used to remove residual sodium from the fuel pins and flow duct, worked satisfactorily because no sodium apparently remained in the subassembly when it was disassembled. It was interesting to note, however, that by the time the subassembly was disassembled at BNW (a matter of days after cleaning) all of the pin surfaces were either smoky gray or brown. Such colors could indicate that a small residual film had not been removed from the metal. 
Conclusions drawn from the results of this flow test are:

- With careful control of oxygen and carbon, sodium does not cause appreciable corrosion of Type 304 SS within the time, temperature, and flow velocity limits of this test.

- That prestressed wire wraps (as these were), exposed to the temperature and flow conditions imposed, will stretch beyond their elastic limit, but the subsequent wire looseness does not cause measurable fretting damage.

- That the general design of the prototypic FFTF fuel element subassembly is workable.

It should be noted, further, that the angular position of the subassembly apparently did not impose any penalties as expressed by either vibration or corrosion damage. The flow duct designed for this subassembly showed minute dimensional changes (which did not affect the test), but was generally satisfactory. 


\section{FUEL ASSEMBLY FABRICATION}

\section{Pin Fabrication}

The fue1 pin for the Mark I CCTL subassembly is delineated by Drawing SK-3-13187. Since this was an out-of-reactor test, depleted, pressed, and sintered $\mathrm{UO}_{2}$ pellets were substituted for both insulator pellets and the $\mathrm{UO}_{2}-\mathrm{PuO}_{2}$ fuel pellets. The depleted $\mathrm{UO}_{2}$ closely approximated the mass of the $\mathrm{UO}_{2}-\mathrm{PuO}_{2}$ fuel column. Standard fuel pin fabrication techniques were used in the fuel pin assembly process. Typically, a lower end cap was TIG welded to a length of prepared tubing; 33 in. of depleted $\mathrm{UO}_{2}$ pellets were loaded into the tube, followed by a 6 in. stainless steel rod (as a substitute for nickel reflector), a spring, and then a plenum tube. The top end cap, properly oriented dianetrally, was set in place by forcing dow on the plenum tube and conpressing the spring forcing down on the plenum tube and conpressing the spring. The top end cap was TIG welded in place, with welds radiographed to assure complete closure.

The completed fuel pin was placed in a special wire wrap apparatus, and the wire was attached under a tensile load of $7 \mathrm{lb}(10,000 \mathrm{psi})$. The wire was first attached to the top end cap by a TIG weld and was finally fastened to the bottom end cap in the same manner. The wire was wrapped on a 12 -in. pitch.

Flow Duct Fabrication

The flow duct for the CCTL subassembly is described in Drawing SK-3-13157. The rather difficult transition from round to hexagonal required development work on the part of the fabricators, but acceptable units were delivered in time to be used for the test. 


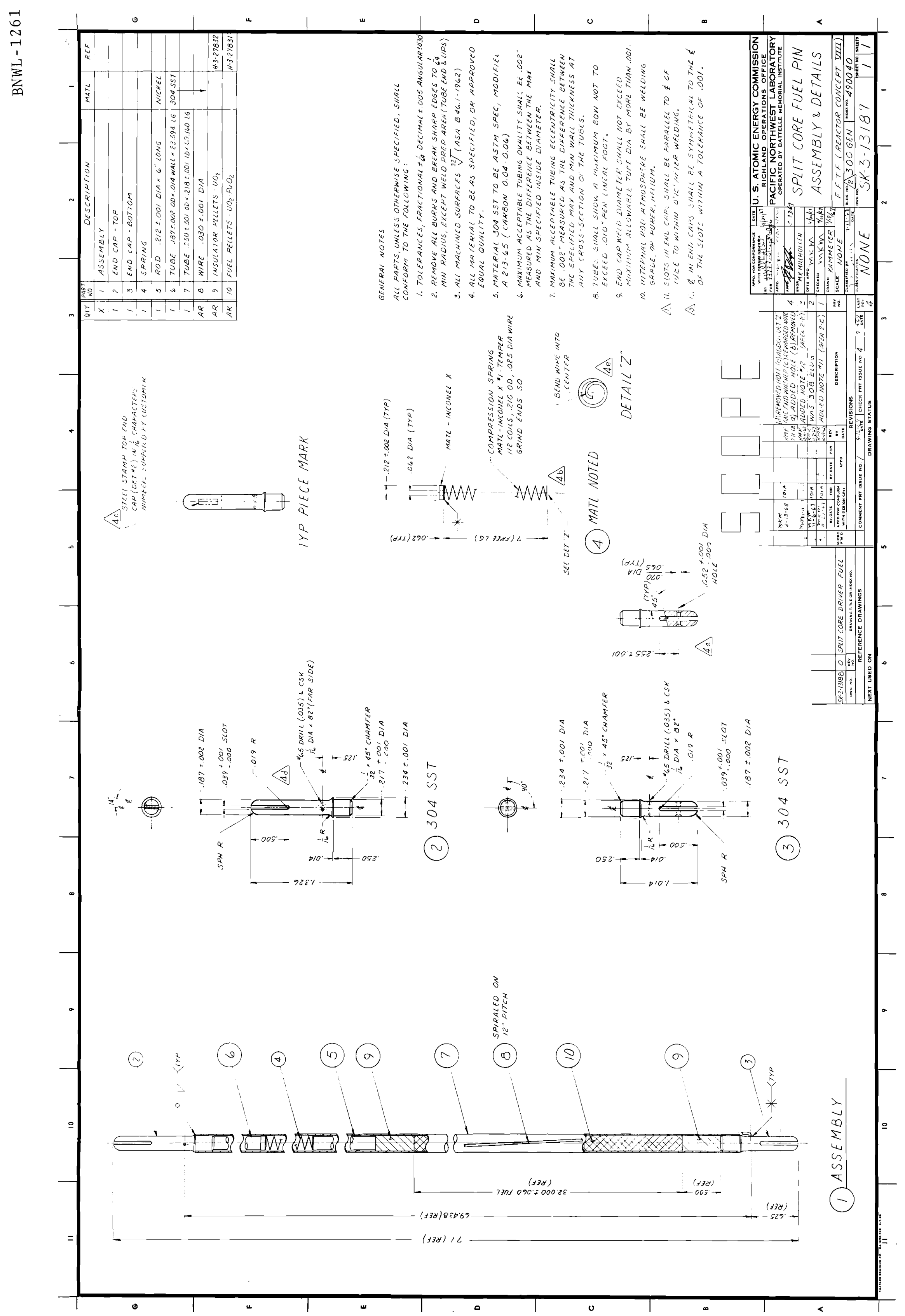




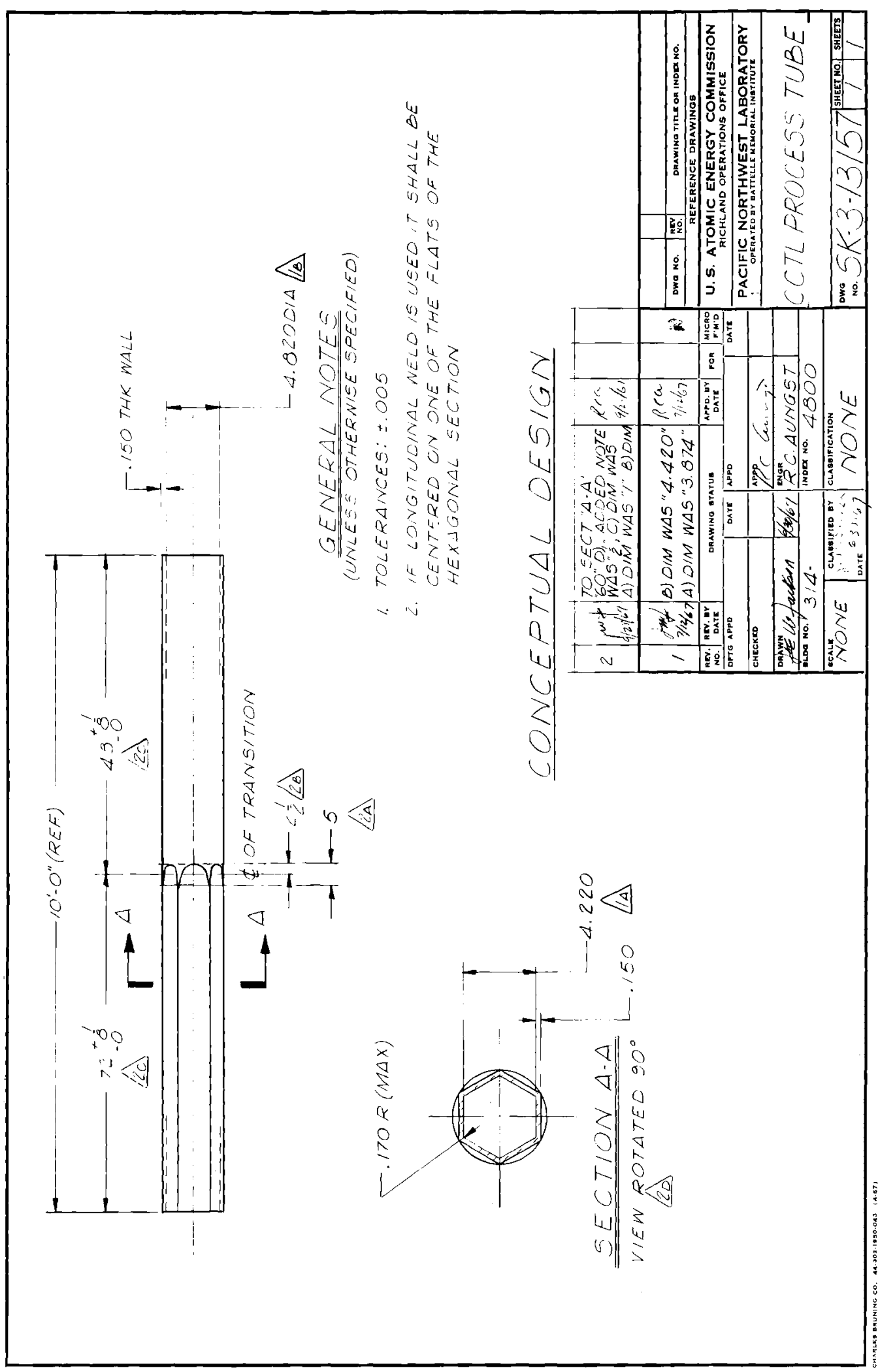


BNWL -1261

Subassembly Fabrication

The completed fuel pins were preassembled into strip 1ayers (Figures 1 and 2) by pinning and then welding the bottom end caps to the grid strips. The strip layers comprised of varied numbers of pins, depending on their subassembly position, were individually welded to a bottom grid plate (Figure 3) which built up the hexagonal array (Figures 4, 5, and 6). Strips of pins were held in position in an assembly fixture during the welding operation. After all pin layers were welded in place, the top spacer fitting was placed in the slots in the top end caps and welded to three pins (Figure 7). The flow duct was lowered down over the pin bundle and fastened to the bottom grid plate by three locking bars that penetrated opposite walls of the flow duct and slots in the grid plate. The bars were TIG welded to the flow duct walls (Figure 8). Details of the assembly are shown in Drawing SK-3-13188 (Sheets 1 and 2).

The flow duct with pin bundle in place was moved to a horizontal position where a short 37-pin cluster of reflector pins was fastened into the duct below the fuel pin bundle, (Figures 9 and 10). Plans originally called for fastening the reflector bundle to the bottom grid arrangement of the fuel pin bundle, but it was decided to fix the reflector only to the flow duct by two locking bars which penetrated and were welded to opposite walls of the flow duct, as shown in the Work Sheet (Lower Reflector Assembly and Details for CCTL) on page 21 . 
BNWL - 126

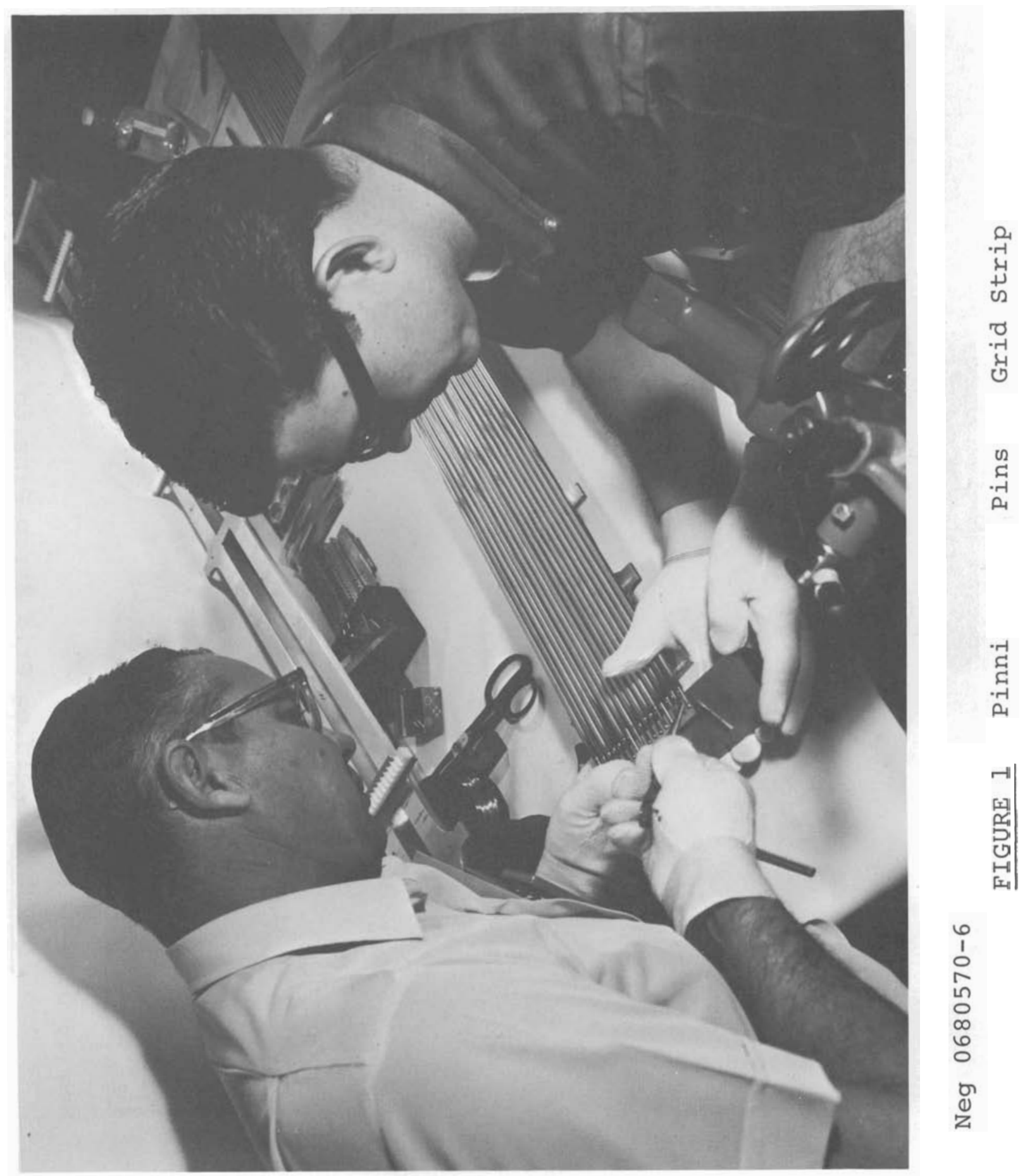


BNWL - 1261

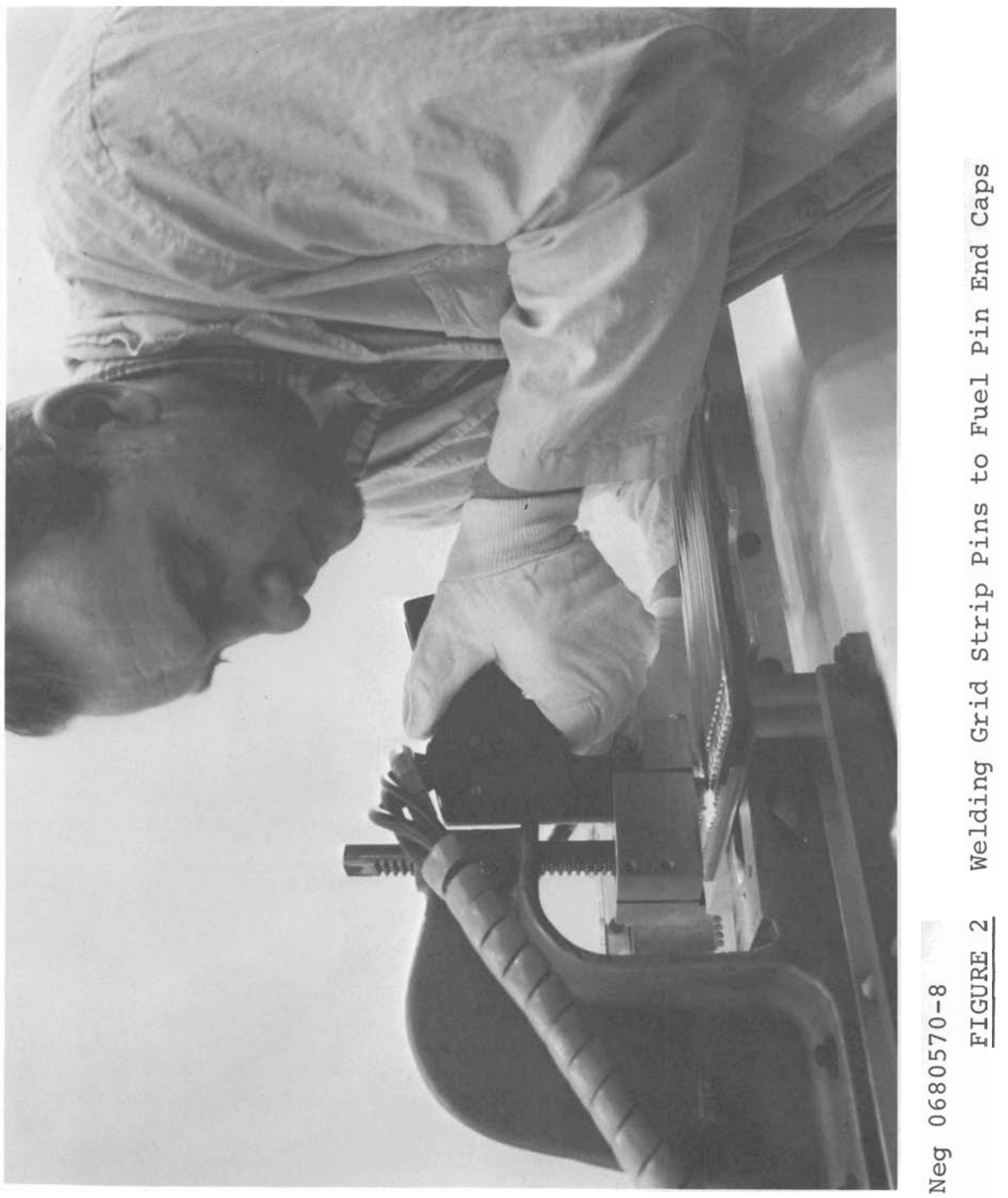


BNWL - 1261

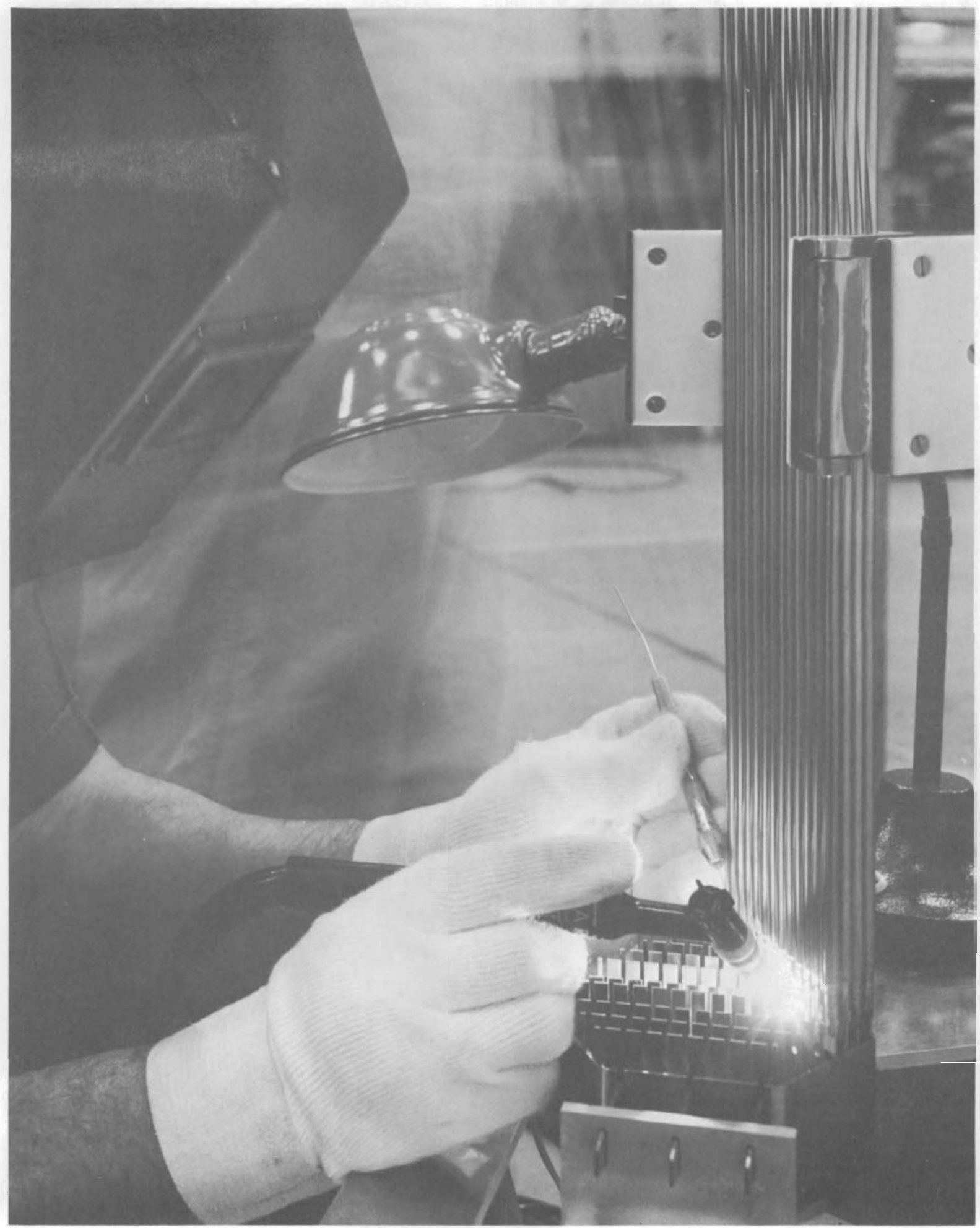

Neg 0680570-1

FIGURE 3 . Welding Grid Strip to Grid Plate 
BNWL -1261

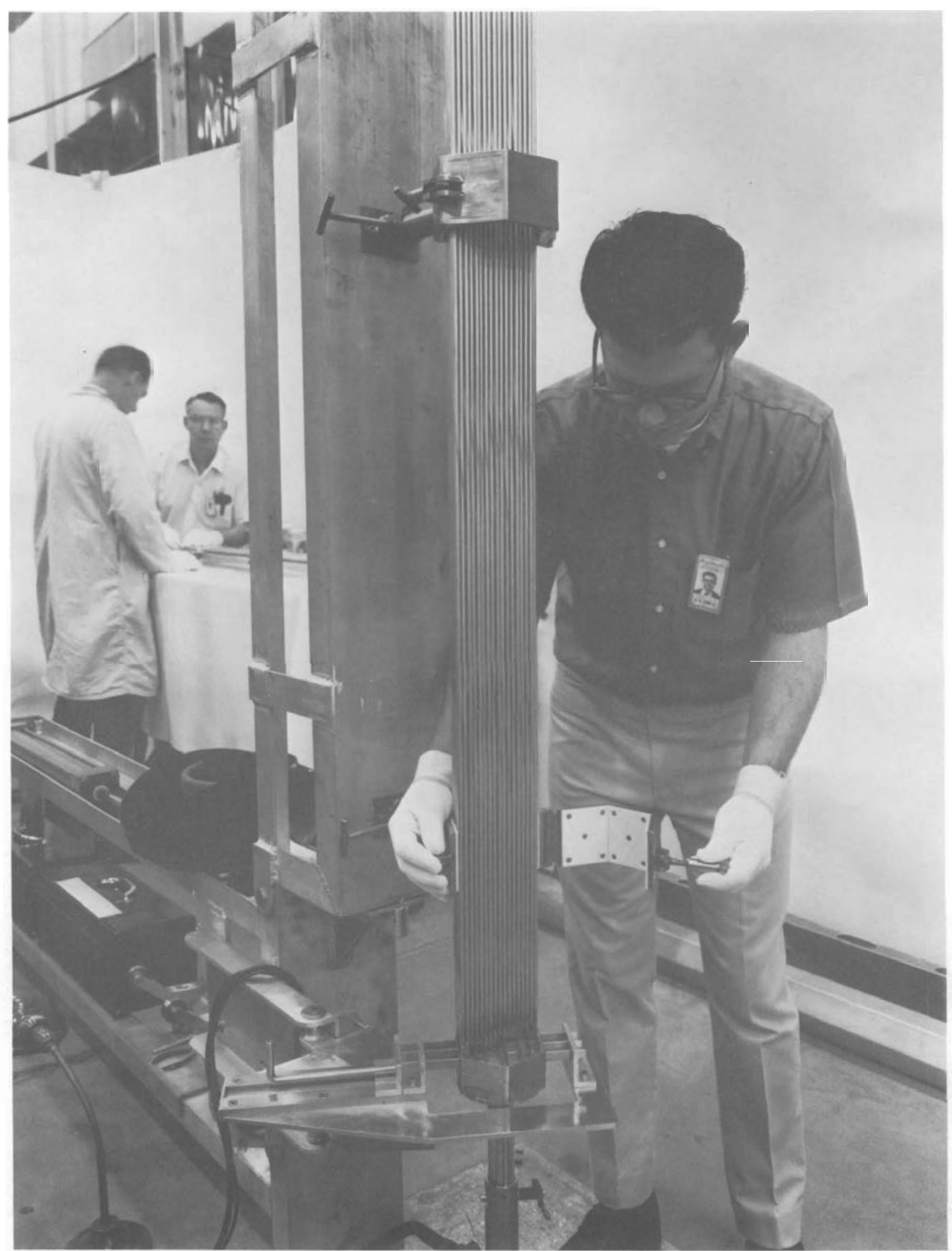

Neg 0680570-7

FIGURE 4. Pin Bundle Partially Assembled 


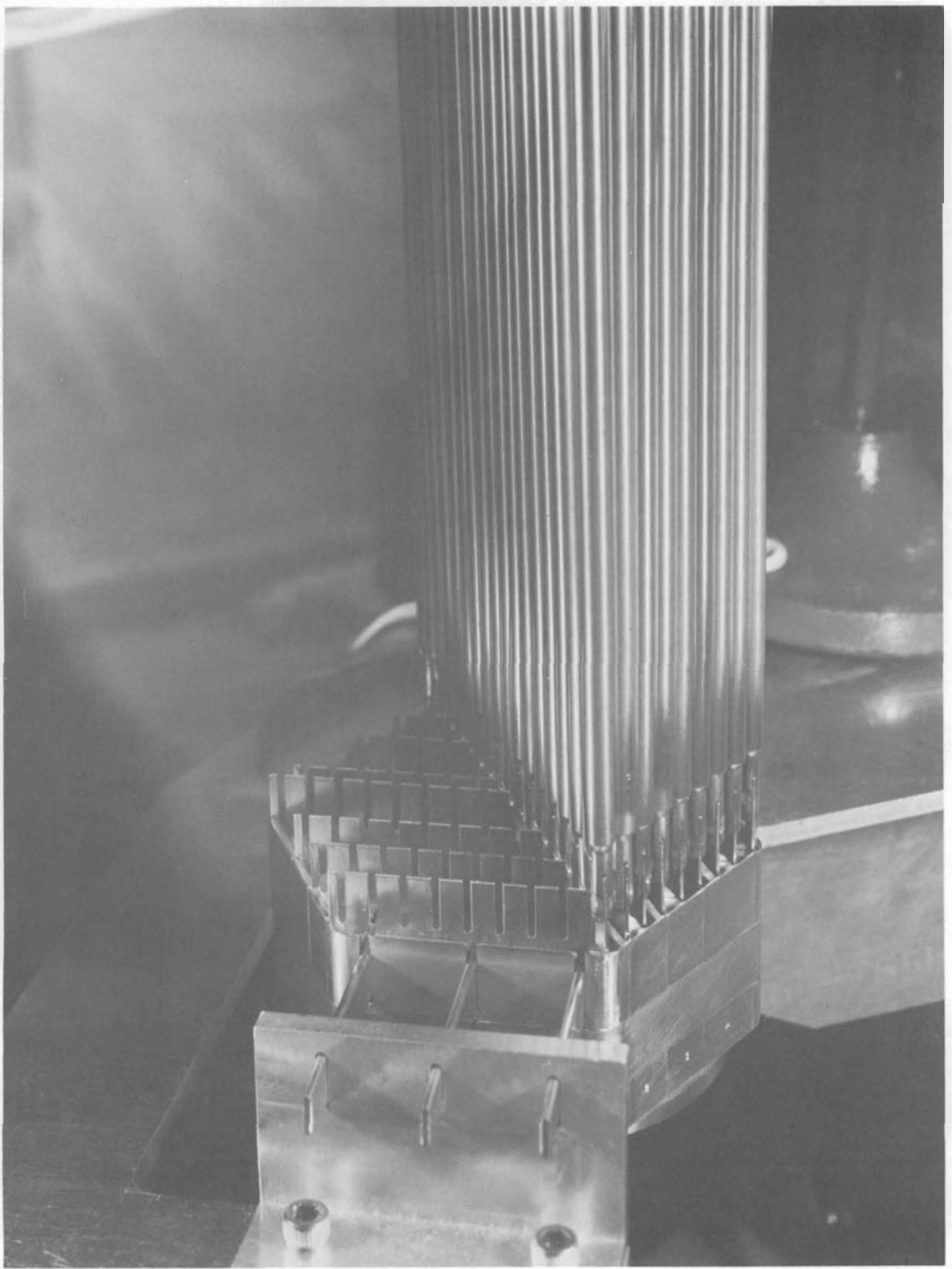

Neg 0680570-25

FIGURE 5. Details of Strip Layers and Grid Strips Partially Assembled Cluster 
BNWL - 1261

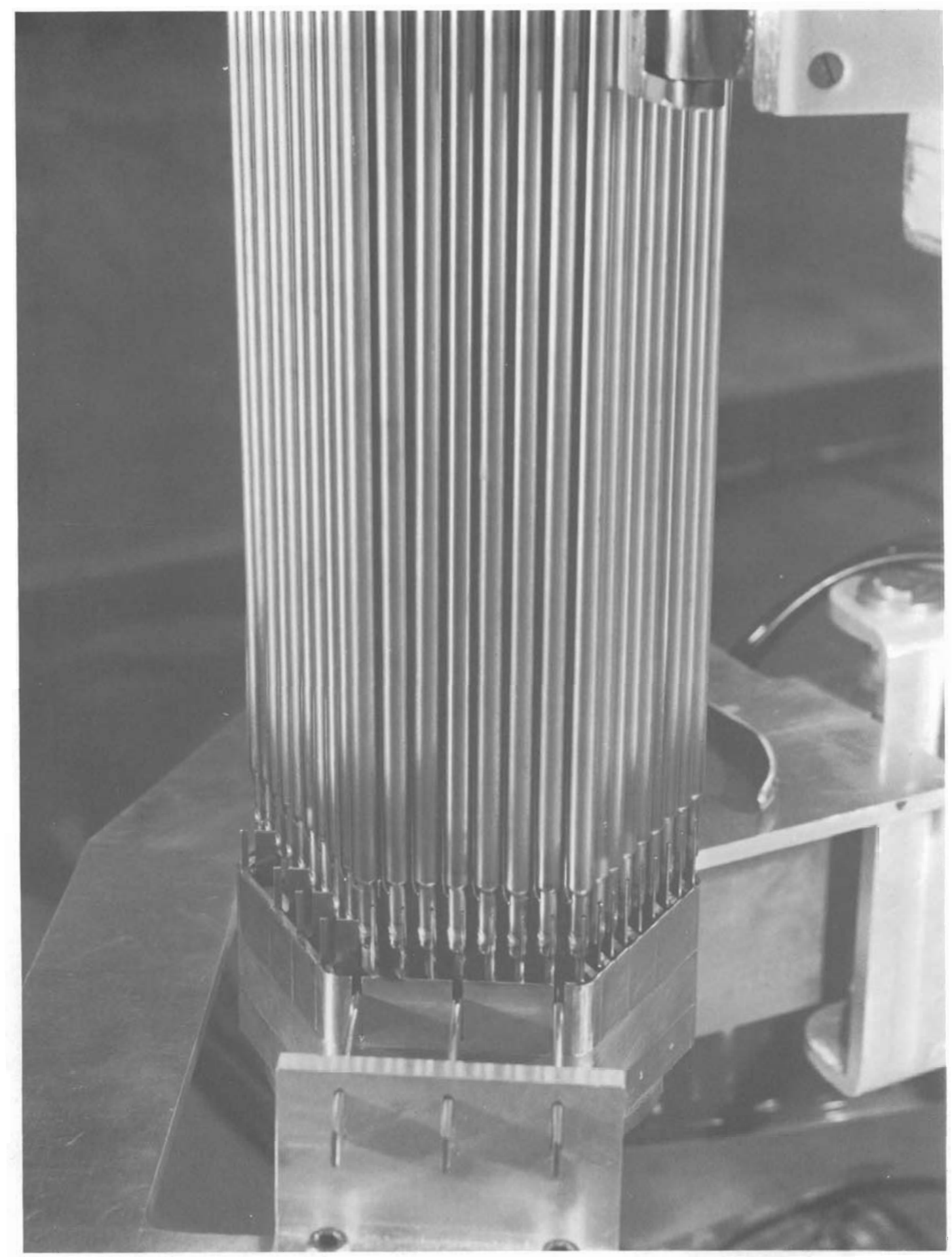

Neg 0680570-23

FIGURE 6. Bottom of Assembly Before Last strip Layer Was Welded In 
BNWL-1261

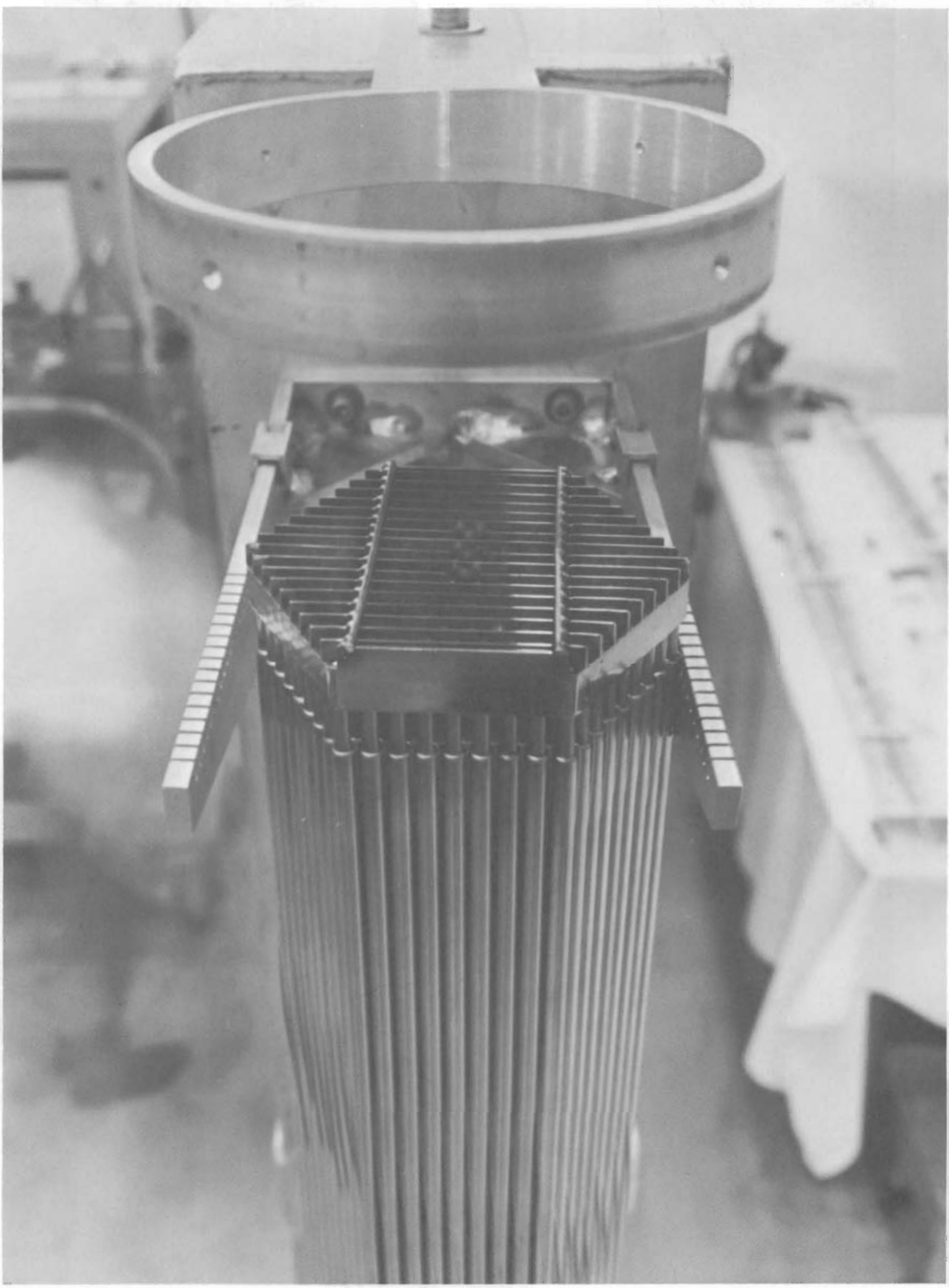

Neg 0680570-27

FIGURE 7. Top Spacer Fitting in Place 
BNWL -1261

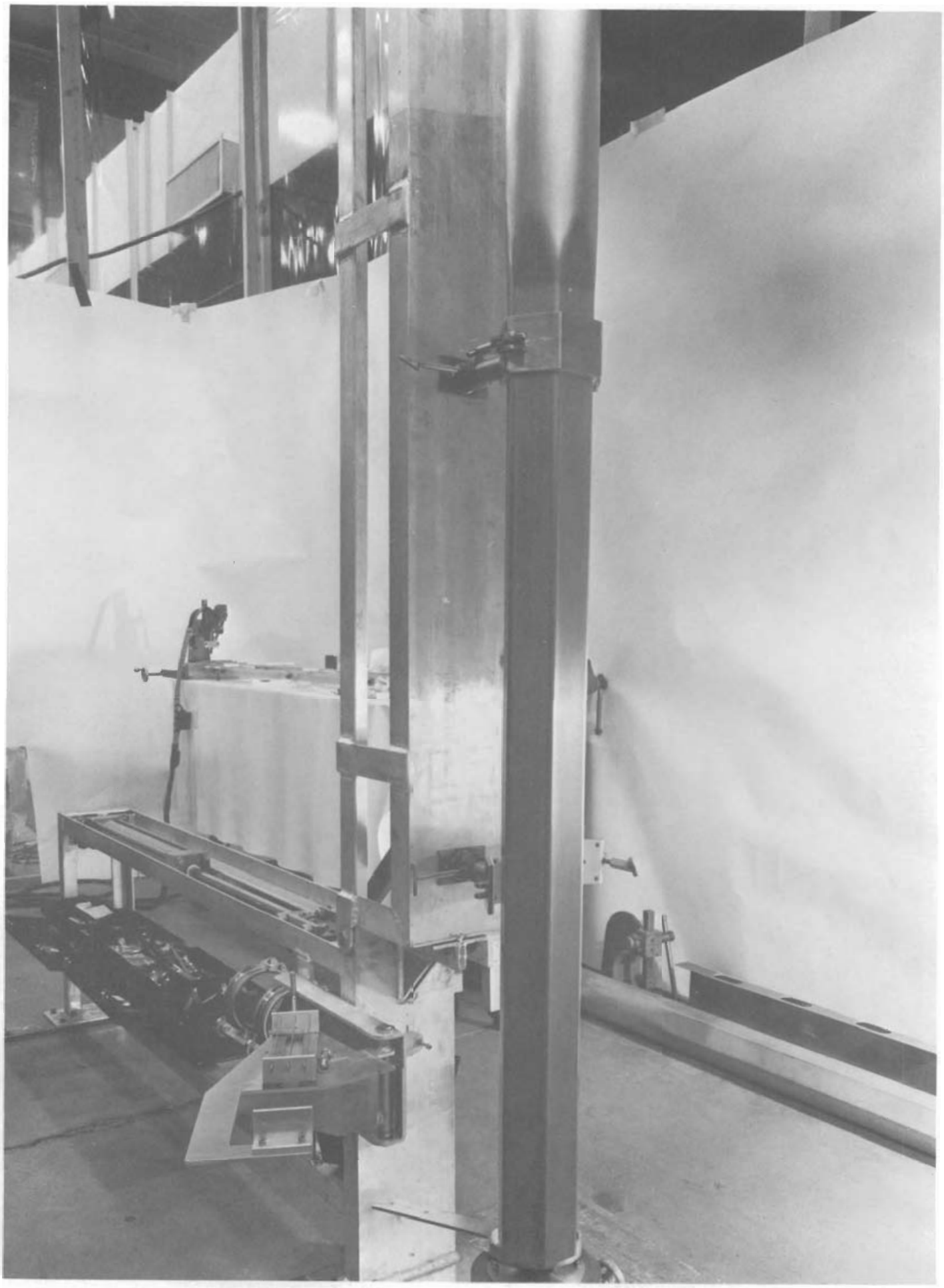

Neg 0680570-43

FIGURE 8. Flow Duct in Place and Welded to Pin Bundle 


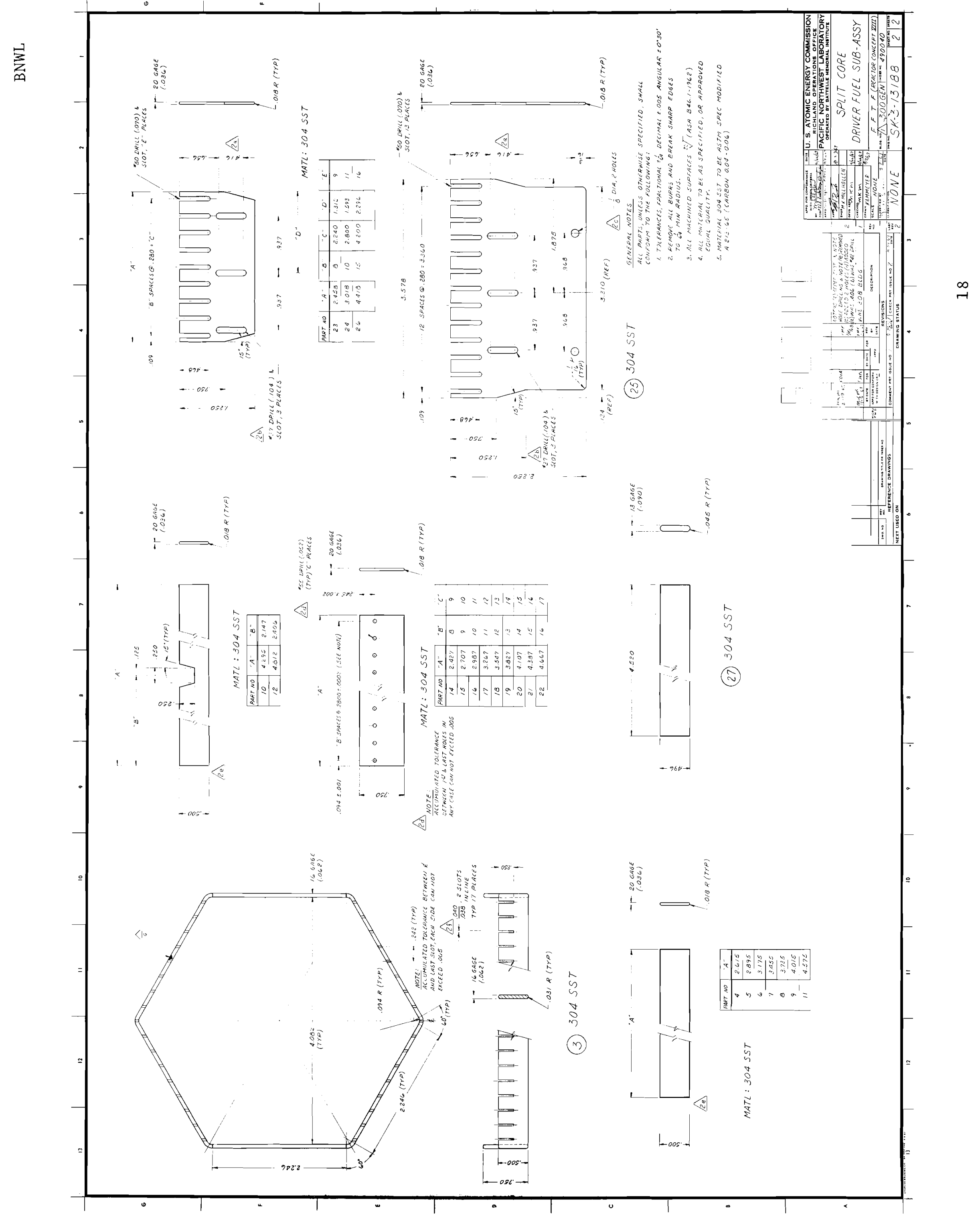




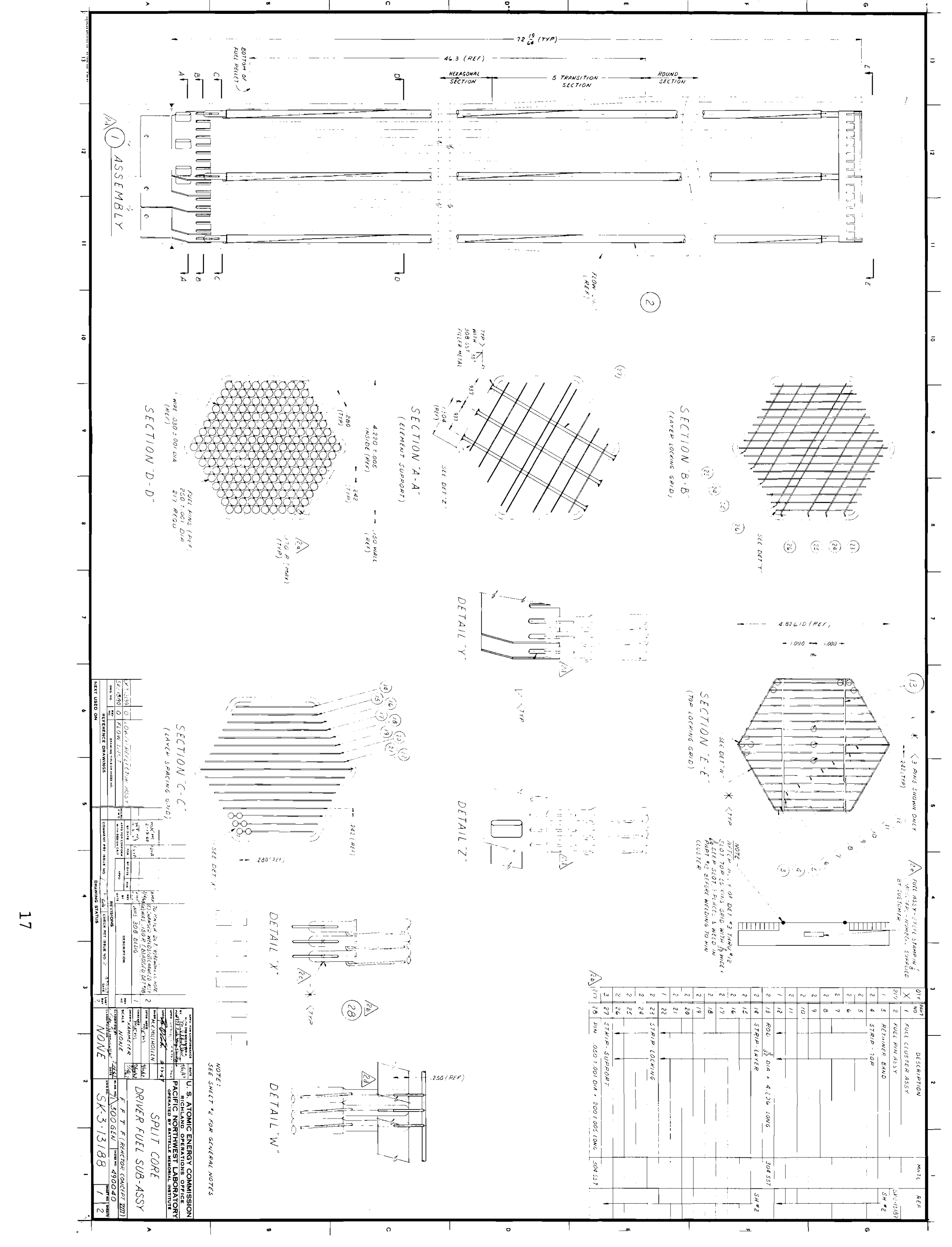

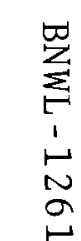


BNWL - 1261

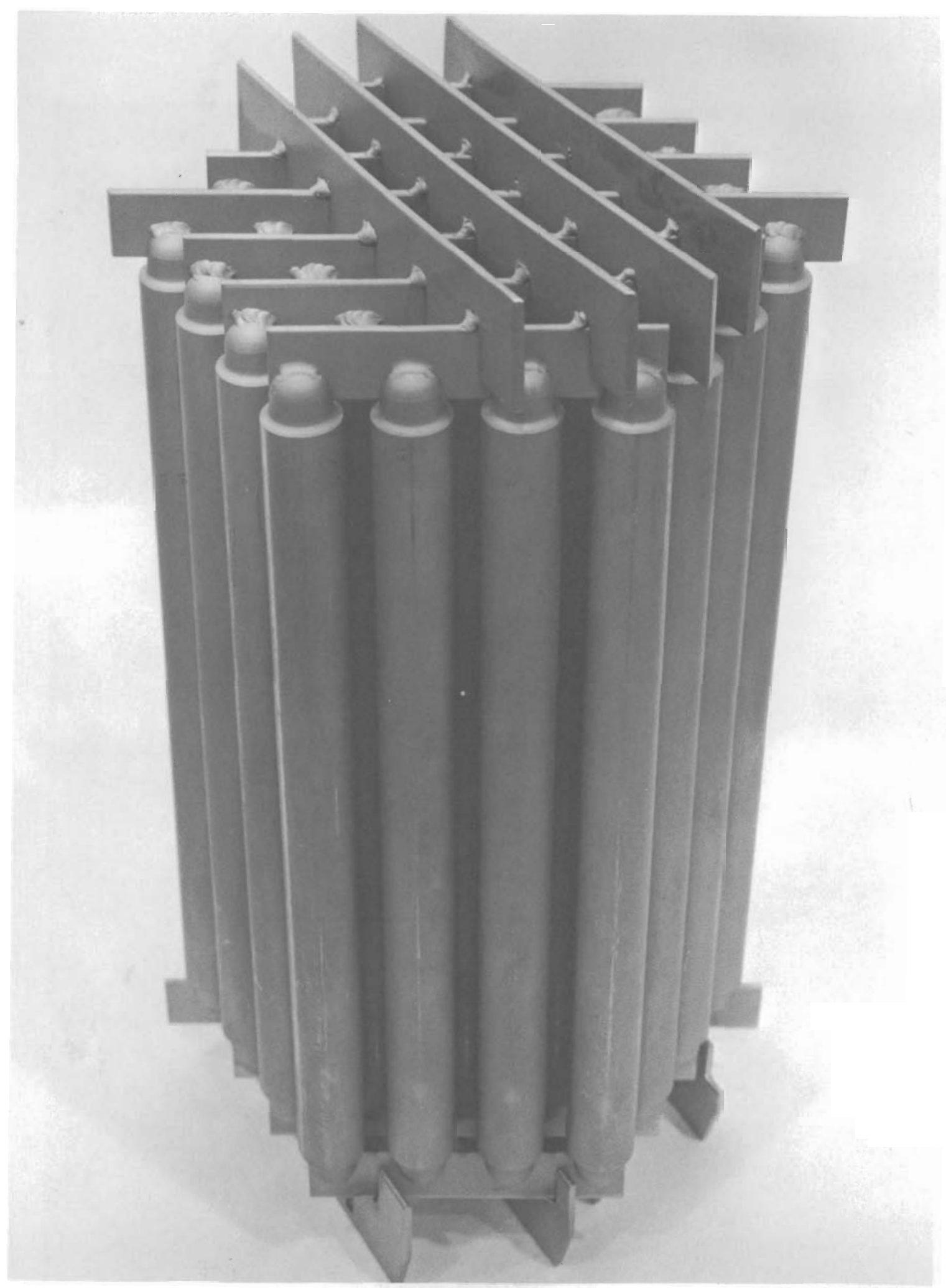

Neg 06805070-38

FIGURE 9. Reflector Pin Bundle 
BNWL - 1261

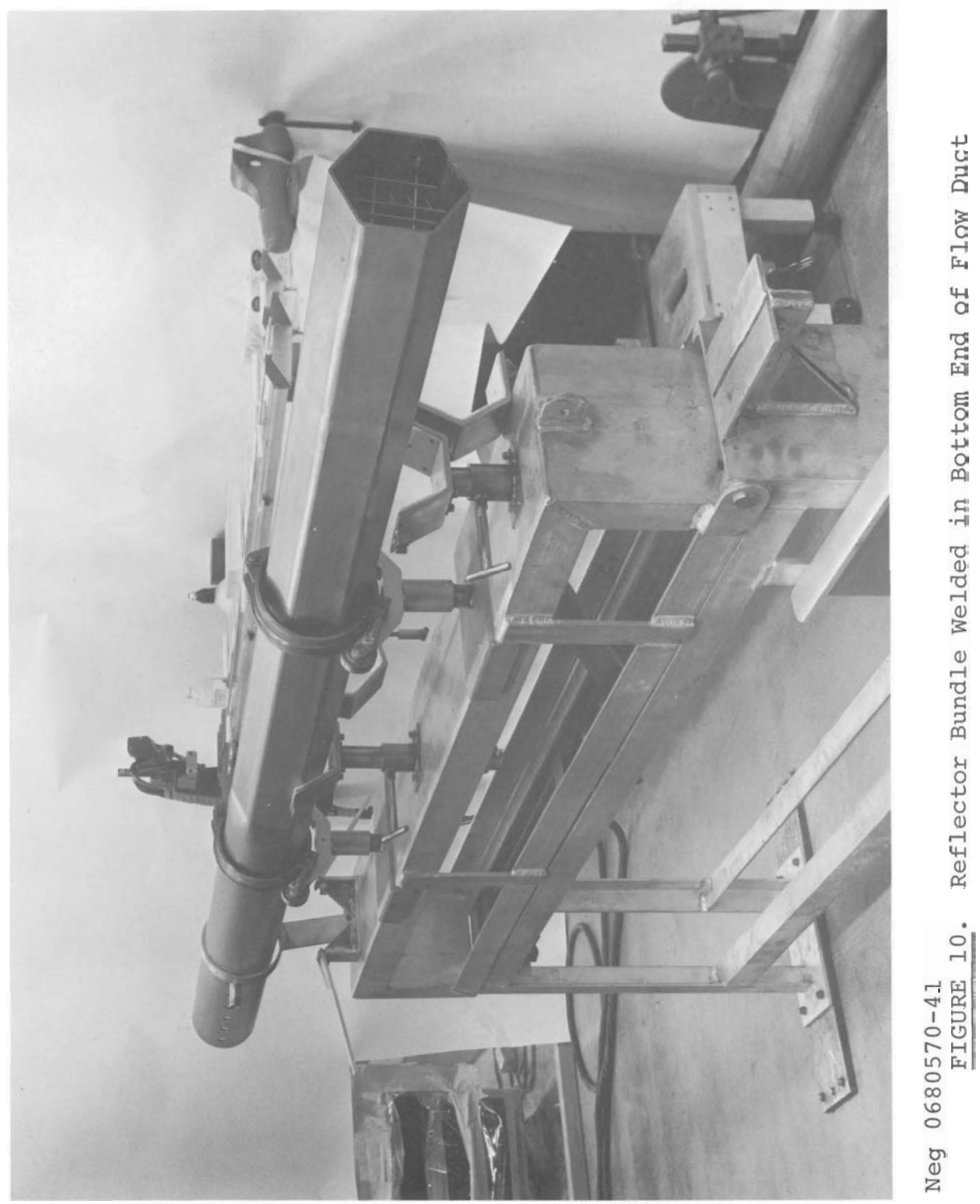




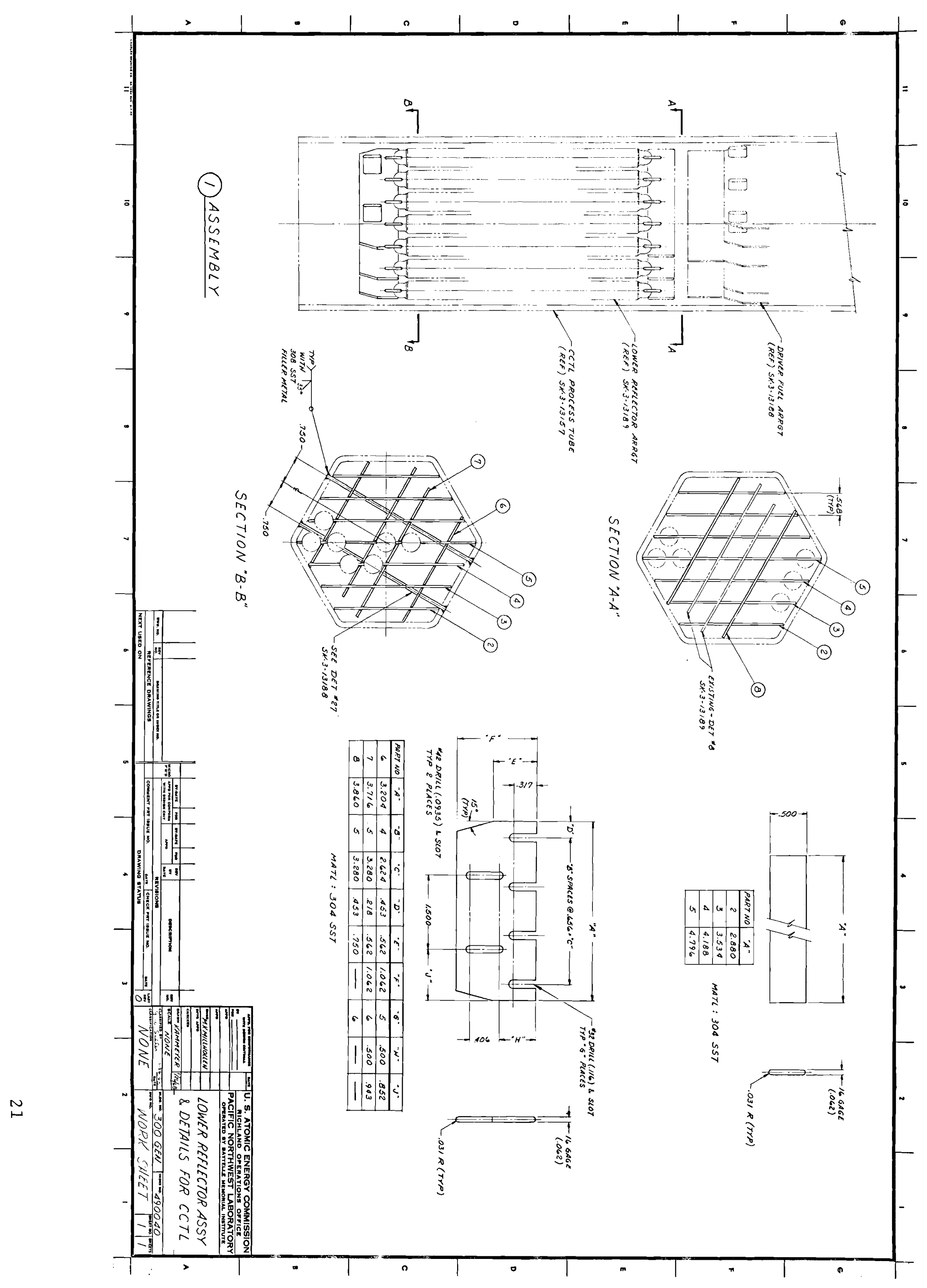


TRANSPORTATION TO ARGONNE NATIONAL LABORATORY

The fabricated assembly was shipped in a wooden container whose minimum specifications were in accordance with ICC

Shipping Container Specification No. 15-B, Section 78.169.

The dimensions of inner shipping box constructed were $1 \mathrm{ft}$ by

$1 \mathrm{ft}$ by $10 \mathrm{ft}$ in length, with the box constructed in two

halves. Inside were 13, two-inch wide supports, spaced eight

inches apart. The subassembly rested on these padded, wooden struts (Figure 11). Padded, wooden inserts were installed in the ends of the duct to keep the pins in place.

The inner box was packed in a wooden shipping crate with padding placed between the two shipping containers. The padding was a resilient 24 by 26 by 2 in. hair-type padding. The shipping weight of the subassembly was $530 \mathrm{lb}$.

To minimize any vibration that could damage the assembly (primarily those which would be incurred if the container were dropped or handled roughly), the subassembly was couriere to ANL by BNW personnel.

One BNW staff member couriered the subassembly as follows:

- Richland to Pasco by AEC truck.

- Pasco to Portland by rail.

- Portland RR station to airport by truck.

This member then observed the crate's loading onto the cargo jet. The plane was met in Chicago by another BNW staf member who oversaw the transfer of the subassembly to an AEC truck, which took the package to Argonne National Laboratory.

The assembly left Richland, Washington, on February 22 ,

1968, and was delivered to Argonne on February 23, 1968. 


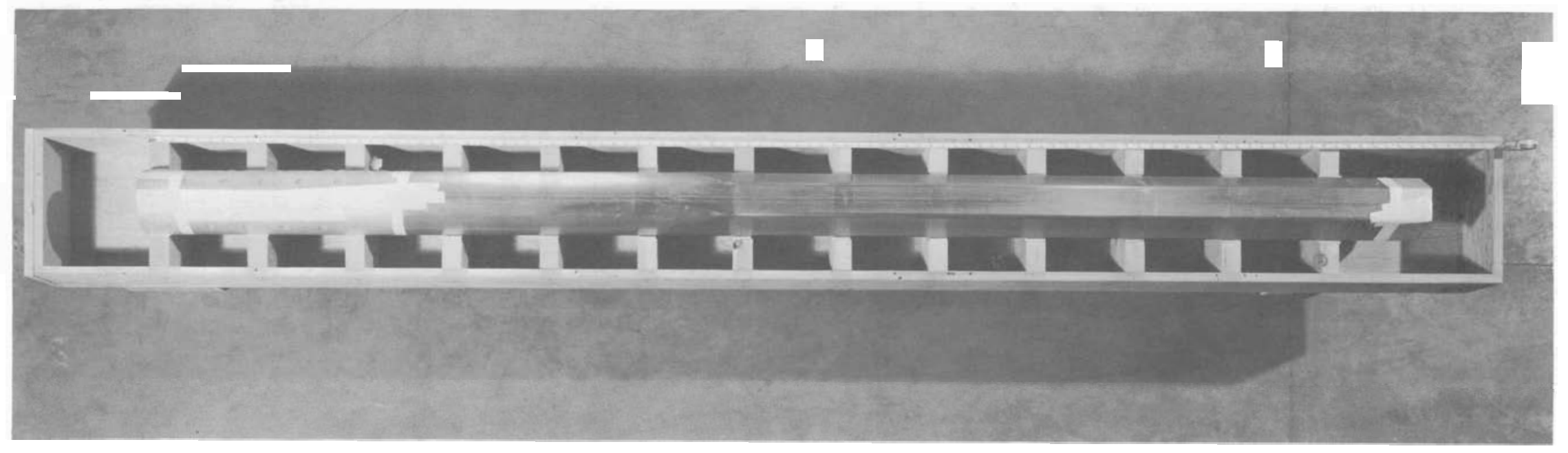

Neg ANL112-9607 T-1

FIGURE 11. Mark I Subassembly in Inner Shipping Container

(Courtesy of Argonne National Laboratory) 
BNWL -1261

\section{ALTERATIONS TO ADAPT TO CCTL}

The Mark I CCTL/FFTF fuel bundle was designed and fabricated according to the split-core reference design. The maximum angle of skew in the reference design was $7^{\circ}$; however, due to the geometry of the CCTL test vessel, the maximum angle possible for the Mark I cluster was $4^{\circ} 30^{\prime}$, the position at which it was tested.

The subassembly shipped to ANL was $8 \mathrm{ft} 7$ in. in length. The entrance region was hexagonal in shape; the outlet region was circular, (Drawing SK-3-13157). ANL attached end fixtures to the subassembly flow duct prior to its installation in the CCTL. They also attached two pressure taps: One located 2 in. below the lower reflector pin bundle; the other 2 in. above the top of the pin bundle. Guide rings were attached to space the subassembly in the 1oop. The upper guide ring was tack welded approximately $21 / 2 \mathrm{ft}$ above the top of the pin bundle; the lower guide was attached by means of set screws $31 / 2 \mathrm{ft}$ below the top of the pin bundle. The entire structure installed into the CCTL was nearly $20 \mathrm{ft} 1$ ong (Figure 12).

CHARGING SUBASSEMBLY INTO CCTL AND TESTING

The subassembly was delivered to ANL at the end of February 1968. During the month of March 1968, the hardware necessary to install the subassembly in the CCTL was connected to the subassembly, and the pressure taps were installed and calibrated.

The Mark I fuel assembly was installed into the CCTL on April 28, 1968. The loop was not immediately filled with sodium because a sodium plug blocked the line from the storage tank to the loop itself. The line was cut, the plug removed, and the line repaired. The loop was filled with sodium on May 8, 1968; the pump was started on May 13, 1968, with the pump manufacturer's representative present. 
BNWL - 1261

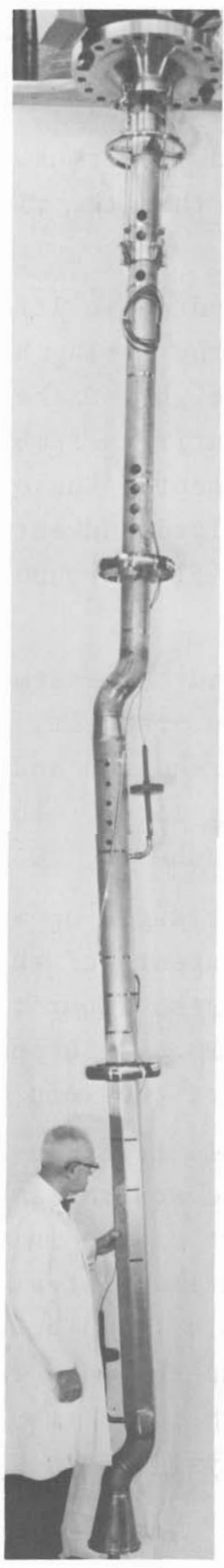

FIGURE 12. FFTF Mark I Subassembly Prior to Installation in the CCTL (Courtesy of Argonne National Laboratory) 
As the pump came up to speed ( $800 \mathrm{rpm}, 400 \mathrm{gal} / \mathrm{min} \mathrm{f} 1 \mathrm{ow}$ ) on the initial startup, the pressure drop across the assembly instantaneous $1 y$ decreased from 30 psi to 8 psi. After this occurred, two more sets of pressure drop versus flow data were taken. Both were considerably lower than the first set of data (Figure 13).

Investigation showed that the hydraulic lifting force of the flowing sodium was greater than the spring holddown mechanism force plus the submerged weight of the bundle. This force imbalance permitted the entire assembly to be lifted off the lower seating arrangement. The entire Mark I assembly lifted off the inlet grid plate and sat back down in such a manner as to permit sodium flow around the assembly as well as through it.

The loop was cooled, drained, and the assembly removed. The holddown mechanism was redesigned, rebuilt, and the assembly reinstalled. The loop was reheated and the pump circulation commenced again six weeks later. The first extended operating run commenced on June 24, 1968.

On June 24,1968 , the loop was started up with a sodium temperature of $400{ }^{\circ} \mathrm{F}$. One of the intents of the test was to closely monitor the carbon and oxygen impurity contents of the loop sodium, i.e., $\leq 20 \mathrm{ppm}$ carbon, $\leq 10 \mathrm{ppm}$ oxygen. The oxygen was trapped out by means of the loop cold trap.

Problems were encountered in cold trap flow control and in obtaining chemical analyses of the sodium samples removed from the 1oop. During the first part of the initial run (June through August 1968), the impurity content of oxygen in the loop sodium was too high (Table 1 ). The oxygen was fairly well under control by the time the loop reached goal temperature $\left(1060^{\circ} \mathrm{F}\right)$. Control of the cold trap flow and turnaround time on the chemical analysis of the sodium samples 
BNWL - 1261

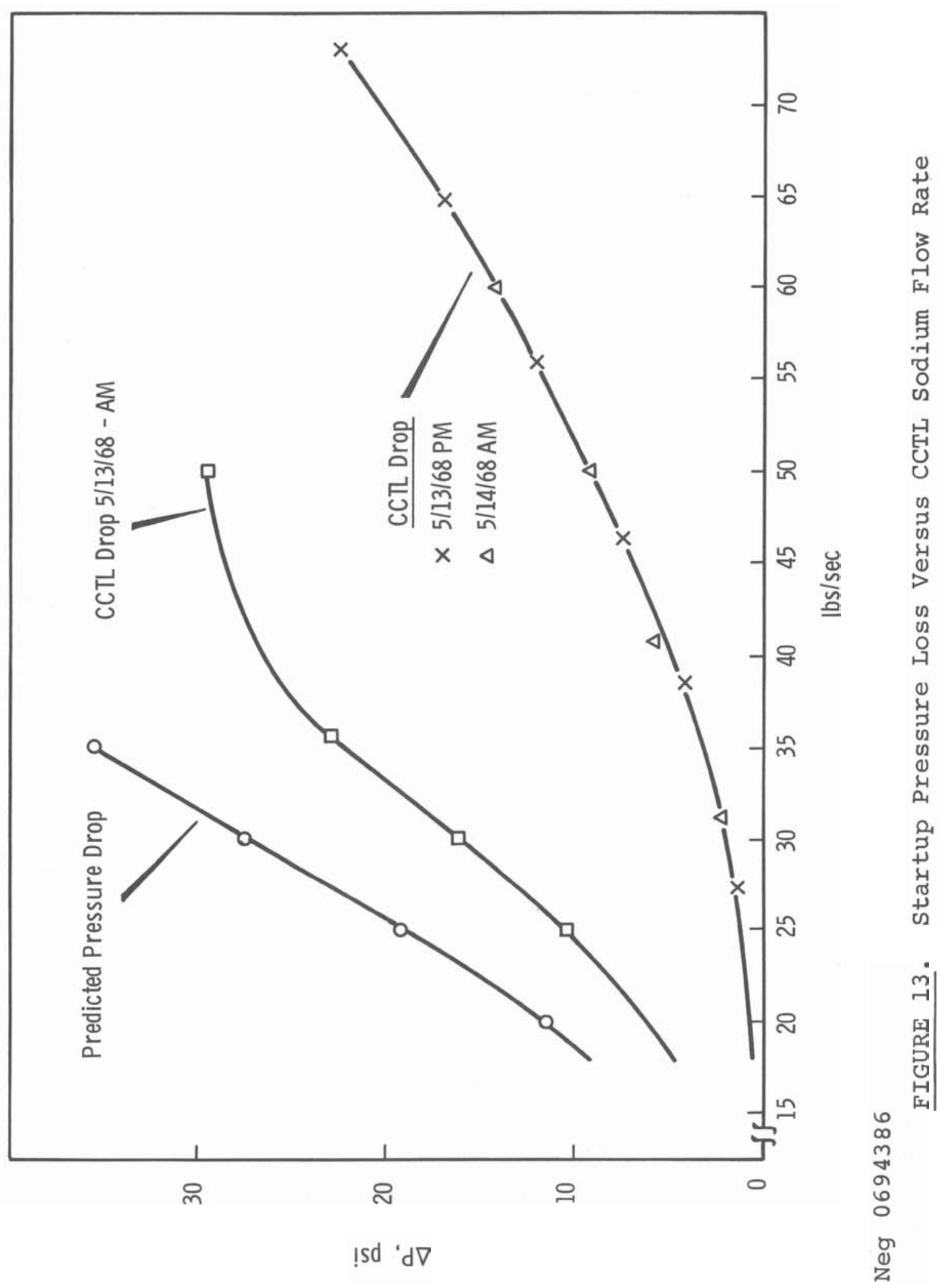


taken from the loop were problems throughout the test. Chemical analysis values were obtained three to four weeks after the samples had been removed from the loop. The cold trap was located in the deep pit, and each sample obtained from it was removed under hazardous conditions.

\section{TABLE 1. Cold Trap Data}

\begin{tabular}{|c|c|c|c|}
\hline $\begin{array}{c}\text { Date } \\
\text { (July) } \\
\end{array}$ & $\begin{array}{c}\text { System } \\
\text { Temperature, } \\
{ }_{\mathrm{o}} \mathrm{F}\end{array}$ & $\begin{array}{l}\text { Cold Trap } \\
\text { Flow, } \\
\text { gal/min } \\
\end{array}$ & $\begin{array}{c}\text { Plugging } \\
\text { Temperature, } \\
{ }^{\circ} \mathrm{F}\end{array}$ \\
\hline 3 & 600 & 35 & 486 \\
\hline 5 & 610 & 10 & 375 \\
\hline 8 & 600 & 12 & 260 \\
\hline 10 & 750 & 12 & 225 \\
\hline 14 & 800 & 5 & 350 \\
\hline 19 & 1060 & 5 & 296 \\
\hline
\end{tabular}

Near the end of July 1968, the lower face seal in the CCTL pump began to leak. The upper face seal leak rate was approximately $0.45 \mathrm{ml} / \mathrm{hr}$; whereas, the lower seal leaked at a rate of 0.4 liter $(400 \mathrm{ml})$ per hour. The upper seal was exposed to sodium vapor; the lower seal was not. Chemical tests showed no trace of sodium in the oil that leaked out of the lower seal. The decision was made to continue operation with the leaky seal while keeping it closely monitored through hourly viscosity and leak-rate measurements.

On August 16, 1968, the CCTL was shut down because of a leak in the bellows seal throttle valve on the downstream side of the cold trap. The valve bellows failure was due to increased sensitization of the very thin walled structure of the bellows in a sodium atmosphere. Investigation by ANL showed that the cause of excessive leakage was the cocking of the rotating half of the lower shaft seal--cocking 
attributed to the drive pins binding in their mating holes. Examination of the mating holes revealed a manufacturing inaccuracy that prevented the drive pins from sliding freely throughout their length.

Replacement seals were obtained by ANL, the drive holes of the drive-shaft sleeve were reamed, and the seals relapped. Bench tests of the reconditioned seal arrangement showed that the leakage rate decreased by a factor of 300 .

The seals were reinstalled in the CCTL pump, and the loop brought back into operation on October 25, 1968. The down-time to correct the valve-bellows failure and the pumpseal leakage was 70 days.

The CCTL operated on an $8 \mathrm{hr} /$ day basis from October 25 until November 5,1968 , at which time it was returned to round-the-clock operation.

The Mark I test was terminated approximately two weeks early on April 17, 1969, because of a minor fire at a control valve near the cold trap. Upon discovery of the sma1l, valve fire, the sodium was immediately dumped from the 10op, and loop cooling was begun. Since the heavily insulated loop cools by natural convection, this process takes several days. During cooling, a rubber boot was put on the top flange of the test vesse1, and the subassembly was raised about $1 \mathrm{ft}$. This allowed the sodium to drain freely from the lower regions of the test fixture. During cool-down and cleaning, the assembly was kept under an inert gas (argon) atmosphere for two purposes: to keep oxygen (air) away from sodium and to preserve the cladding surface in the same condition it maintained during loop operation. A polyethylene bag was taped to the boot prior to removal of the subassembly from the CCTL to provide the envelope for the inert atmosphere (Figure 14). 


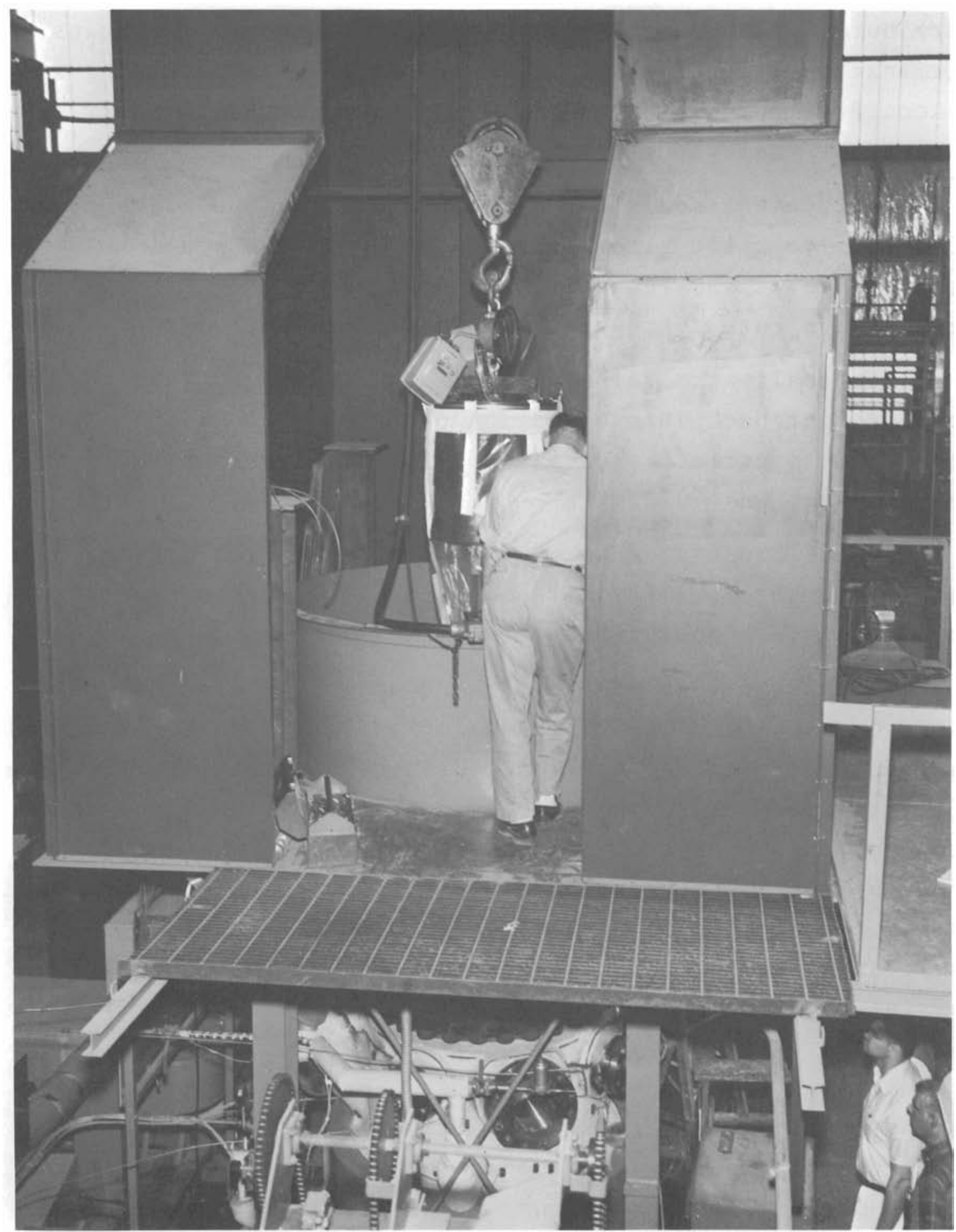

Neg ANL133-1981

FIGURE 14. Removal of FFTF Mark I subassembly from the CCTL (Courtesy of Argonne National Laboratory) 
Because solidified sodium prevented the subassembly guide rings from clearing the guide structure (Figure 15), two additional lifting cables, each rated at 3900 pounds, were attached prior to the removal of the subassembly. Since the original cables had been exposed to the sodium vapor throughout the test, the new cables were an added safety measure.

A dynamic argon purge was maintained on the subassembly during the removal process, and a polyethylene sheet was taped around the assembly during removal of the fixture from the CCTL to the deep pit (Figures 16 and 17).

\section{CLEANING THE SUBASSEMBLY}

After the assembly had been lowered into the deep pit, the outlet holes in the duct were plugged with rubber stoppers and Dowanol-EB was introduced into the subassembly. (The polyethylene sheet was removed.)

A thermometer strapped to the duct showed a temperature increase of less than $5^{\circ} \mathrm{F}$, an increase indicating that a well-controlled reaction was taking place between the Dowanol-EB and the residual sodium. Argon was periodically bubbled through the assembly to provide a mixing action within the pin cluster. This allowed the cleaner to circulate and work effectively.

The next day, the Dowanol-EB was replaced with absolute ethyl alcohol, which was left in the duct for $3 \mathrm{hr}$. Again, frequent argon purges were used to provide mixing action.

Both the Dowanol-EB and the alcohol were clear after cleaning, an indication that nearly all of the sodium had drained off the pin cluster when the loop was drained. The exterior of the duct had virtually no sodium on it, except in the areas of the guide rings (Figure 18). After the internal cleaning, the assembly was placed on a table for 


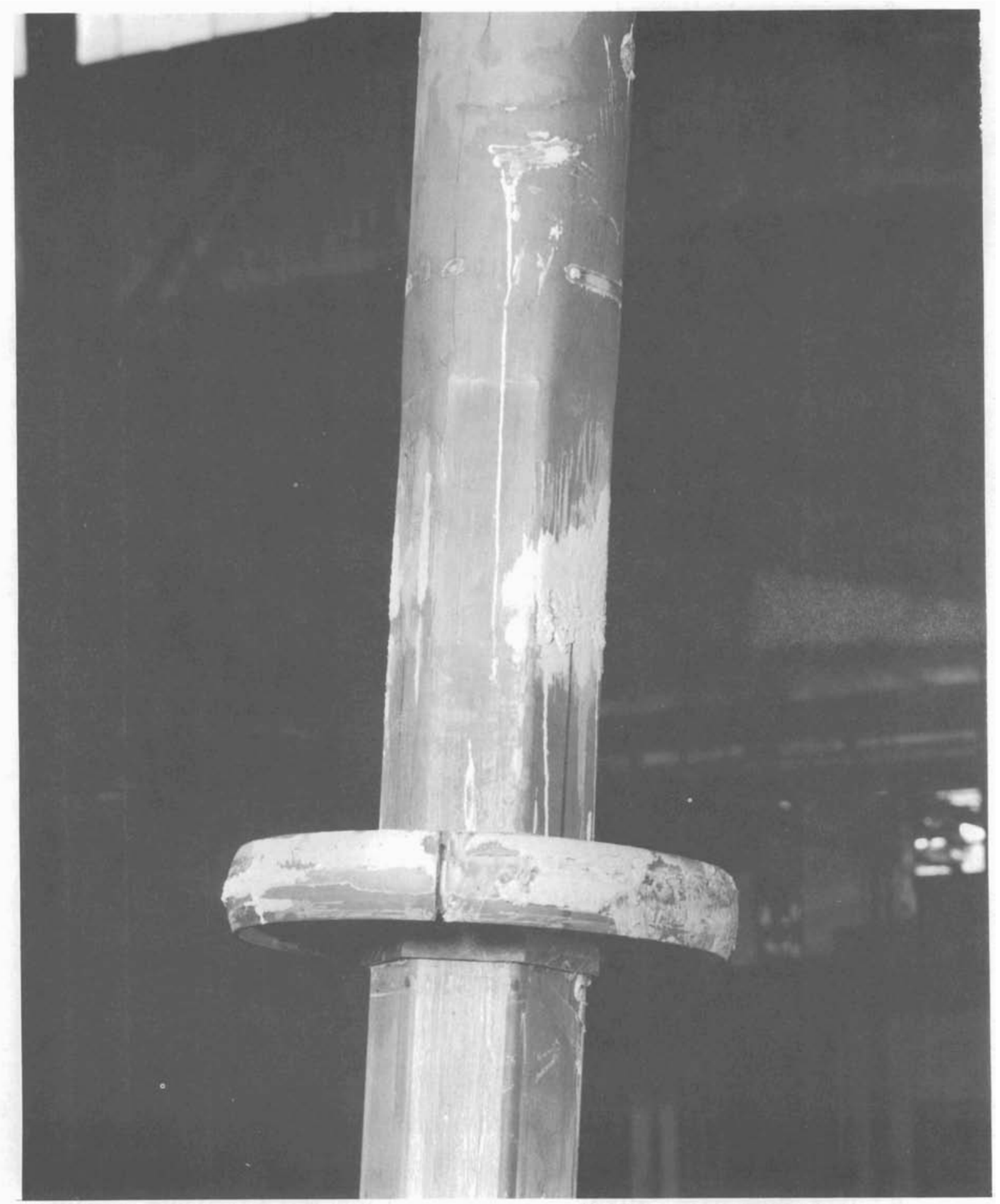

Neg ANL113-1993

FIGURE 15. Sodium Buildup on Guide Ring (Courtesy of Argonne National Laboratory) 


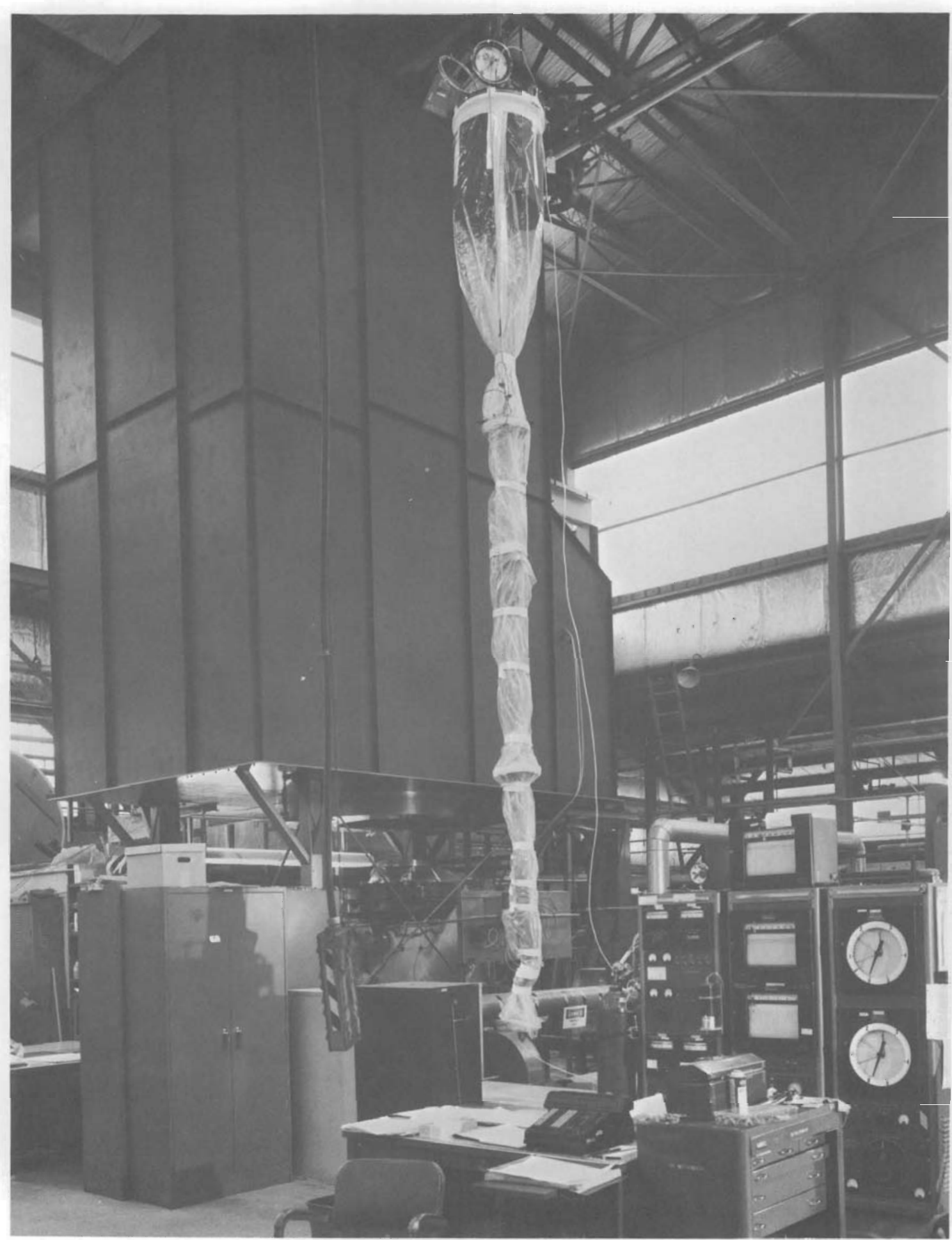

Neg ANL113-1979

FIGURE 16. Mark I Subassembly During Transfer from CCTL to Deep Pit (Courtesy of Argonne National Laboratory) 


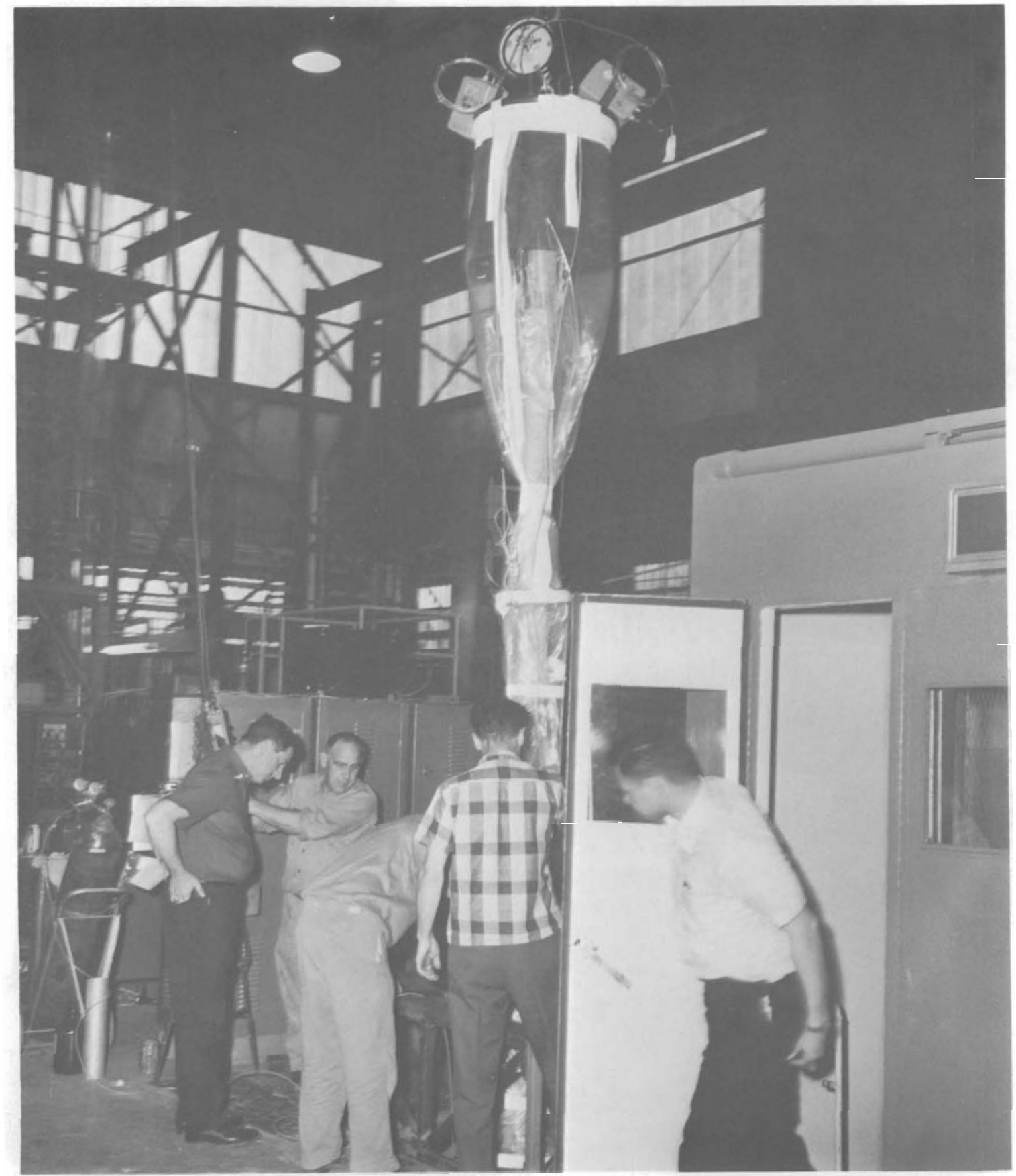

Neg ANL113-1980

FIGURE 17. Mark I Subassembly Being Lowered into Deep Pit for Cleaning (Courtesy of Argonne National Laboratory) 


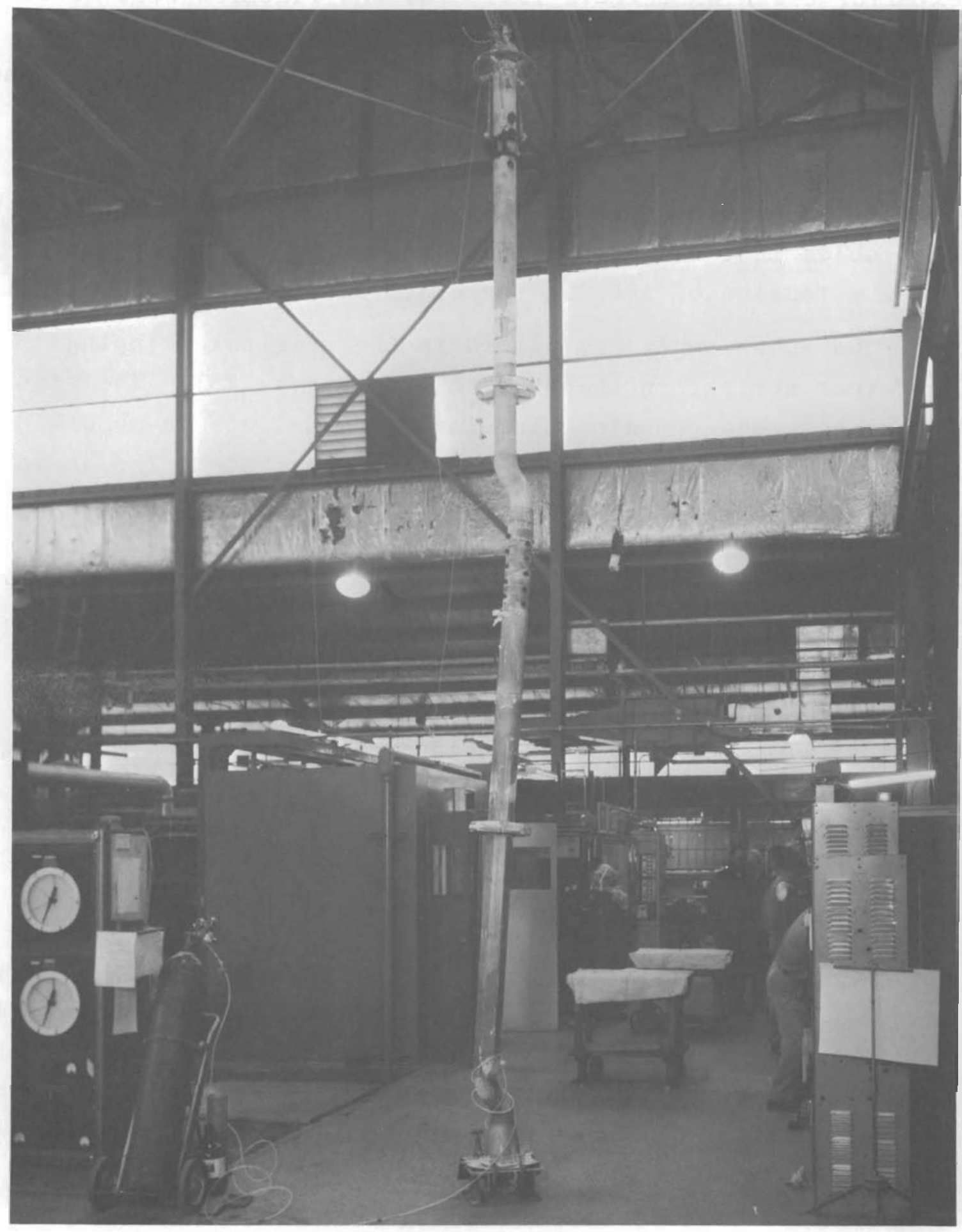

Neg ANL113-1995

FIGURE 18. Mark I Subassembly After Interior Cleaning (Duct Exterior Not Cleaned)

(Courtesy of Argonne National Laboratory) 
exterior cleaning (Figure 19). The end fixtures were sawed off to permit visual examination of the top of the pin bundle and the bottom of the reflector bundle (Figures 20 and 21). Both appeared remarkably clean.

Prior to shipment, the cables used to remove the test fixture from the loop were destructively examined. One of the cables that had been exposed to the sodium vapor broke under a tension of 100 1b, the other at 1500 lb (Figure 22).

The subassembly was placed in the original shipping container for return shipment to BNW (Figure 23). The gloves on the assembly contain molecular sieve pellets to absorb moisture from the air inside the shipping crate. The boxed and crated subassembly was transferred by AEC truck from. Argonne National Laboratory to Chicago's O'Hare Field; then to Portland and Pasco by air. A11 loading and unloading operations at Argonne, O'Hare, Portland, and Pasco airports were closely observed by BNW personnel. Although one end of the crate was dropped 6 to 12 in. at Pasco, the padding around the duct and the spongy cushioning between the dual shipping crates should have absorbed the shock and prevented any damage.

\section{DISASSEMBLY AND EXAMINATION OF THE SUBASSEMBLY}

The disassembly and examination of the subassembly followed a predetermined plan which included removing the subassembly from the shipping crate and placing it on the assembly fixture in a horizontal position. The bottom reflector pin assembly was removed from the duct by grinding out the locking bar welds in the flow duct walls. No change in the assembly was visible except that the pins had a black surface layer (Figure 24). The entire flow duct containing the fuel pin subassembly was then positioned vertically in the assembly fixture, and the six welds, attaching the locking bars to the 


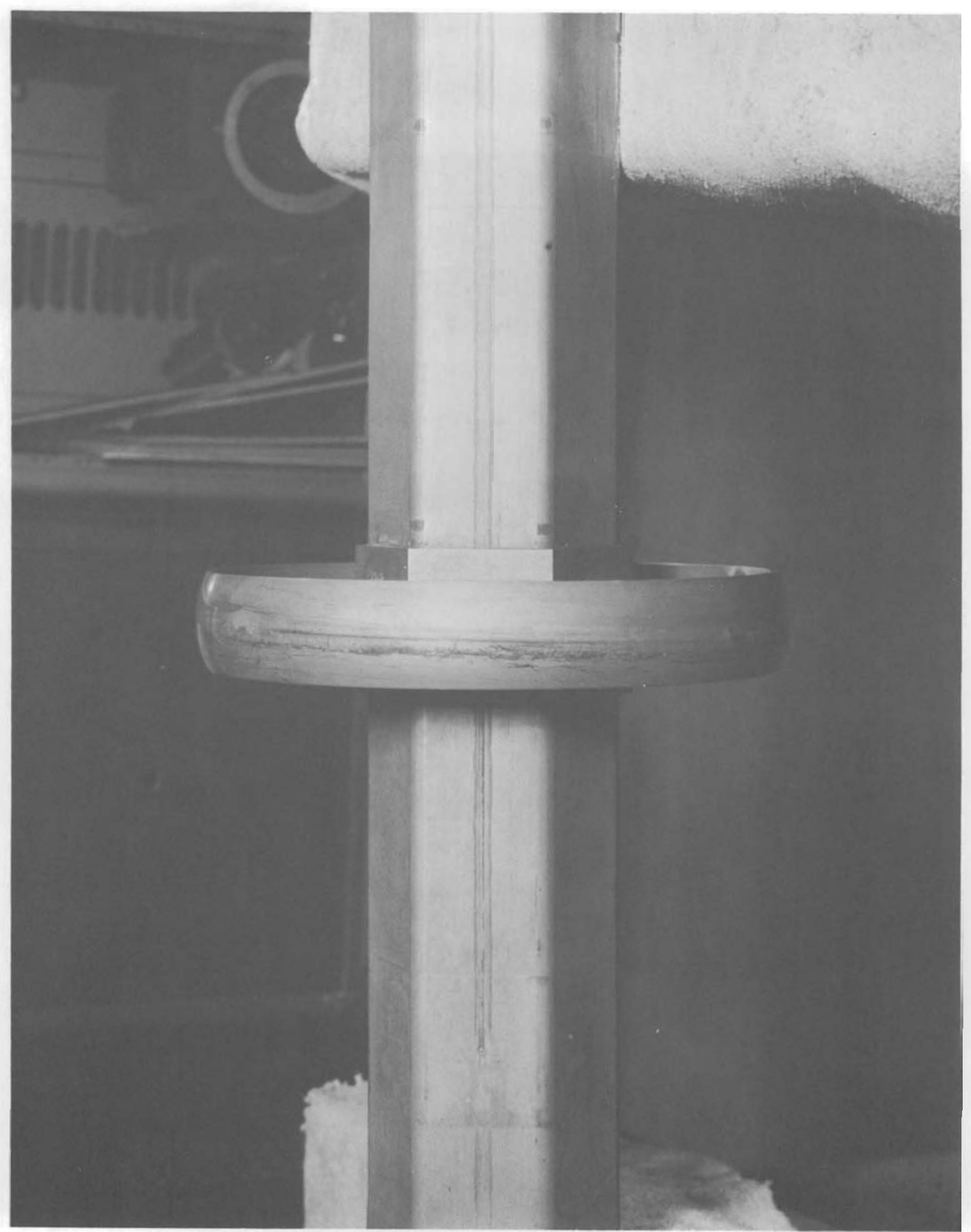

Neg ANL133-1992

FIGURE 19. Lower Guide Ring Section of Duct After Exterior Cleaning (Courtesy of Argonne National

Laboratory) 
BNWL-1261

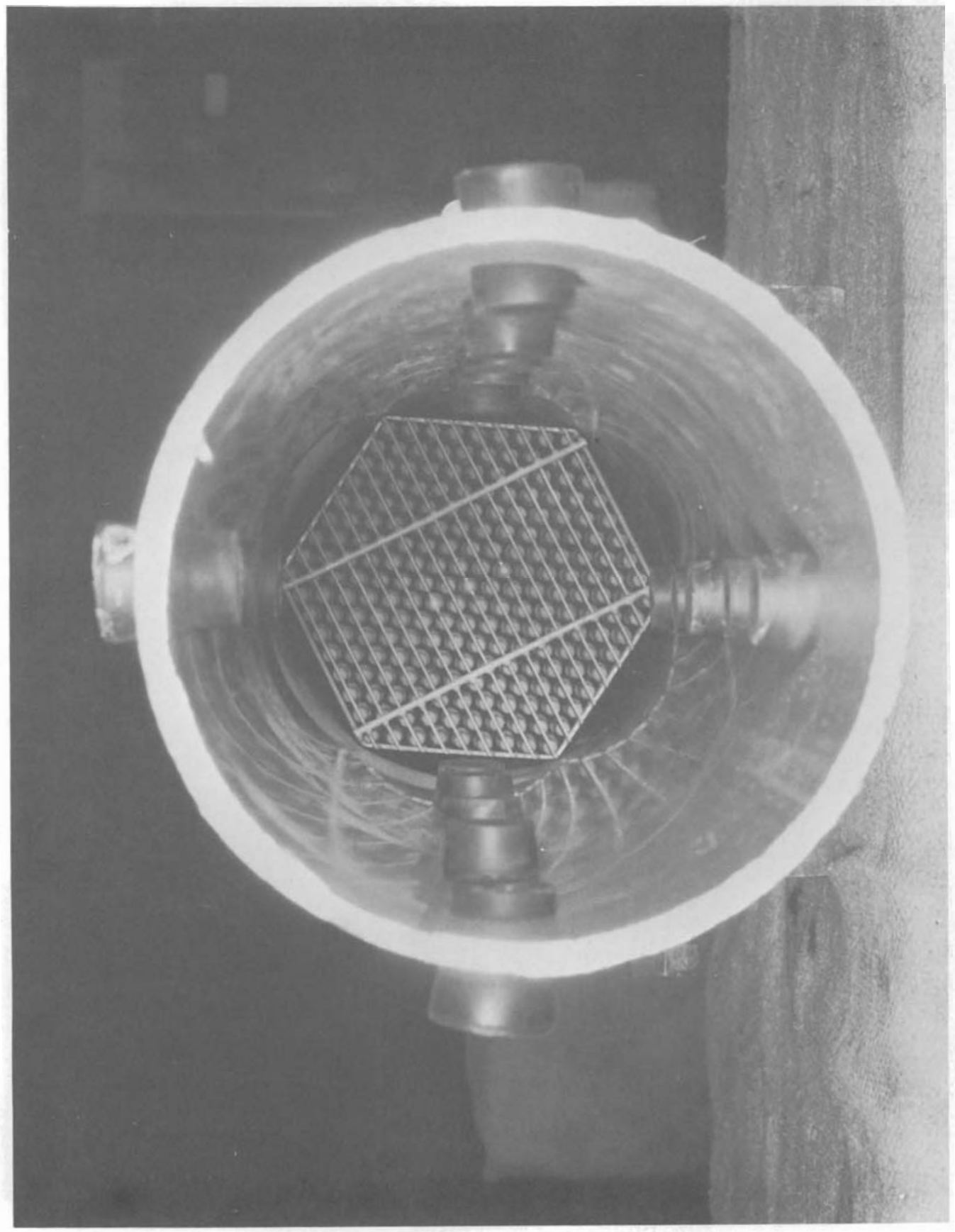

్ㅣㅁ

일

다.

덕

तิ

(1) O

ป

4 능

(1)

岃 1

-

거

. $\mathrm{C}$

$4 \cdot-1$

(1) +

$+\frac{\pi}{2}$

H

$+$

ร

ค 담

些

ซै 4

व 


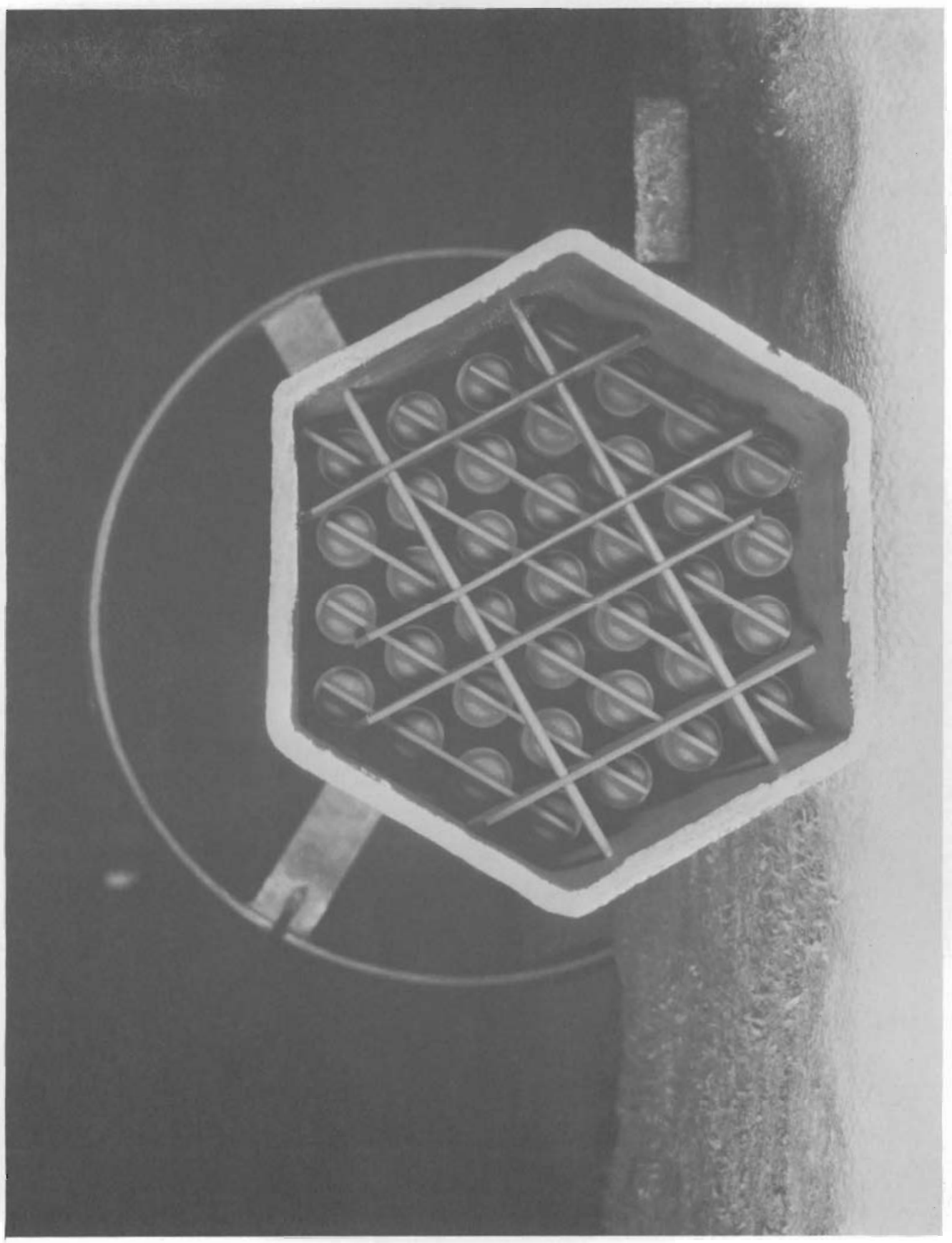

总

\begin{tabular}{l}
4 \\
0 \\
3 \\
0 \\
\hline
\end{tabular}

ह

47

$+4$

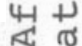

4

넝으

- त्

(4)

$+-1$

政

$+\cdot$

$0+$

ว

त्ठ

๘

(1) or

त्

㝖

韋

प्र

$+4$

$\infty$ 近

ต 거

1 00

m म

-

学

N

का 됨

ठ

乙 


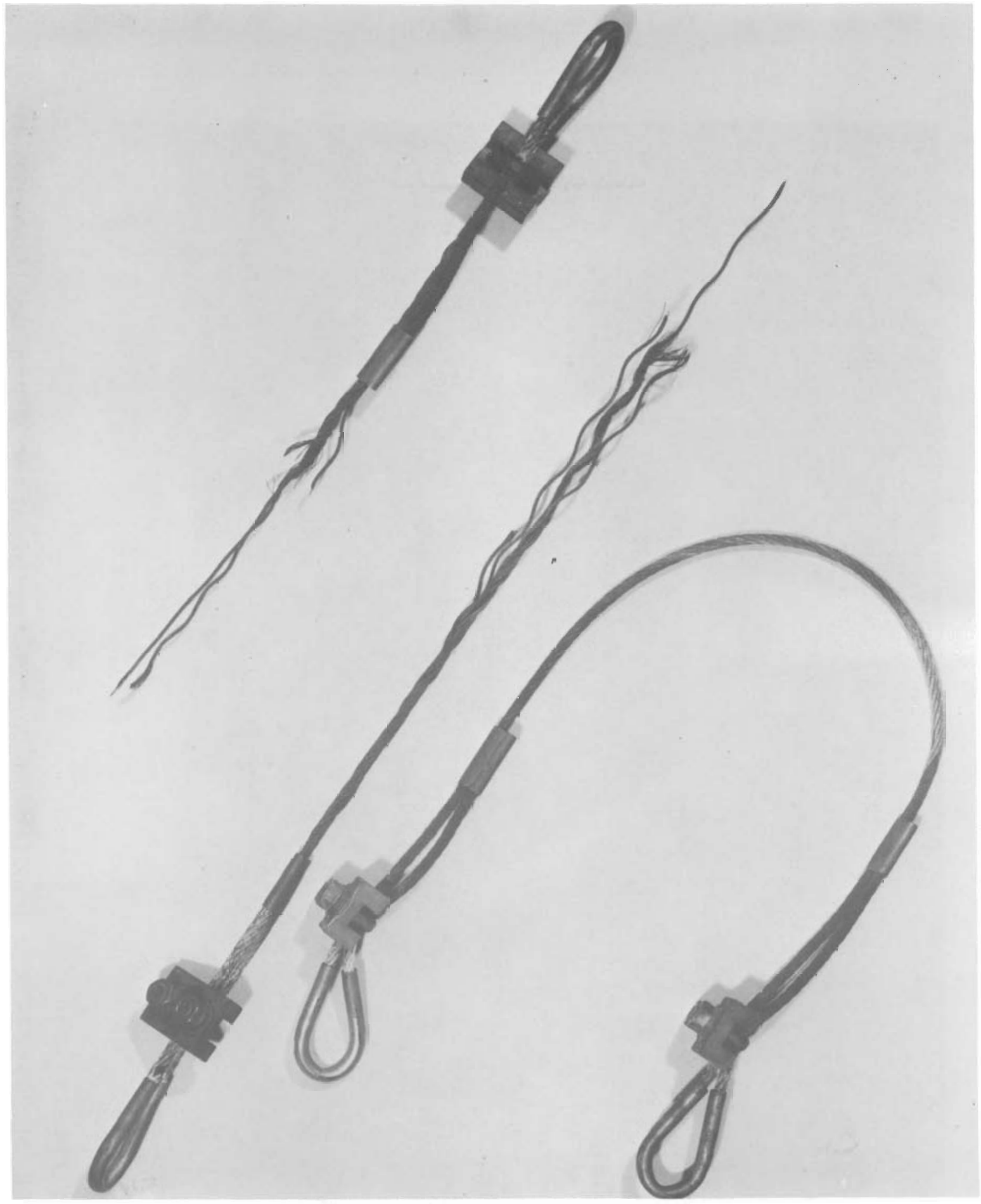

Neg ANL113-1997

FIGURE 22. Sodium Exposed Support Cable After Tension Test of 100 lb (Courtesy of Argonne National Laboratory) 


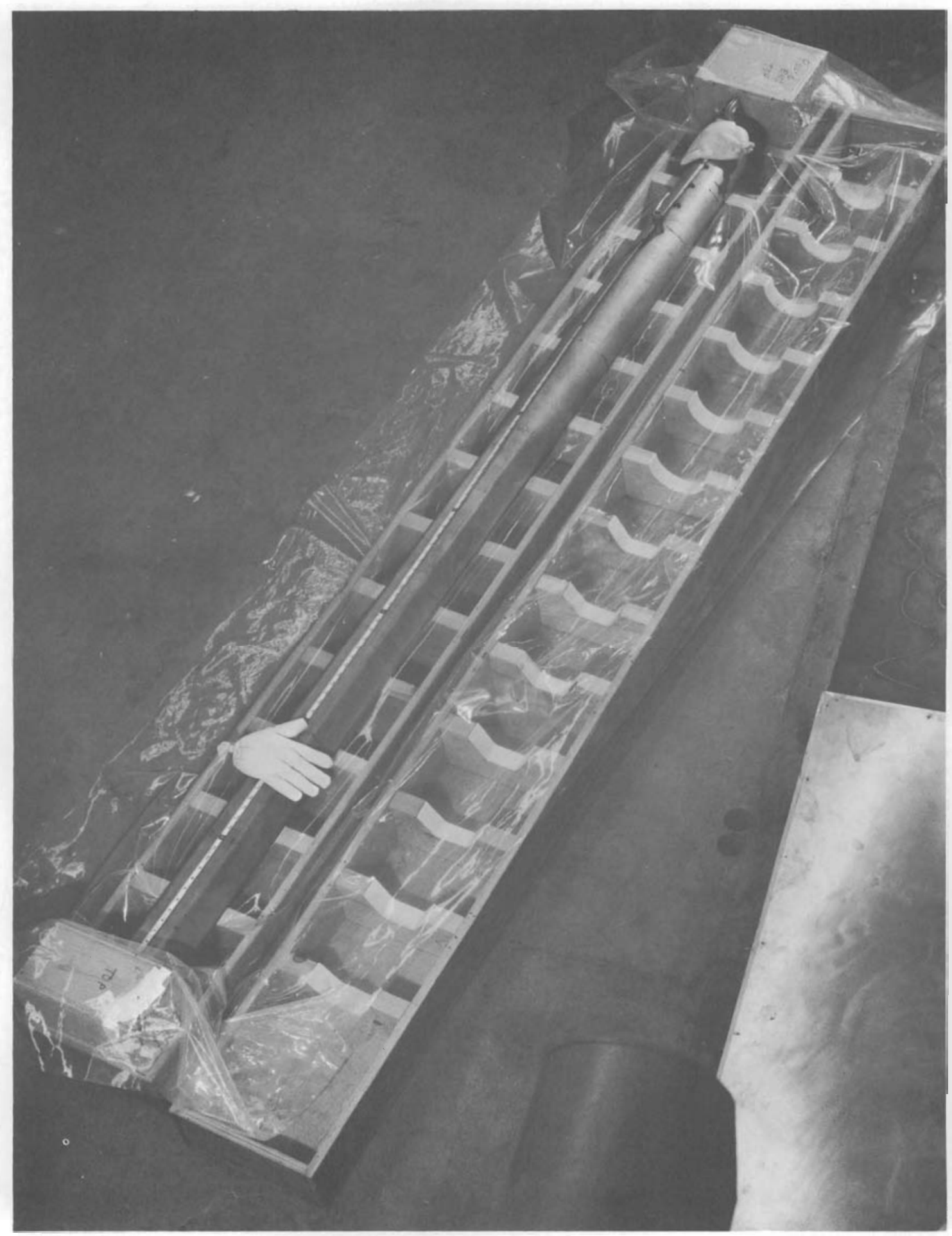

Neg ANL113-2000

FIGURE 23. Crated Subassembly prior to shipment (Courtesy of Argonne National Laboratory) 
BNWL - 1261

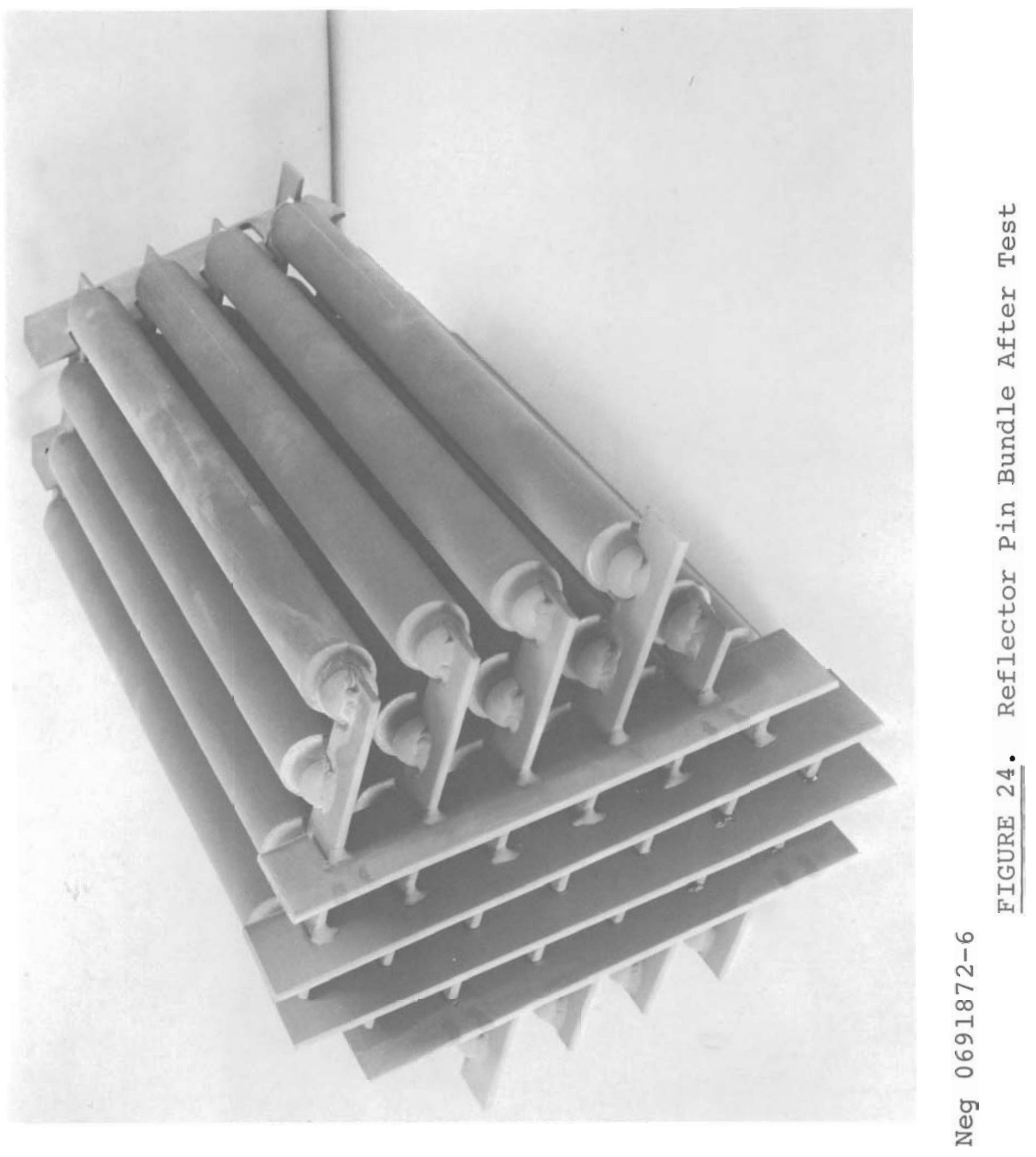


duct, were removed by grinding (Figure 25). The flow duct was lifted from the pin bundle, and the outside layers of pins, the outer wire wrap, the top grid plate, and the bottom locking grid were visually examined and the loose wire wraps were discovered. Measurements were taken across bundle flats at intervals of $1 \mathrm{ft}$ along the length, and the pin bundle was moved to a horizontal position (Figure 26).

A visual examination was made of the flow duct, including the inner surface (Figure 27). Post-test measurements taken from the flow duct for comparison with pretest dimensions include:

- OD across the flats and corners at $1 \mathrm{ft}$ intervals along the length of the hexagonal section

- $O D$ at $1 \mathrm{ft}$ intervals along the length of the circular section

- ID and wall thickness at each end

- Bow in the hexagonal section

- Drop, or radial distance from an imaginary extension of the round section of the duct to the middle of each flat

- Twist in the hexagonal section.

Both ends were also checked with ring and plug gauges. The ring gauge accepted the round end of the duct (i.e., the OD of the round end of the duct was acceptable) but did not accept the hexagonal end. Neither the hexagonal end of the duct nor the round end of the duct accepted the plug gauge. Therefore, the OD and ID of the hexagonal end and the ID of the round end of the duct were in a "no go," or out of tolerance, condition after being removed from the test loop. 
BNWL - 1261

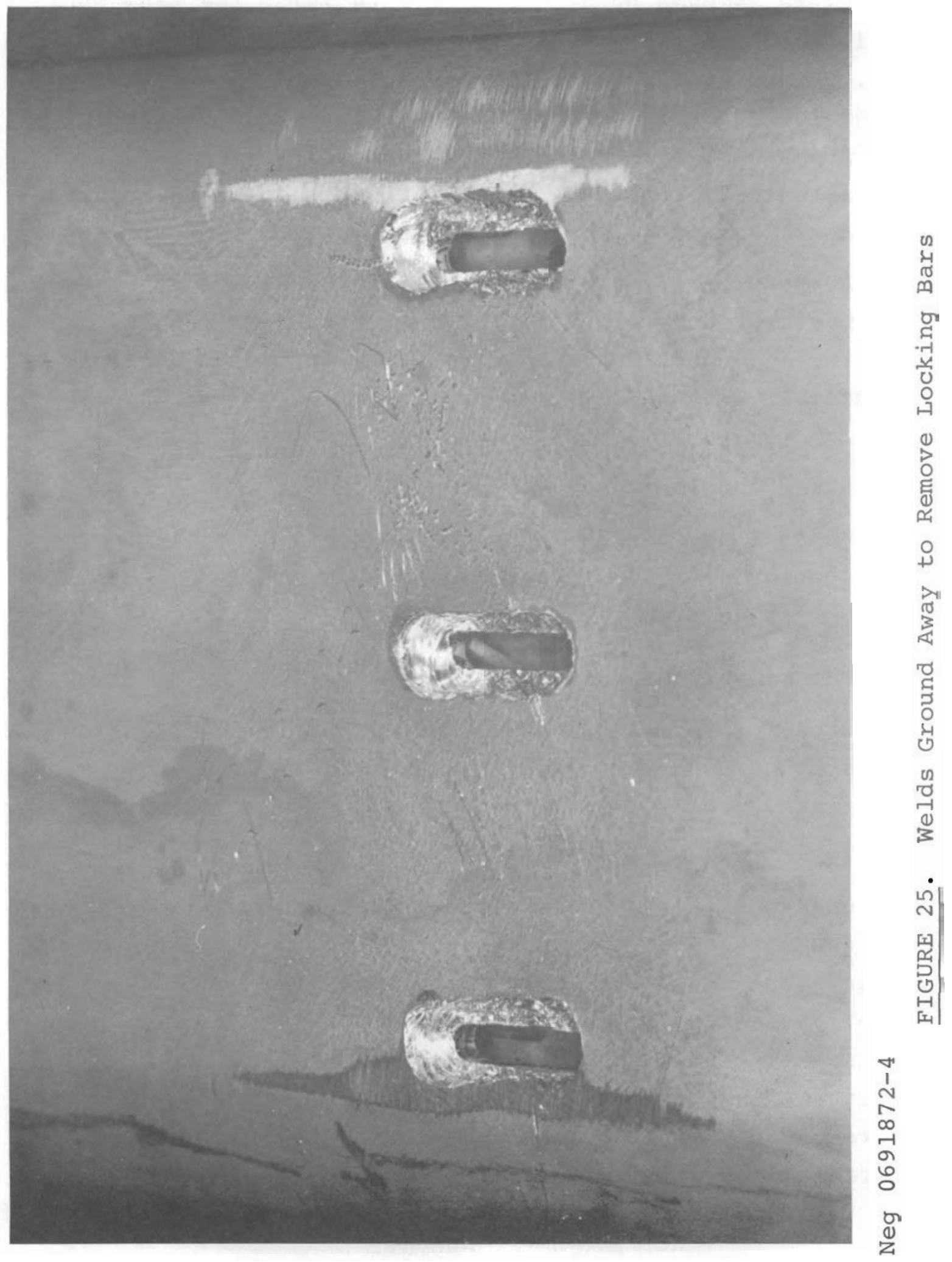


BNWL - 1261

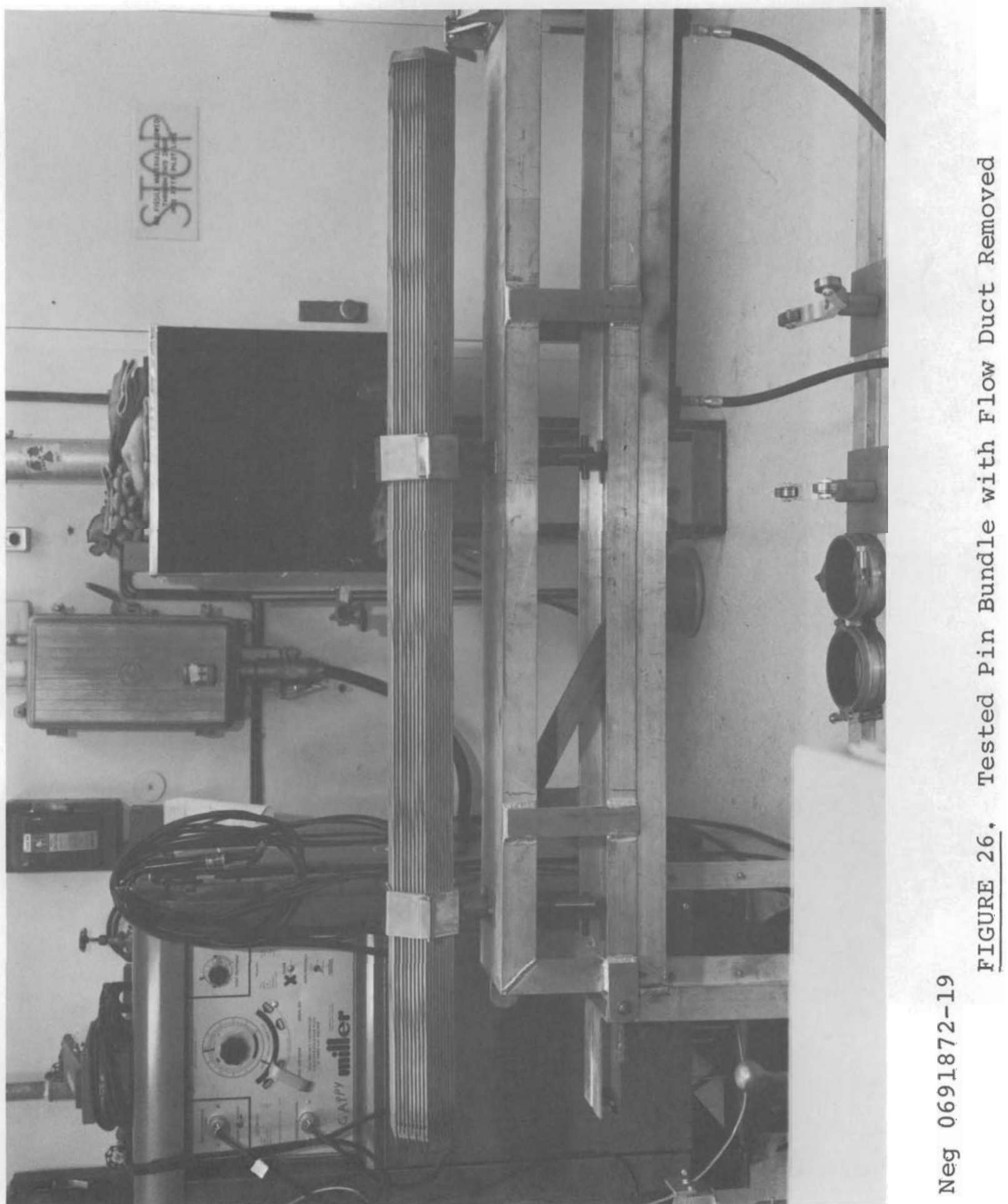


BNWL-1261

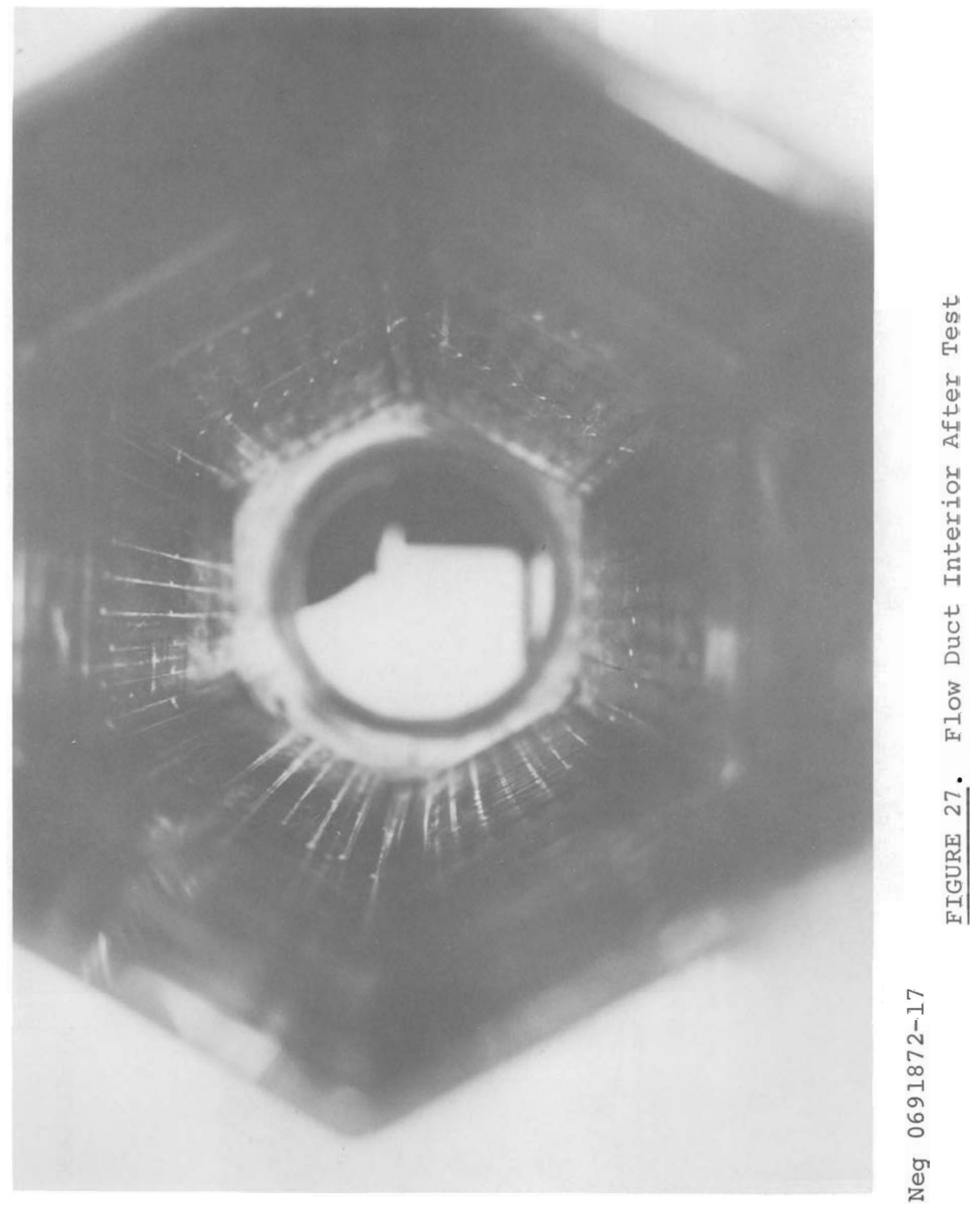


The locations of the measurements taken are shown in the diagram below. The measurements with pretest measurements are given in Tables 2 through 5 .

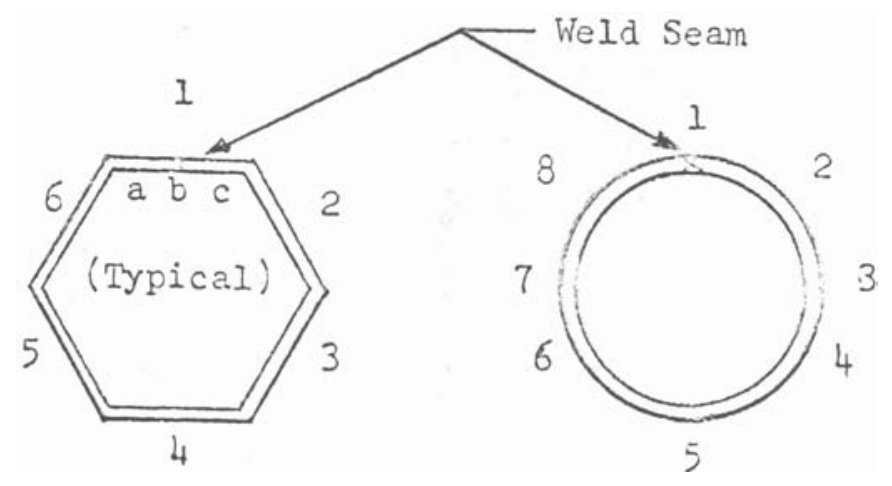

Duct Measurement Locations

(Looking from each end of the duct towards the middle.)

A $1 \mathrm{ft}$ long section was cut out of the hexagonal end of the duct, and one flat was cut from this section (Figures 28, 29, and 30). A visual examination of the inside surface revealed scratches caused by the assembly and removal of the pin bundle, and scuff marks caused by vibrating wires near the duct surface. The surface roughness, measured with a profilometer in the Tech Shops, was 35 to $45 \mu$ in. No difference in surface roughness was detected across the scuff marks.

After the duct was removed from the bundle, diametral measurements were taken across each flat at $1 \mathrm{ft}$ intervals along the length of the bundle. These measurements, taken with the bundle in a vertical position, are tabulated in Table 6 according to the corresponding duct flats as given in the above diagram. 
TABLE 2. Duct Diametral Measurements - Hex End

\begin{tabular}{|c|c|c|c|c|c|c|c|c|c|c|c|c|}
\hline \multirow{3}{*}{$\begin{array}{l}\text { Distance } \\
\text { from Hex } \\
\text { End, ft } \\
\end{array}$} & \multicolumn{12}{|c|}{ Pretest Location, in. } \\
\hline & \multicolumn{3}{|c|}{ Flat 1} & \multicolumn{3}{|c|}{ F1at 2} & \multicolumn{3}{|c|}{ Flat 3} & \multicolumn{3}{|c|}{ Across Corners } \\
\hline & $1 \mathrm{a}$ & $1 b$ & $1 c$ & $2 a$ & $2 b$ & $2 c$ & $3 a$ & $3 \mathrm{~b}$ & $3 c$ & $1-2$ & $2-3$ & $3-4$ \\
\hline $1 / 2$ & 4.539 & 4.513 & 4.535 & 4.539 & 4.512 & 4.535 & 4.535 & 4.511 & 4.540 & 5.109 & 5.108 & 5.109 \\
\hline $11 / 2$ & 4.544 & 4.515 & 4.535 & 4.542 & 4.514 & 4.537 & 4.534 & 4.511 & 4.541 & 5.112 & 5.109 & 5.110 \\
\hline $21 / 2$ & 4.547 & 4.517 & 4.538 & 4.541 & 4.514 & 4.537 & 4.534 & 4.512 & 4.542 & 5.113 & 5.108 & 5.111 \\
\hline $31 / 2$ & 4.547 & 4.518 & 4.536 & 4.540 & 4.514 & 4.537 & 4.535 & 4.514 & 4.542 & 5.112 & 5.110 & 5.110 \\
\hline $41 / 2$ & 4.550 & 4.520 & 4.538 & 4.542 & 4.515 & 4.536 & 4.536 & 4.514 & 4.542 & 5.113 & 5.109 & 5.111 \\
\hline $51 / 2$ & 4.550 & 4.520 & 4.538 & 4.541 & 4.516 & 4.537 & 4.535 & 4.514 & 4.542 & 5.114 & 5.111 & 5.111 \\
\hline ID & 4.227 & 4.256 & 4.214 & 4.224 & 4.237 & 4.223 & 4.222 & 4.242 & 4.226 & 4.818 & 4.816 & 4.821 \\
\hline
\end{tabular}

Post-test Location, in.

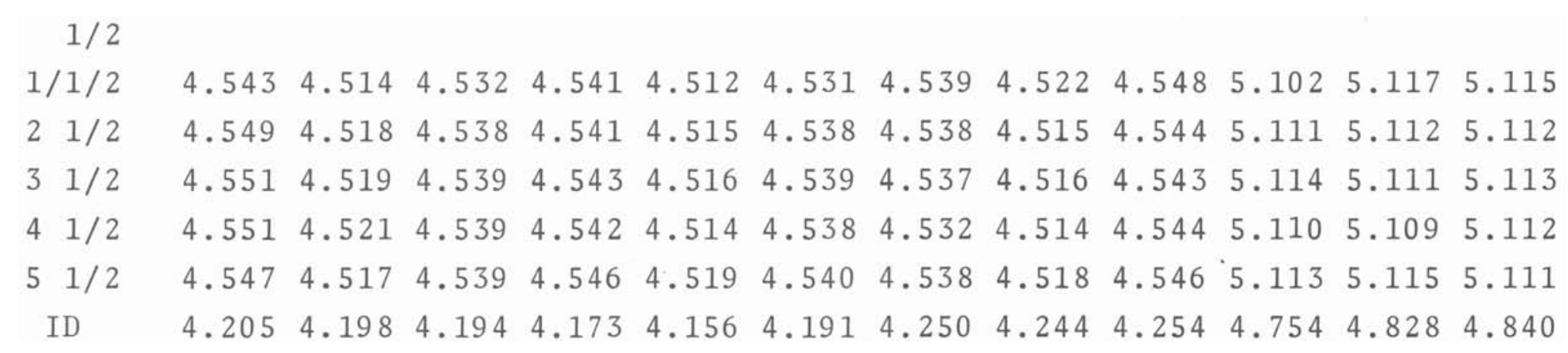


BNWL - 1261

TABLE 3. Duct Diametral Measurements - Round End

\begin{tabular}{|c|c|c|c|c|}
\hline \multirow{2}{*}{$\begin{array}{l}\text { Distance } \\
\text { from Round } \\
\text { End, ft } \\
\end{array}$} & \multicolumn{4}{|c|}{ Pretest Location, in. } \\
\hline & Flat 1 & Flat 2 & F1at 3 & Flat 4 \\
\hline $\begin{array}{ll} & 1 / 2 \\
1 & 1 / 2 \\
2 & 1 / 2 \\
3 & 1 / 2 \\
\text { ID }\end{array}$ & $\begin{array}{c}5.137 \\
5.137 \\
5.134 \\
5.136 \\
---\end{array}$ & $\begin{array}{c}5.130 \\
5.124 \\
5.126 \\
5.124 \\
---\end{array}$ & $\begin{array}{c}5.129 \\
5.129 \\
5.132 \\
5.131 \\
---\end{array}$ & $\begin{array}{c}5.129 \\
5.132 \\
5.132 \\
5.133 \\
---\end{array}$ \\
\hline ID & \multicolumn{4}{|c|}{ Post-test Location, in. } \\
\hline $\begin{array}{cl} & 1 / 2 \\
1 & 1 / 2 \\
2 & 1 / 2 \\
3 & 1 / 2 \\
\text { ID }\end{array}$ & $\begin{array}{l}5.141 \\
5.141 \\
5.132 \\
5.136 \\
4.832\end{array}$ & $\begin{array}{l}5.132 \\
5.119 \\
5.127 \\
5.124 \\
4.824\end{array}$ & $\begin{array}{l}5.127 \\
5.127 \\
5.133 \\
5.131 \\
4.815\end{array}$ & $\begin{array}{l}5.141 \\
5.137 \\
5.131 \\
5.132 \\
4.801\end{array}$ \\
\hline
\end{tabular}

TABLE 4. Wall Thickness at Each End of Duct

Hex End

Thickness, in.

Location Pretest Post-test

$1 a$

b

c

$2 \mathrm{a}$

b

c

$3 a$

b

c

$4 \mathrm{a}$

b

c

$5 a$

b

$c$

$6 a$

b

c
0.157

0.145

0.155

0.157

0.151

0.155

0.154

0.150

0.155

0.155

0.148

0.155

0.154

0.151

0.155

0.155

0.151

0.155
0.155

0.145

0.153

0.154

0.149

0.154

0.154

0.149

0.153

0.154

0.147

0.155

0.153

0.149

0.153

0.155

0.150

0.153
Hex End (contd)

Location Pretest Post-test

1-2

$2-3$

3-4

4- 5

5-6

6-1

0.143

0.144

0.144

0.144

0.144

0.146

0.143

0.146

0.143

0.144

0.144

0.145

Round End

\begin{tabular}{|c|c|c|}
\hline \multirow[b]{2}{*}{ Location } & \multicolumn{2}{|c|}{ Thickness, in. } \\
\hline & Pretest & Post-test \\
\hline $\begin{array}{l}1 \\
2 \\
3 \\
4 \\
5 \\
6 \\
7 \\
8\end{array}$ & $\begin{array}{l}0.147 \\
0.152 \\
0.152 \\
0.153 \\
0.148 \\
0.152 \\
0.152 \\
0.152\end{array}$ & $\begin{array}{l}0.147 \\
0.152 \\
0.153 \\
0.153 \\
0.152 \\
0.152 \\
0.152 \\
0.152\end{array}$ \\
\hline
\end{tabular}


TABLE 5. Bow, Drop, and Twist in Duct Pretest

\begin{tabular}{|c|c|c|c|c|c|c|}
\hline \multirow[b]{2}{*}{$\underline{\text { Flats }}$} & \multicolumn{4}{|c|}{ Bow, in. } & \multirow{2}{*}{$\begin{array}{c}\text { Drop, } \\
\text { in. }\end{array}$} & \multirow{2}{*}{$\begin{array}{l}\text { Twist, } \\
\text { in. }\end{array}$} \\
\hline & $41 / 2 \mathrm{ft}$ & $31 / 2 \mathrm{ft}$ & $21 / 2 \mathrm{ft}$ & $11 / 2 \mathrm{ft}$ & & \\
\hline 1 & -0.057 & -0.089 & -0.102 & -0.084 & 0.447 & 0.004 \\
\hline 2 & -0.040 & -0.051 & -0.057 & -0.043 & 0.480 & \\
\hline 3 & 0.007 & 0.010 & 0.035 & 0.036 & 0.395 & \\
\hline 4 & 0.050 & 0.080 & 0.094 & 0.084 & 0.266 & \\
\hline 5 & 0.036 & 0.048 & 0.054 & 0.046 & 0.258 & \\
\hline \multirow[t]{2}{*}{6} & -0.013 & -0.036 & -0.042 & -0.037 & 0.315 & \\
\hline & \multicolumn{6}{|c|}{ Post-test } \\
\hline 1 & -0.006 & -0.005 & -0.006 & & 0.394 & 0.012 \\
\hline 2 & -0.042 & -0.054 & -0.045 & & 0.415 & \\
\hline 3 & -0.039 & -0.052 & -0.036 & & 0.315 & 0.003 \\
\hline 4 & 0.000 & -0.001 & 0.003 & & 0.211 & \\
\hline 5 & 0.041 & 0.050 & 0.041 & & 0.209 & -0.004 \\
\hline 6 & 0.050 & 0.063 & 0.060 & & 0.293 & \\
\hline
\end{tabular}


BNWL - 1261
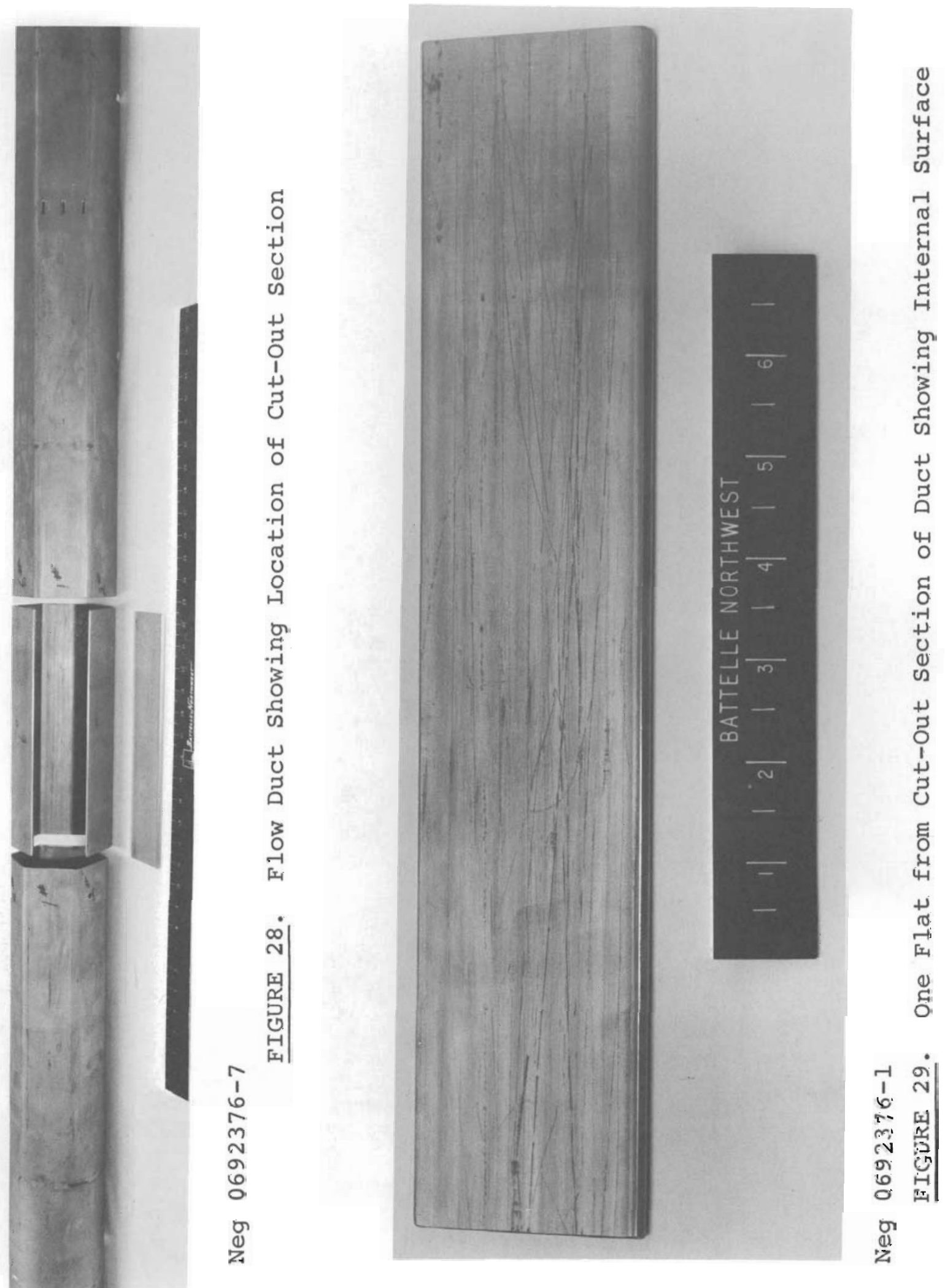
BNWL-1261

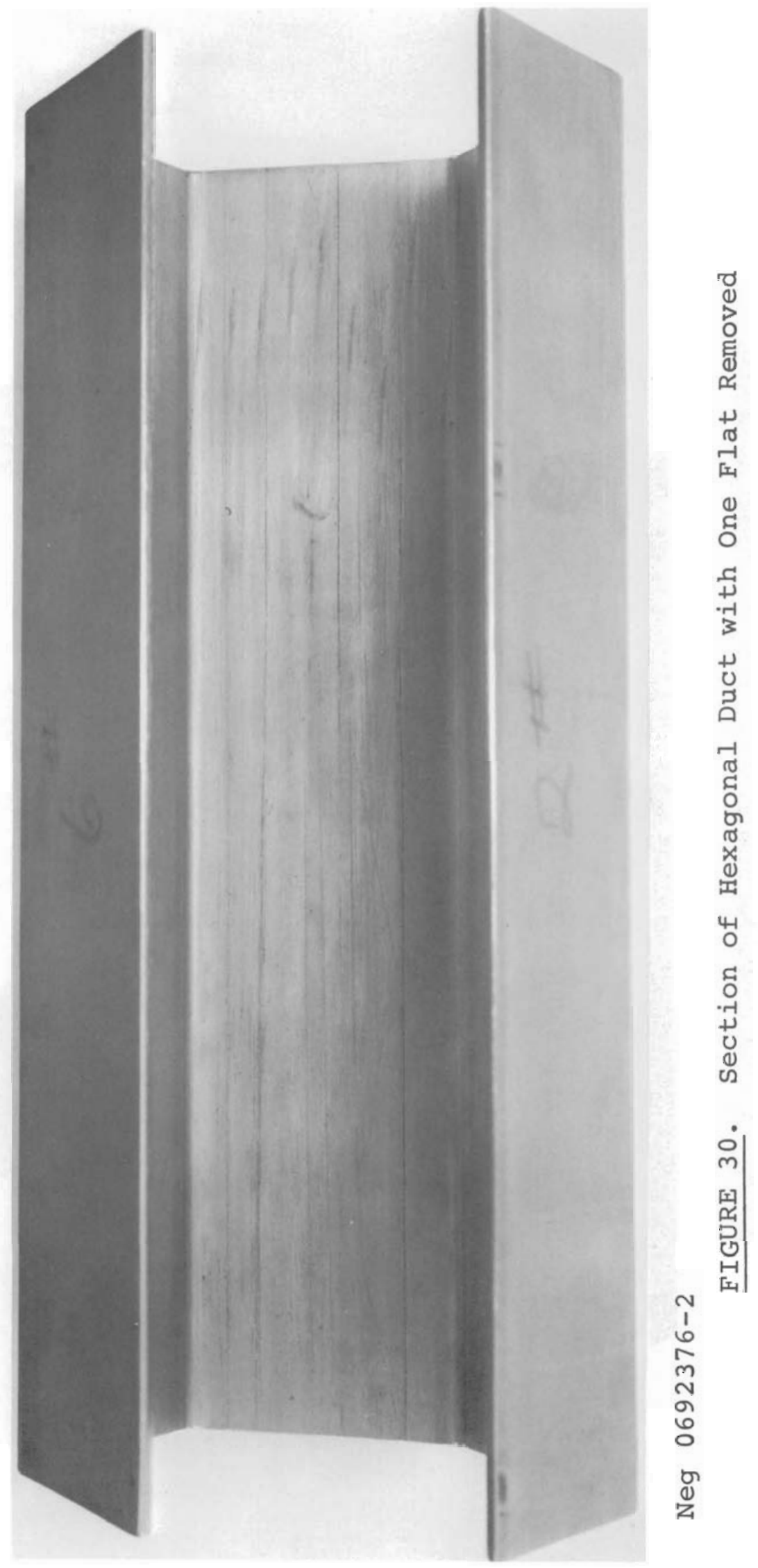


TABLE 6. Bundle Cross-Flat Measurements

\begin{tabular}{|c|c|c|c|c|c|c|}
\hline \multirow[b]{2}{*}{ Flats } & \multicolumn{2}{|c|}{ Diameters } & \multicolumn{3}{|c|}{$t$ Indicated Interval } & \multirow{2}{*}{ in. } \\
\hline & $0-1$ & $1-2$ & $2-3$ & $3-4$ & $4-5$ & \\
\hline $1-4$ & 4.259 & 4.251 & 4.254 & 4.205 & 4.240 & 4.235 \\
\hline $2-5$ & 4.241 & 4.221 & 4.225 & 4.235 & 4.250 & 4.250 \\
\hline $3-6$ & 4.224 & 4.200 & 4.195 & 4.259 & 4.235 & 4.249 \\
\hline
\end{tabular}

When the top grid plate was removed from the bundle (Figures 31 and 32), no evidence of distortion or dimensional change was apparent. The bottom locking grid was examined in place (Figure 33), with no evidence of corrosion, .ear, or dimensional change.

When the fuel pin bundle was again raised to the vertical position, pins were removed by strip layers [starting with the row next to flat 3 in the flow duct (Figure 34)]. The appearance of the pins in the first row is shown in Figures 35, 36 , and 37 .

Pin diameters were measured at $1 \mathrm{ft}$ intervals on the first strip layer (Pins 1 through 9). These values are shown in Table 7. Each pin in the bundle was numbered, as was each strip layer and duct flat (Figure 38 ).

The looseness in the wire wrap was measured in pins numbered 1 through 8, 10 through 30, and 101 through 117 . These measurements were made by pulling the wire away from the pin with $1 / 21 \mathrm{~b}$ tension, the minimum tension necessary to take up the slack in the wires (Figure 39). The gap distance, measured with a taper gauge, was converted to a looseness value with the aid of a graph (Figure 40) constructed specifically for this purpose. The looseness values are given in Table 8 .

Pins 17, 51, and 110 were selected at random for bow measurements (Table 9). 
BNWL -1261

TABLE 6. Bundle Cross-Flat Measurements

\begin{tabular}{|c|c|c|c|c|c|c|}
\hline \multirow[b]{2}{*}{ Flats } & \multicolumn{2}{|c|}{ Diameters a } & \multicolumn{3}{|c|}{ Indicated Interval, } & in. \\
\hline & $0-1$ & $1-2$ & $2-3$ & $3-4$ & $4-5$ & $5-6$ \\
\hline $1-4$ & 4.259 & 4.251 & 4.254 & 4.205 & 4.240 & 4.235 \\
\hline $2-5$ & 4.241 & 4.221 & 4.225 & 4.235 & 4.250 & 4.250 \\
\hline $3-6$ & 4.224 & 4.200 & 4.195 & 4.259 & 4.235 & 4.249 \\
\hline
\end{tabular}

When the top grid plate was removed from the bundle (Figures 31 and 32), no evidence of distortion or dimensional change was apparent. The bottom locking grid was examined in place (Figure 33), with no evidence of corrosion, near, or dimensional change.

When the fuel pin bundle was again raised to the vertical position, pins were removed by strip layers [starting with the row next to Flat 3 in the flow duct (Figure 34)]. The appearance of the pins in the first row is shown in Figures 35, 36 , and 37 .

Pin diameters were measured at $1 \mathrm{ft}$ intervals on the first strip layer (Pins 1 through 9). These values are shown in Table 7. Each pin in the bundle was numbered, as was each strip layer and duct flat (Figure 38).

The looseness in the wire wrap was measured in pins numbered 1 through 8, 10 through 30, and 101 through 117. These measurements were made by pulling the wire away from the pin with $1 / 21 \mathrm{~b}$ tension, the minimum tension necessary to take up the slack in the wires (Figure 39). The gap distance, measured with a taper gauge, was converted to a looseness value with the aid of a graph (Figure 40) constructed specifically for this purpose. The looseness values are given in Table 8 .

Pins 17, 51, and 110 were selected at random for bow measurements (Table 9). 
BNWL-1261

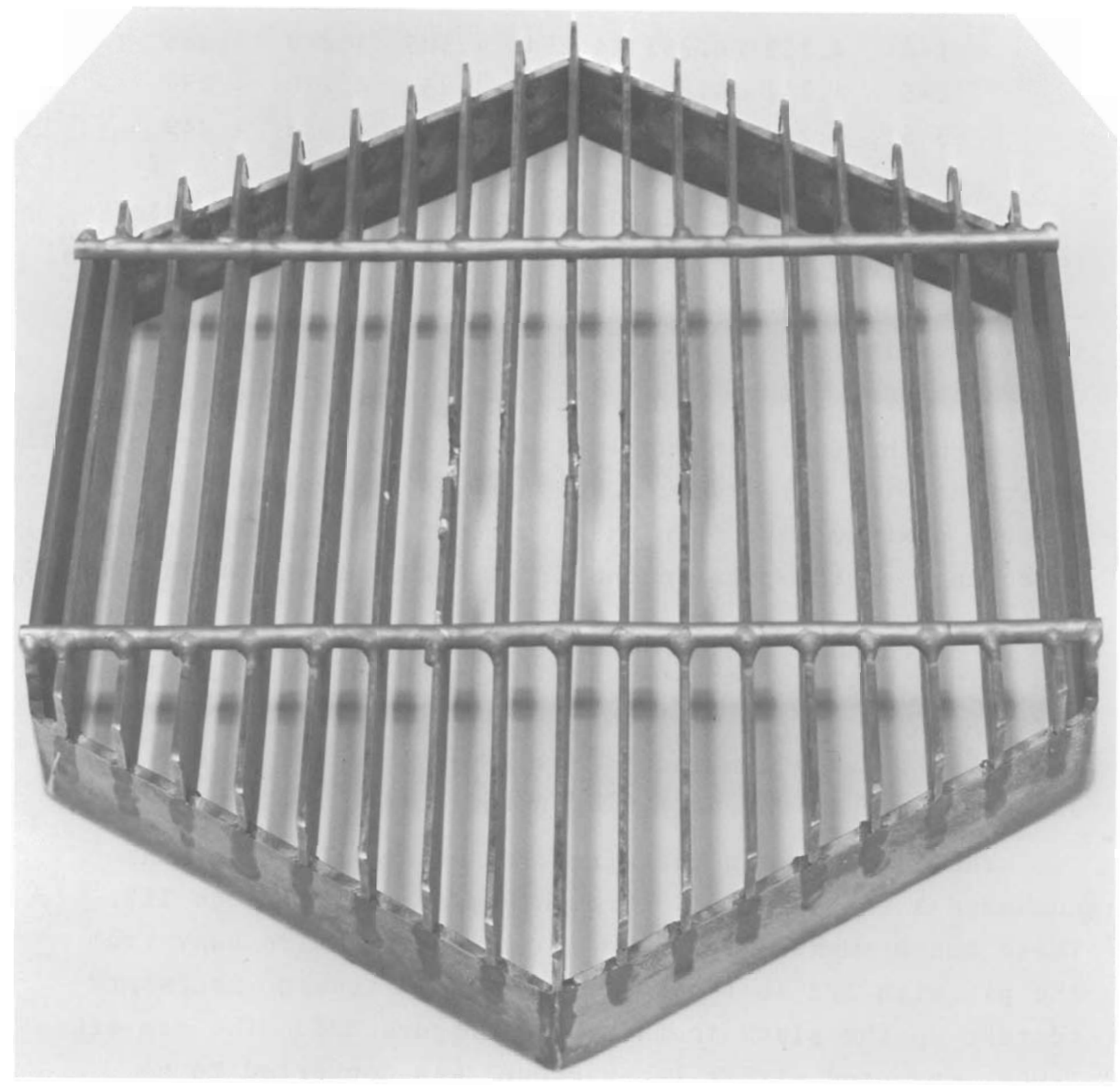

Neg 0692165-1

FIGURE 31. Top Grid Plate After Removal from Pin Bundle 
BNWL-1261

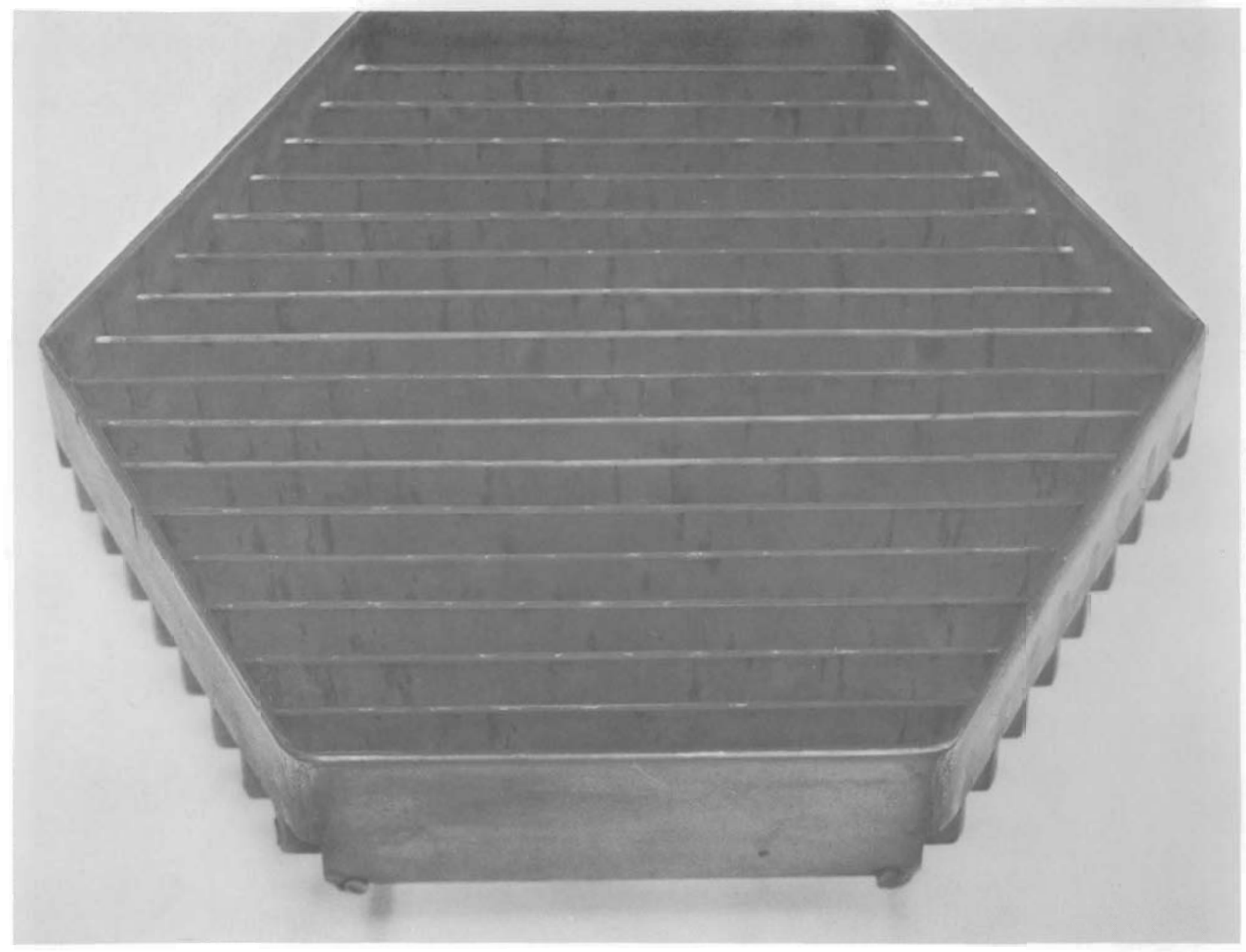

Neg 0692165-2

FIGURE 32. Bottom View of Top Grid Plate After Removal from Pin Bundle 


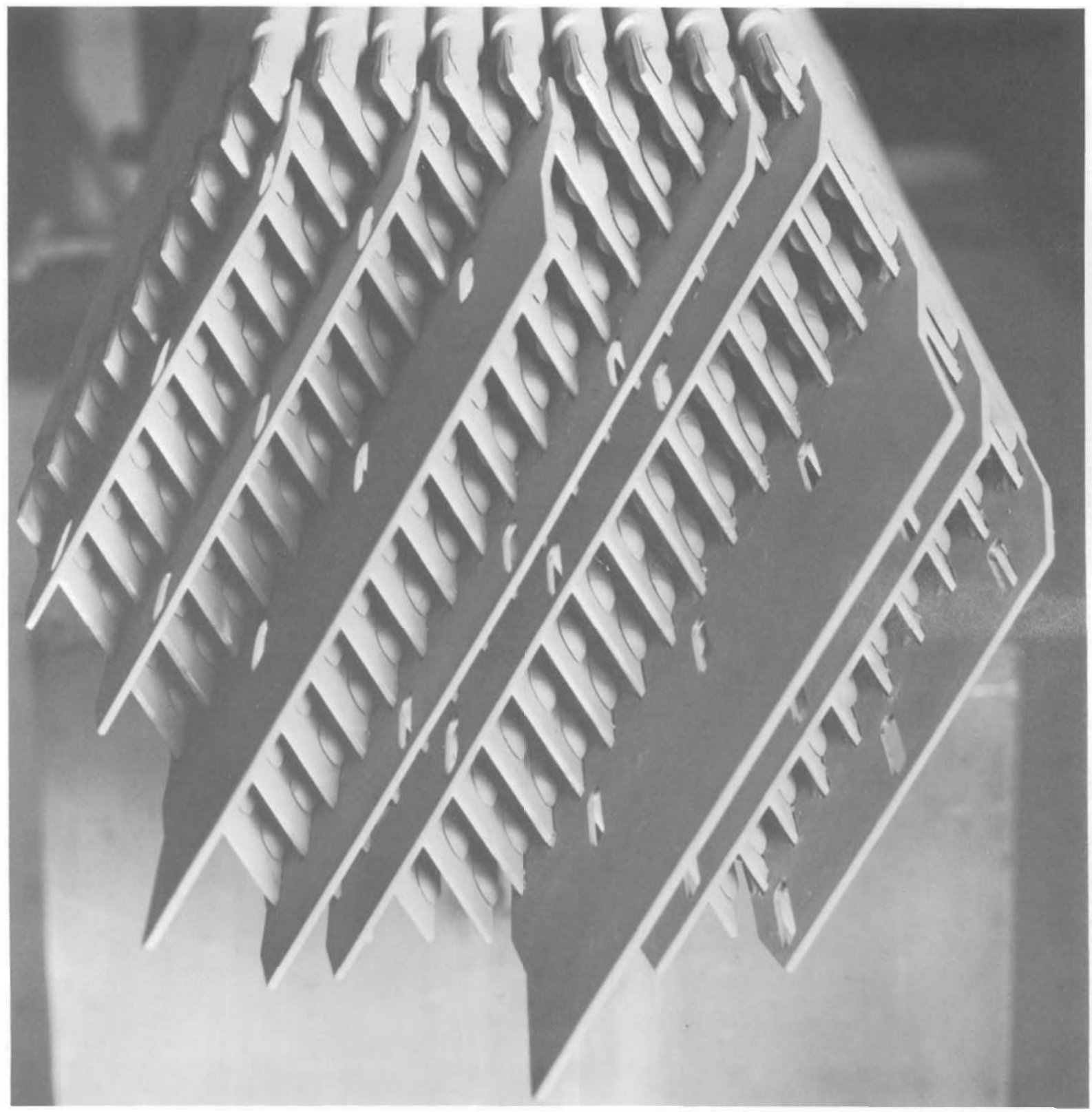

Neg $0691872-20$

FIGURE 33. Bottom Locking Grid After Test 


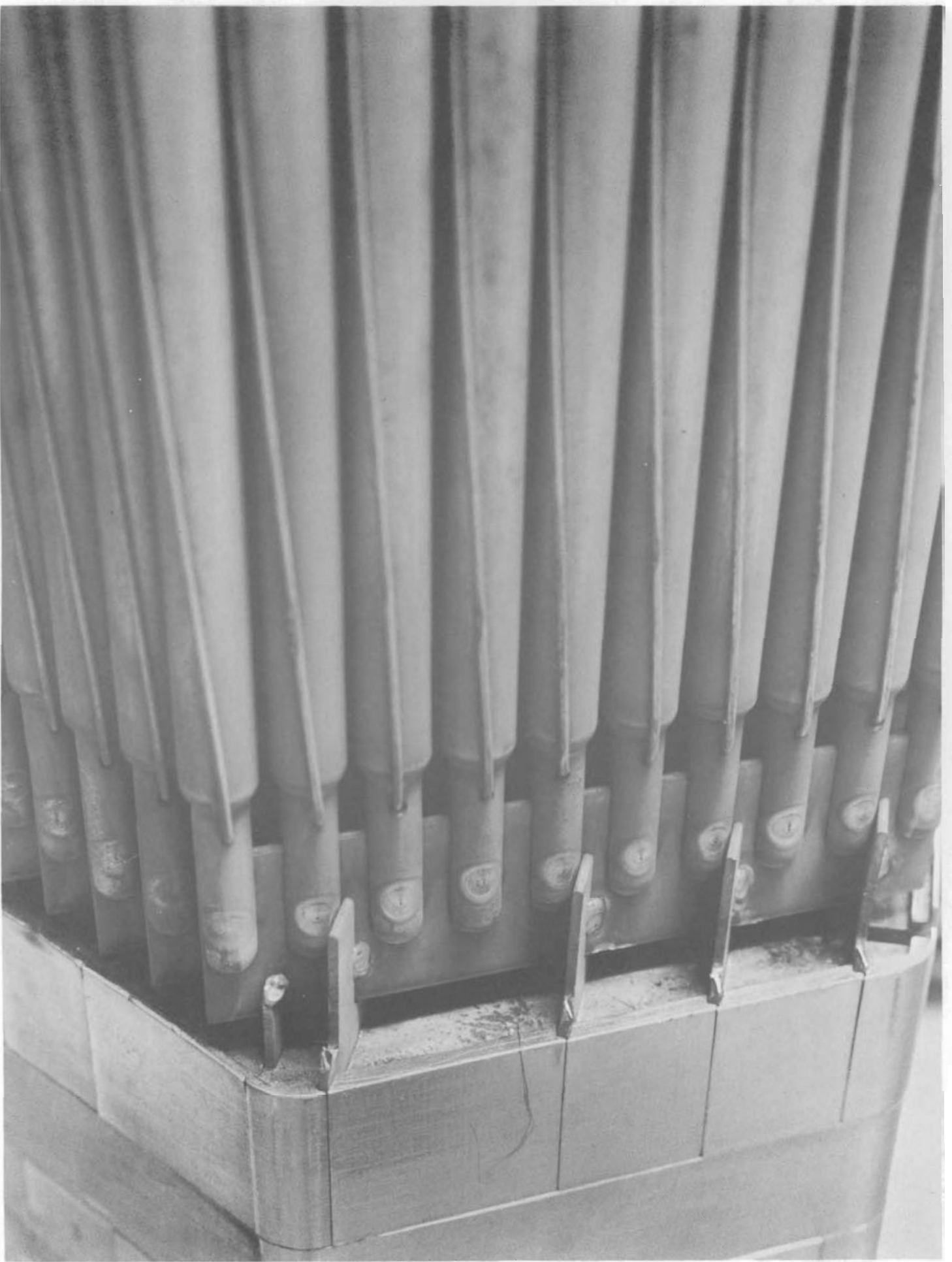

Neg 0692139-5

FIGURE 34. Pin Bundle with First Strip Layer Removed 
BNWL-1261

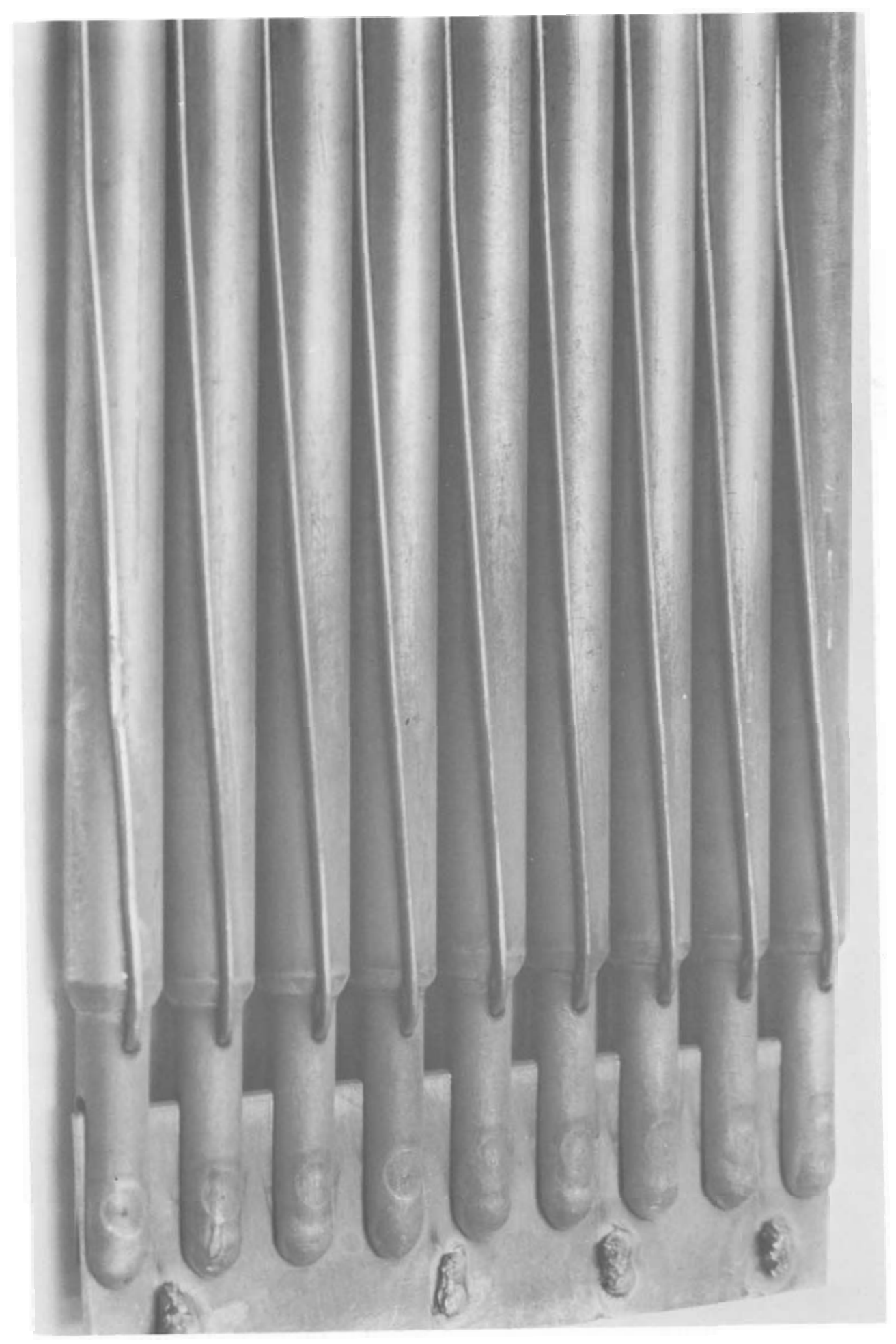

Neg 0692139-4

FIGURE 35. First Pin Layer Removed - Bottom End Cap Region 
BNWL-1261

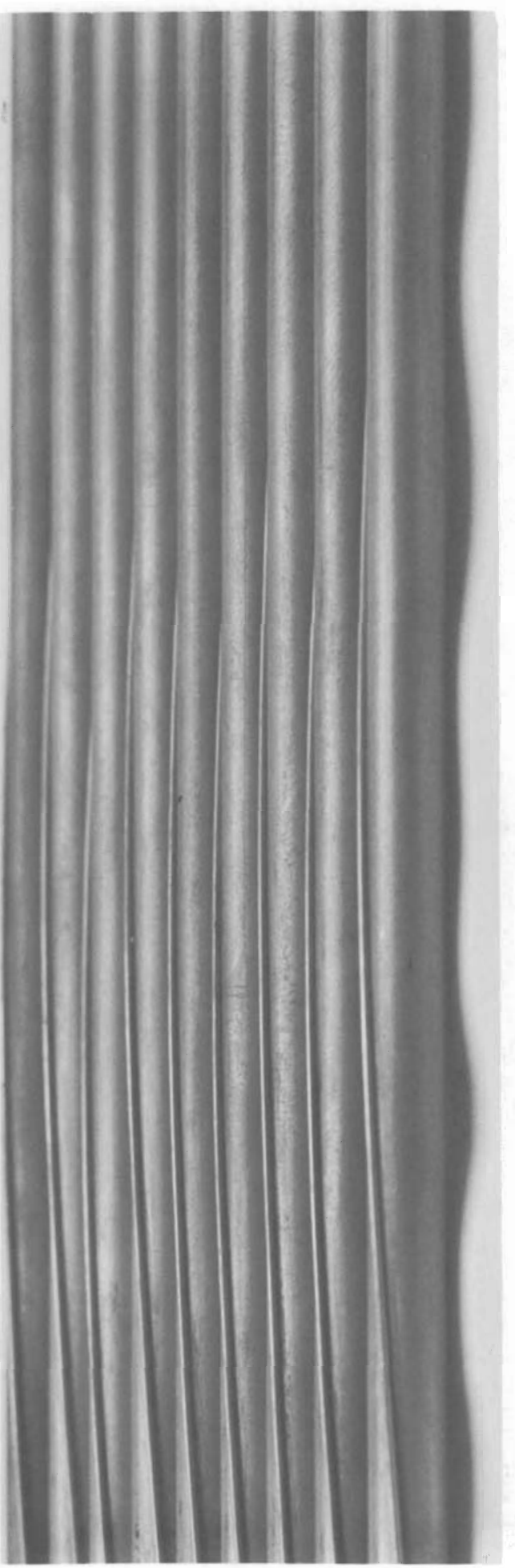

Neg 0692139-6

FIGURE 36. First Pin Layer Removed - Central Region 


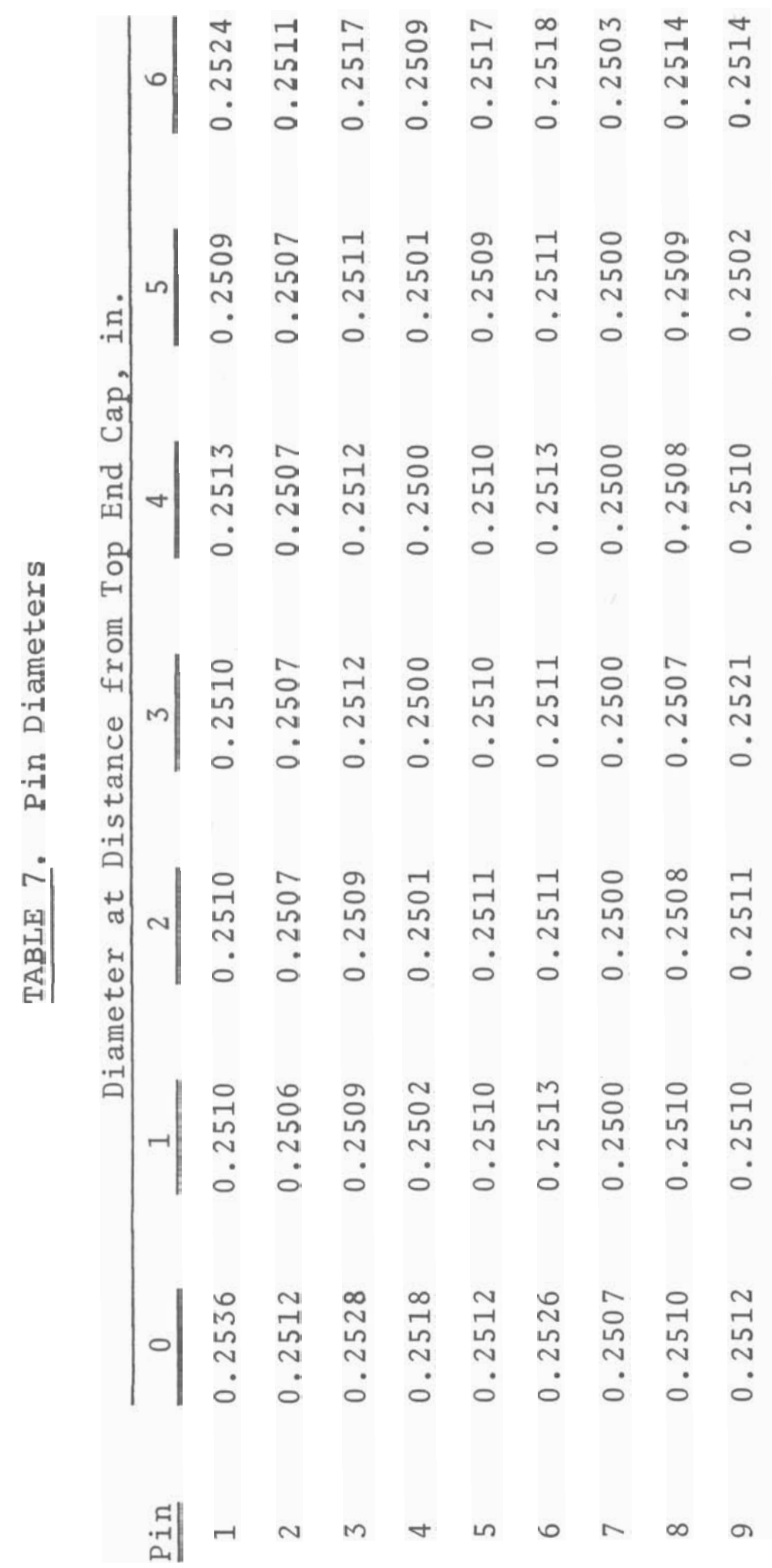


BNWL-1261

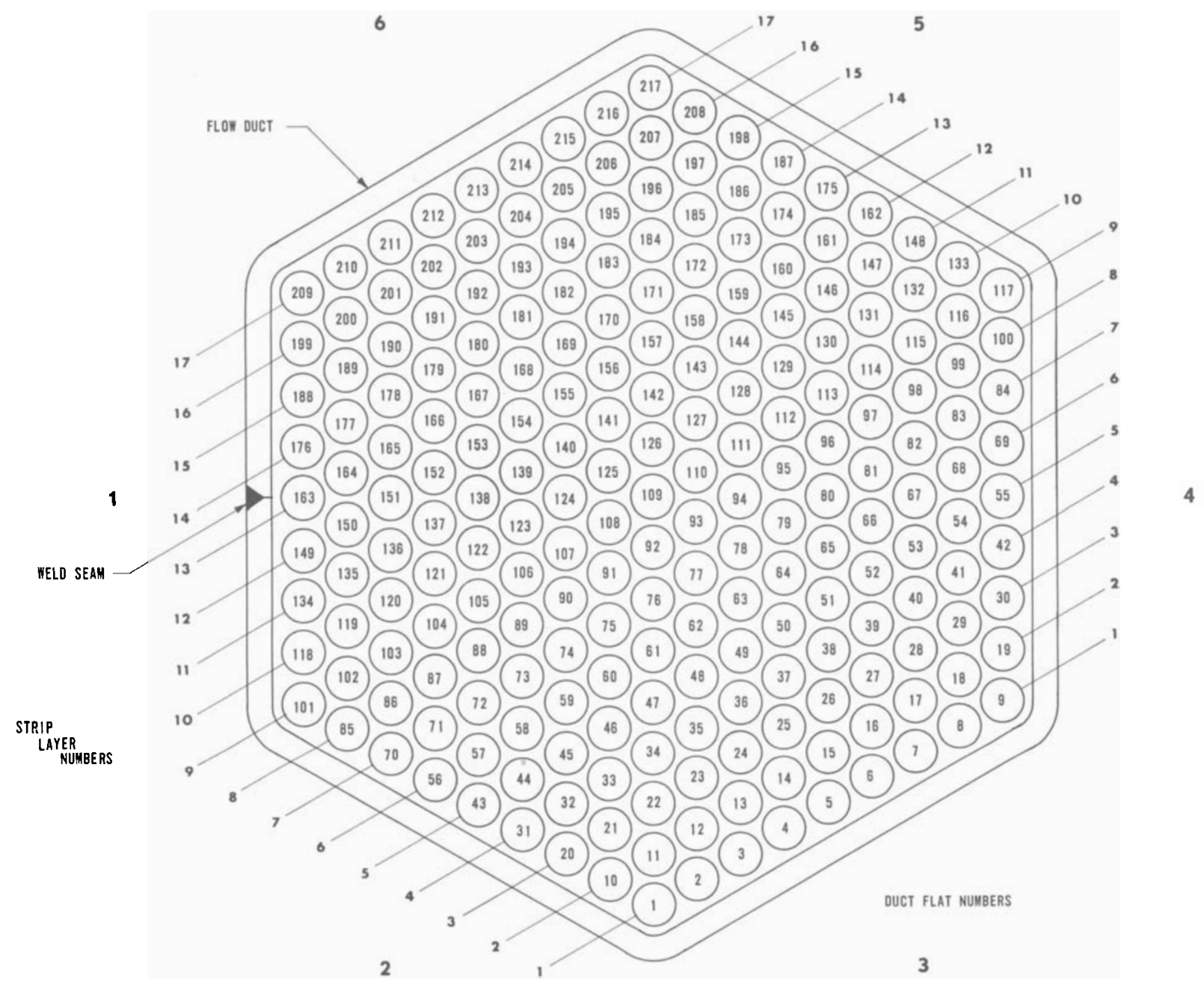

Neg 0693836

FIGURE 38. Bundle Cross Section Showing Pin Numbers 
BNWL- 1261

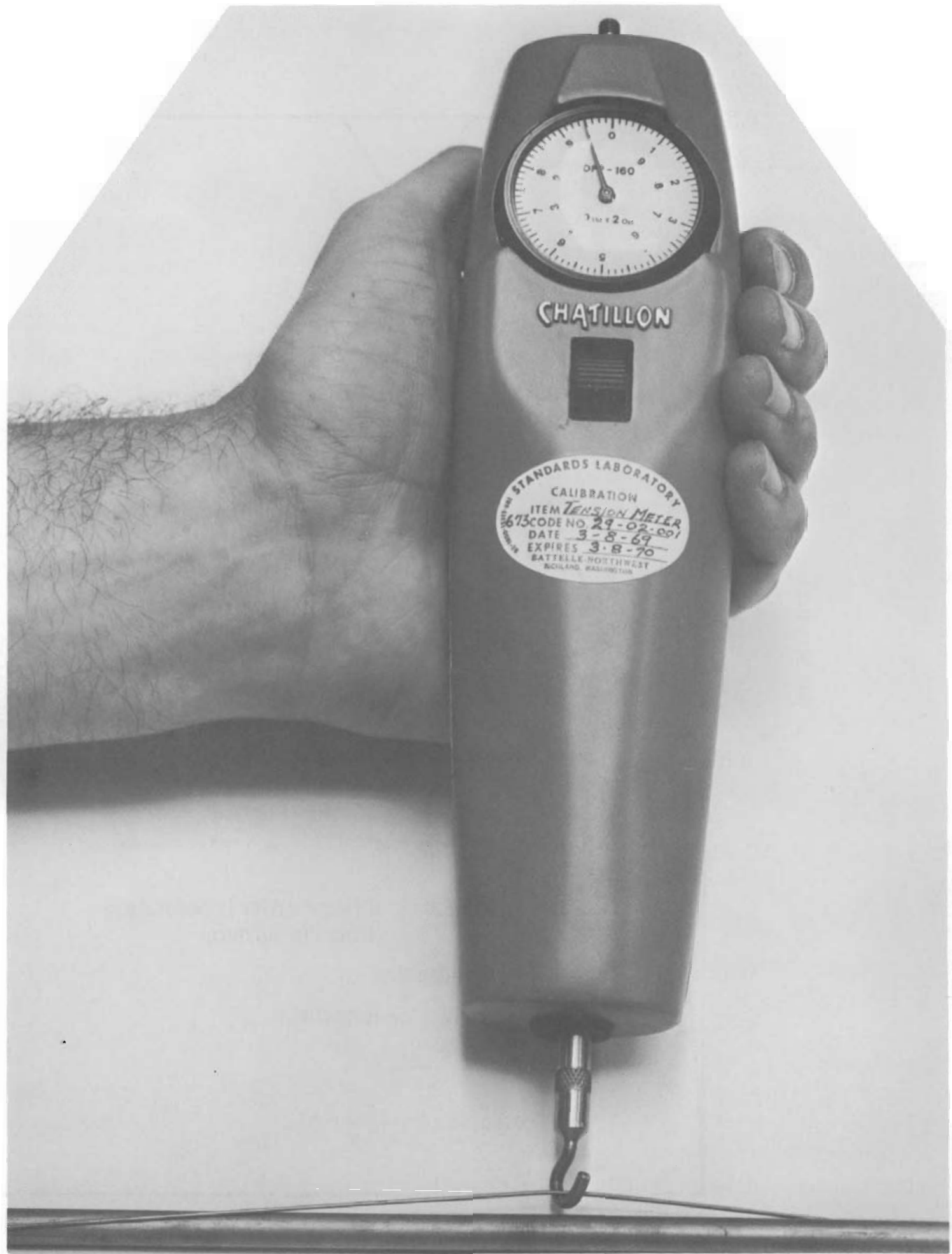

Neg 0692165-6

FIGURE 39. Wire Wrap Slack 


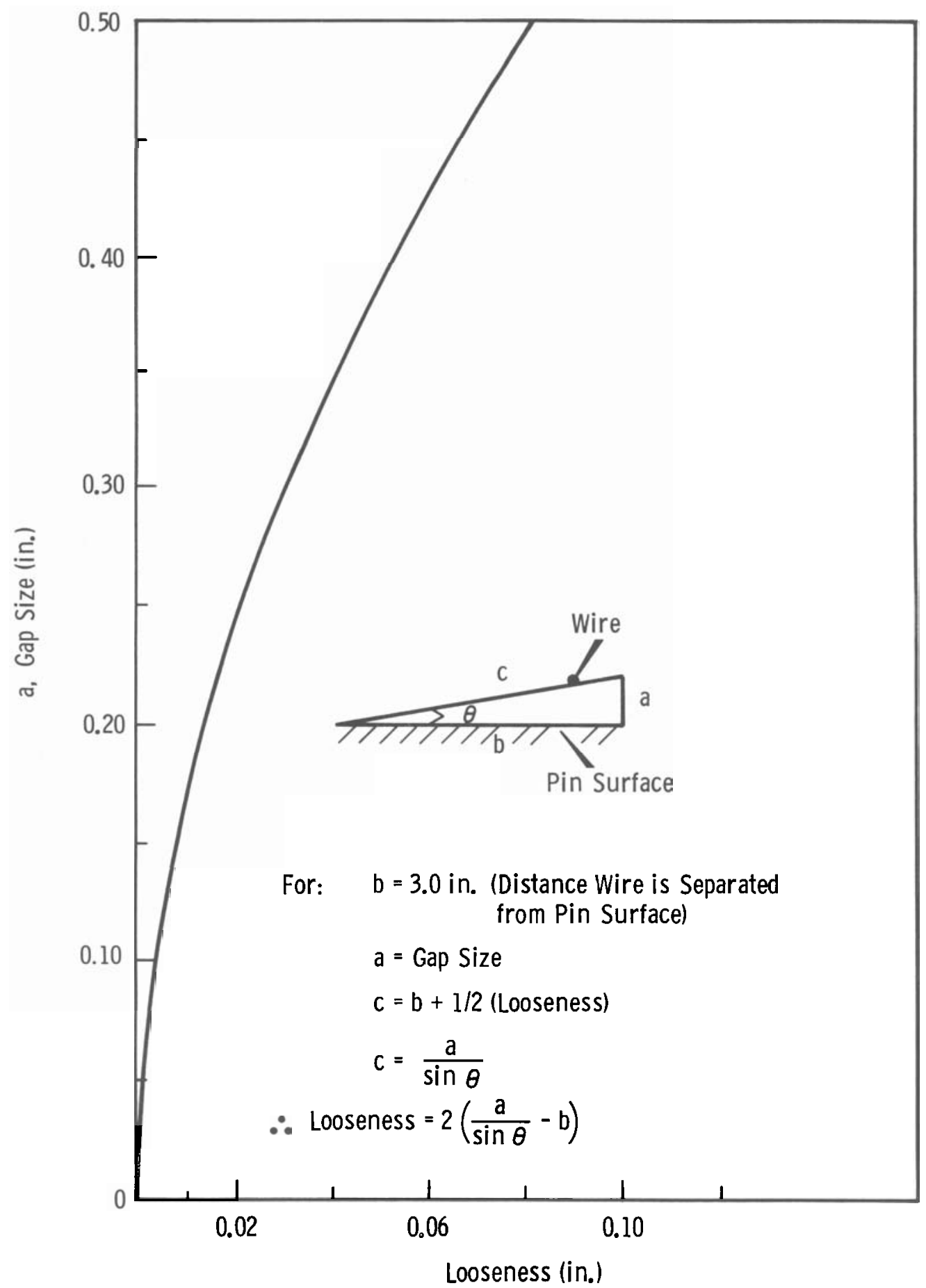

Neg 0693967

FIGURE 40. Curve for Wire Wrap Looseness Versus Gap 
TABLE 8. Wire Wrap Looseness

\begin{tabular}{|c|c|c|c|c|c|}
\hline $\begin{array}{l}\text { Pin } \\
\text { No. }\end{array}$ & $\begin{array}{l}\text { Looseness, } \\
\text { in. }\end{array}$ & $\begin{array}{l}\text { Pin } \\
\text { No. }\end{array}$ & $\begin{array}{c}\text { Looseness, } \\
\text { in. }\end{array}$ & $\begin{array}{l}\text { Pin } \\
\text { No. }\end{array}$ & $\begin{array}{c}\text { Looseness, } \\
\text { in. }\end{array}$ \\
\hline 1 & 0.003 & 17 & 0.004 & 102 & 0.006 \\
\hline 2 & 0.003 & 18 & 0.003 & 103 & 0.004 \\
\hline 3 & 0.003 & 19 & 0.003 & 104 & 0.003 \\
\hline 4 & 0.005 & 20 & 0.002 & 105 & 0.003 \\
\hline 5 & 0.006 & 21 & 0.002 & 106 & 0.002 \\
\hline 6 & 0.004 & 22 & 0.002 & 107 & 0.003 \\
\hline 7 & 0.003 & 23 & 0.003 & 108 & 0.002 \\
\hline 8 & 0.004 & 24 & 0.003 & 109 & 0.004 \\
\hline 10 & 0.006 & 25 & 0.002 & 110 & 0.004 \\
\hline 11 & 0.005 & 26 & 0.003 & 111 & 0.004 \\
\hline 12 & 0.005 & 27 & 0.004 & 112 & 0.004 \\
\hline 13 & 0.004 & 28 & 0.003 & 113 & 0.004 \\
\hline 14 & 0.002 & 29 & 0.003 & 114 & 0.005 \\
\hline 15 & 0.002 & 30 & 0.004 & 115 & 0.003 \\
\hline \multirow[t]{2}{*}{16} & 0.002 & 101 & 0.005 & 116 & 0.002 \\
\hline & & & & 117 & 0.005 \\
\hline
\end{tabular}

TABLE 9. Pin Bow

Pin

Number

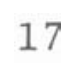

51

110
Bow at Distance from Top End Cap, in.

\begin{tabular}{lrlllllll}
\hline $0 \mathrm{ft}$ & $1 \mathrm{ft}$ & $\frac{2 \mathrm{ft}}{1}$ & $\underline{\mathrm{ft}}$ & $4 \mathrm{ft}$ & $5 \mathrm{ft}$ & $6 \mathrm{ft}$ \\
-0.001 & -0.002 & 0.003 & 0.008 & -0.003 & -0.005 & 0.012 \\
0.001 & 0.002 & 0.002 & 0.001 & 0.002 & 0.005 & 0.013 \\
0.010 & 0.004 & 0.003 & 0.003 & 0.003 & 0.003 & 0.005
\end{tabular}


BNWL -1261

Pins 9, 51, 110 were sectioned for a metallographic examination based on comparisons with micrographs of archive wire and cladding material (Figures 41 through 45). Two samples from Pin No. 9 cladding were prepared for examination (Figures 46 through 49). A section from the Pin No. 9 wire wrap was also polished, etched, and photographed (Figures 50 and 51). Two sections of cladding were examined from. Pin No. 51 (Figures 52 through 55), and one was examined from Pin No. 110 (Figures 56 and 57).

None of the photomicrographs showed appreciable intergranular attack or surface damage, on either cladding or wire wrap samples. All of the exposed samples exhibited the carbide precipitation in the grain boundaries created by the temperature $\left(1060^{\circ} \mathrm{F}\right)$ of the test.

A section of the wire wrap from Pin No. 9 was tensiletested and compared to a tensile test on the archive wire (Table 10). A section of the Pin 9 tubing was burst-tested (Figure 58) and compared to a burst test on archive material. As expected, results showed a burst pressure of 9950 psi for the archive sample and a burst pressure of 10,980 psi for the run test sample with its heavy carbide precipitation in the grain boundaries.

TABLE 10. Wire Wrap Tensile Test (room temperature)

\begin{tabular}{|c|c|c|}
\hline & $\begin{array}{l}\text { Archive } \\
\text { Sample }\end{array}$ & $\begin{array}{l}\text { Flow Test } \\
\text { Sample }\end{array}$ \\
\hline U1timate Tensile Stress, psi & 97,140 & 107,000 \\
\hline $0.2 \%$ Offset Yield Strength, psi & 40,000 & 62,860 \\
\hline Total Elongation, \% & 92.3 & 31.63 \\
\hline Uniform Elongation, $\%$ & 67.72 & 31.0 \\
\hline
\end{tabular}




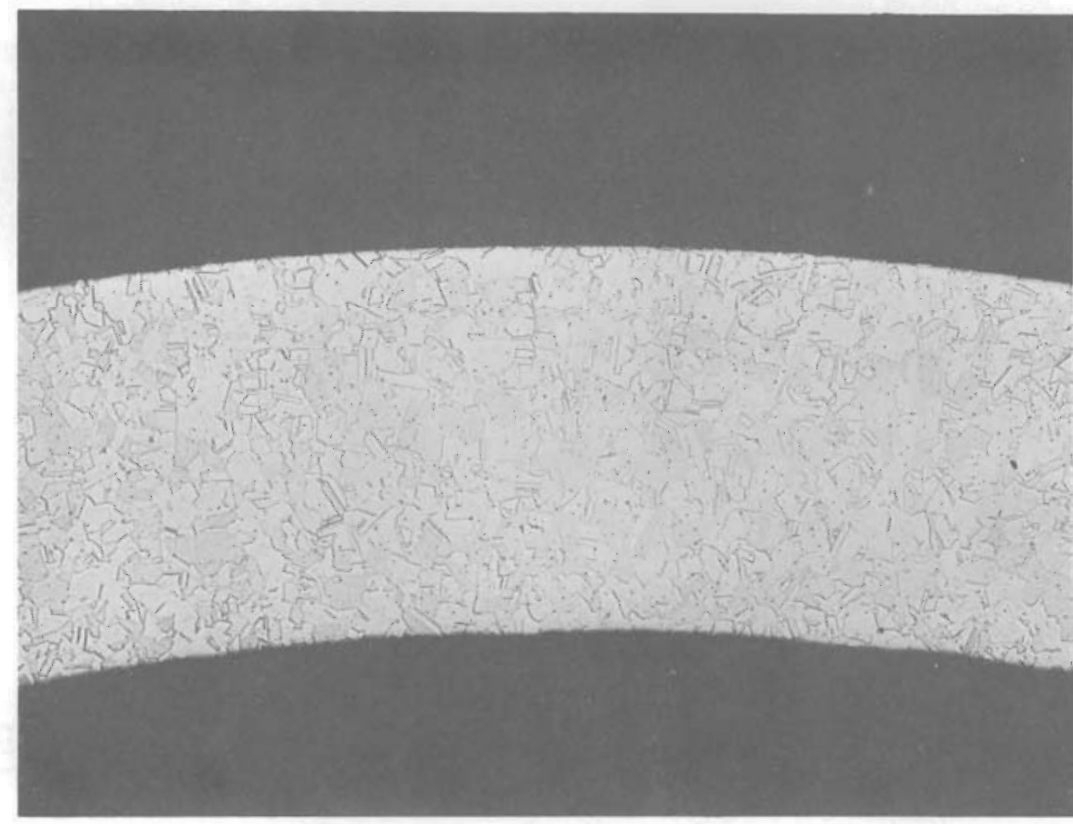

Neg 469759 A

100X

FIGURE 41. Section of Type 304 SS Tubing Archive Sample

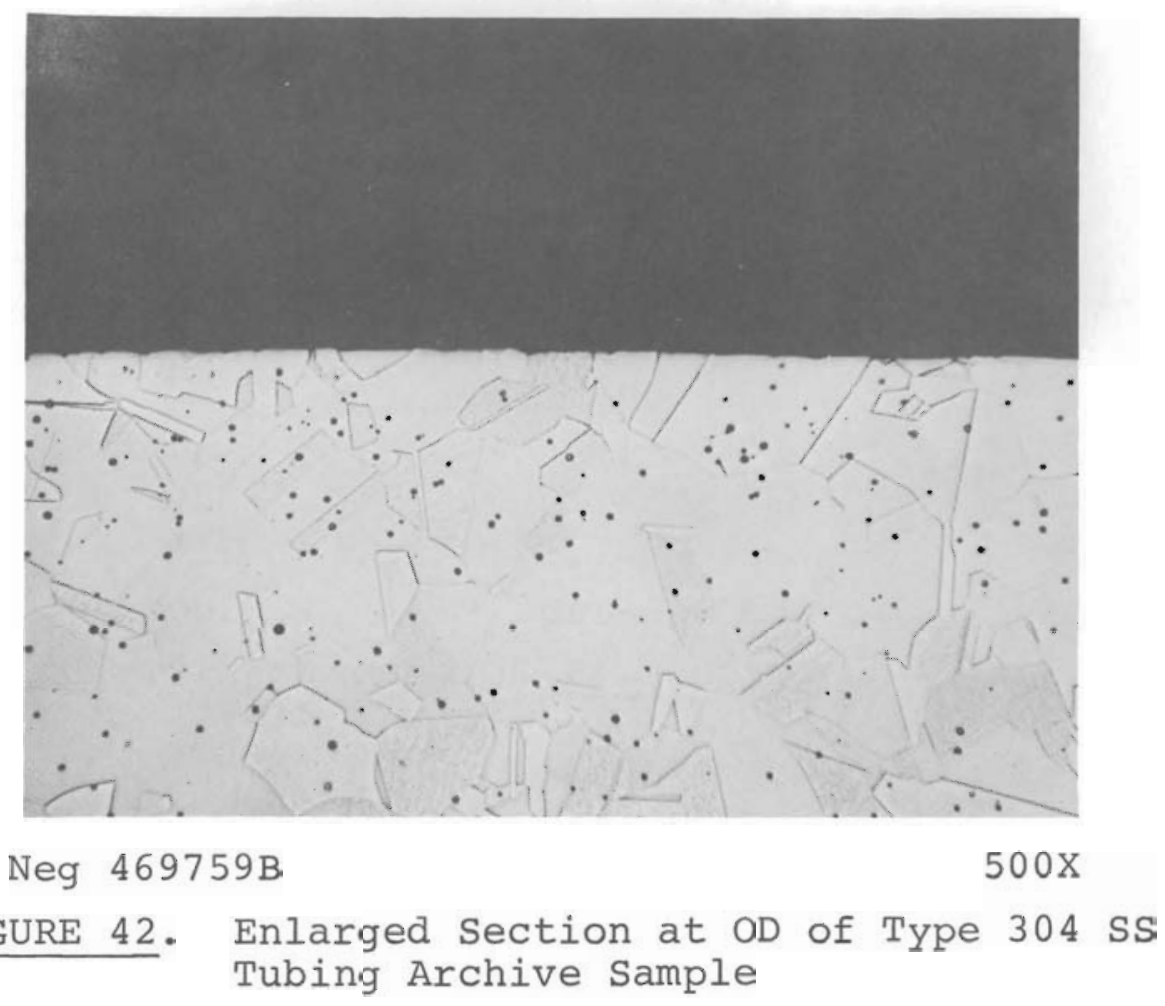



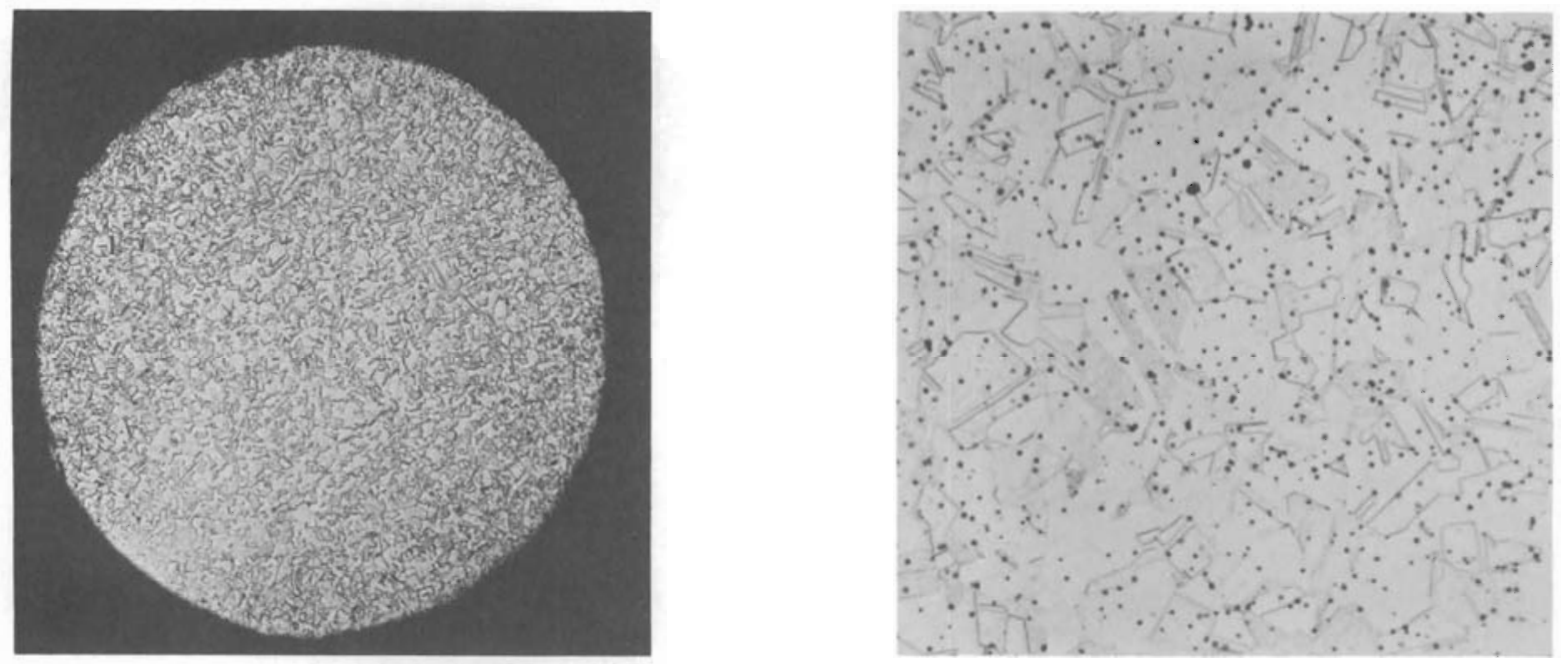

Neg 469608A

FIGURE 43 . Section of 0.030 Diameter, Type 304 SS Wire Archive Sample
Neg 469608B

\section{FIGURE 44.}

Type 304 sS Wire Wrap Archive Sample Enlarged

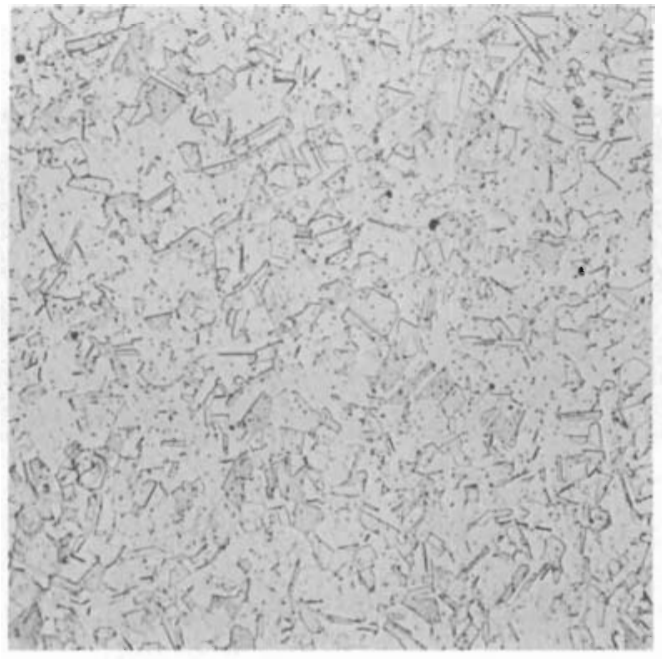

Neg $469608 \mathrm{C}$

$500 \mathrm{x}$

FIGURE 45.

Higher Magnifi-

cation of

Type 304 SS

Wire Wrap

Archive

Sample 


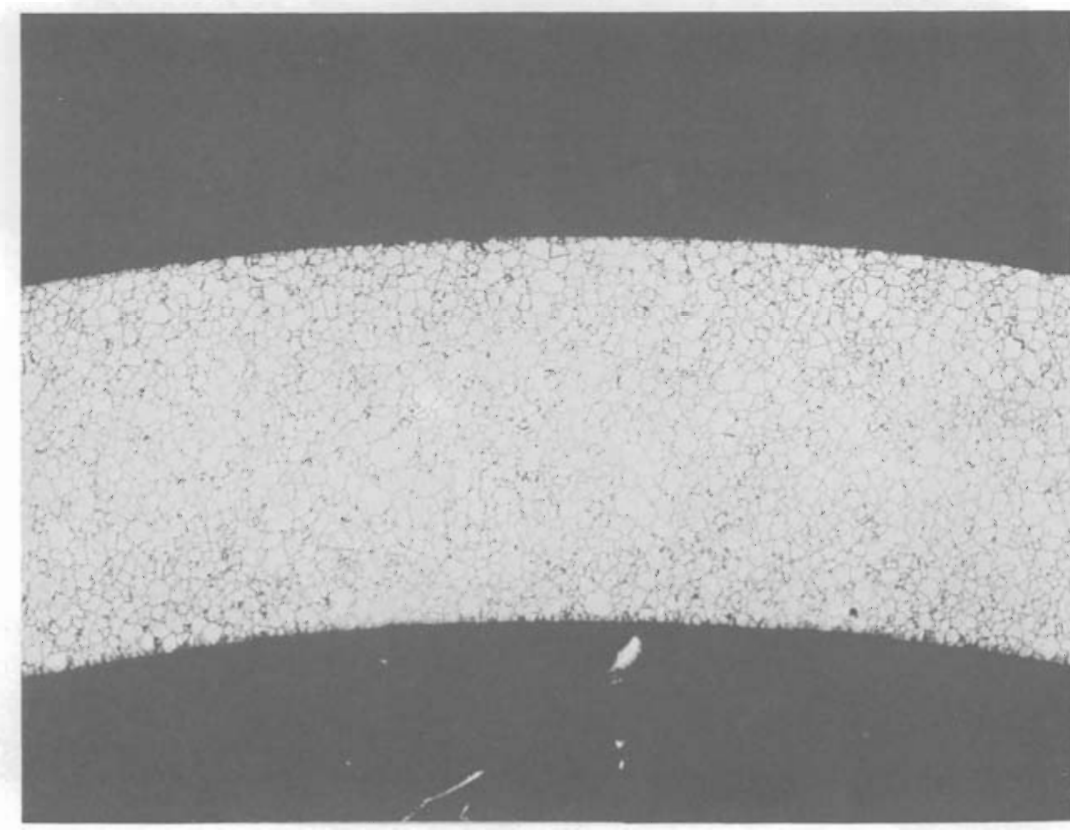

Neg $4691096 \mathrm{~A}$

FIGURE 46. Transverse Tubing Section from Plenum Region of Fuel Pin 9

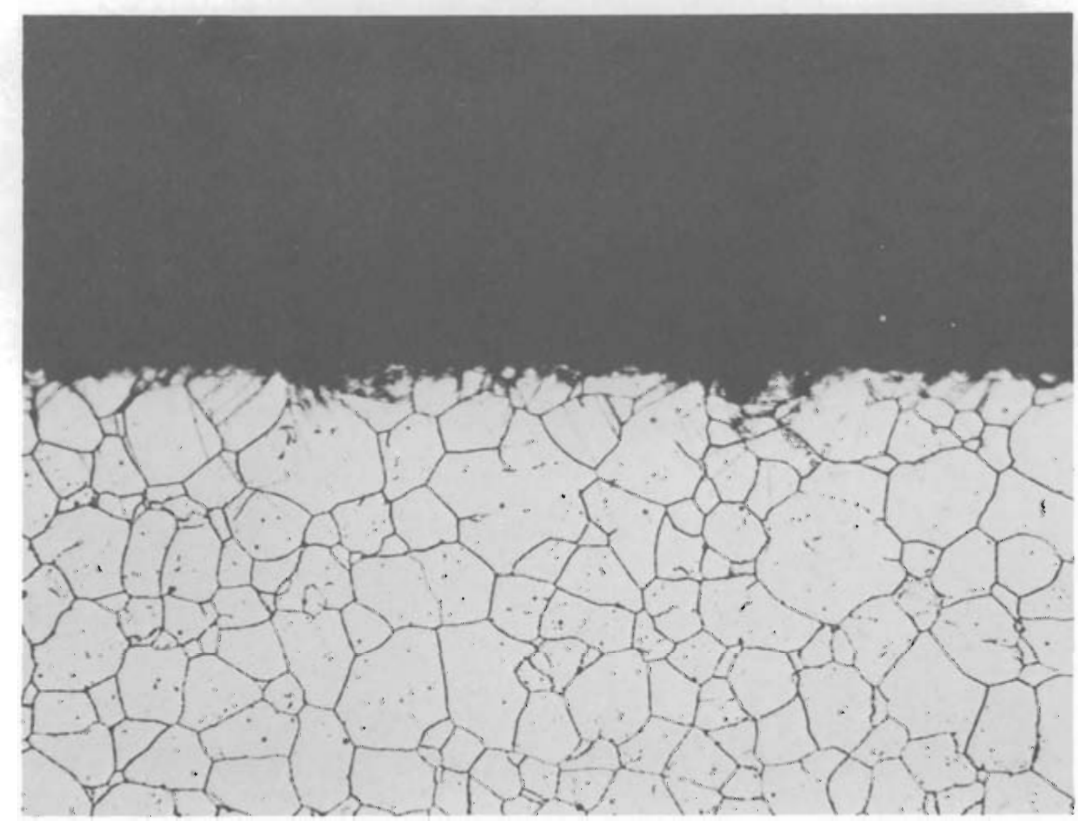

Neg $4691096 \mathrm{~B}$

FIGURE 47. Enlargement at OD of Tube Section from Pin 9 Plenum. Region 


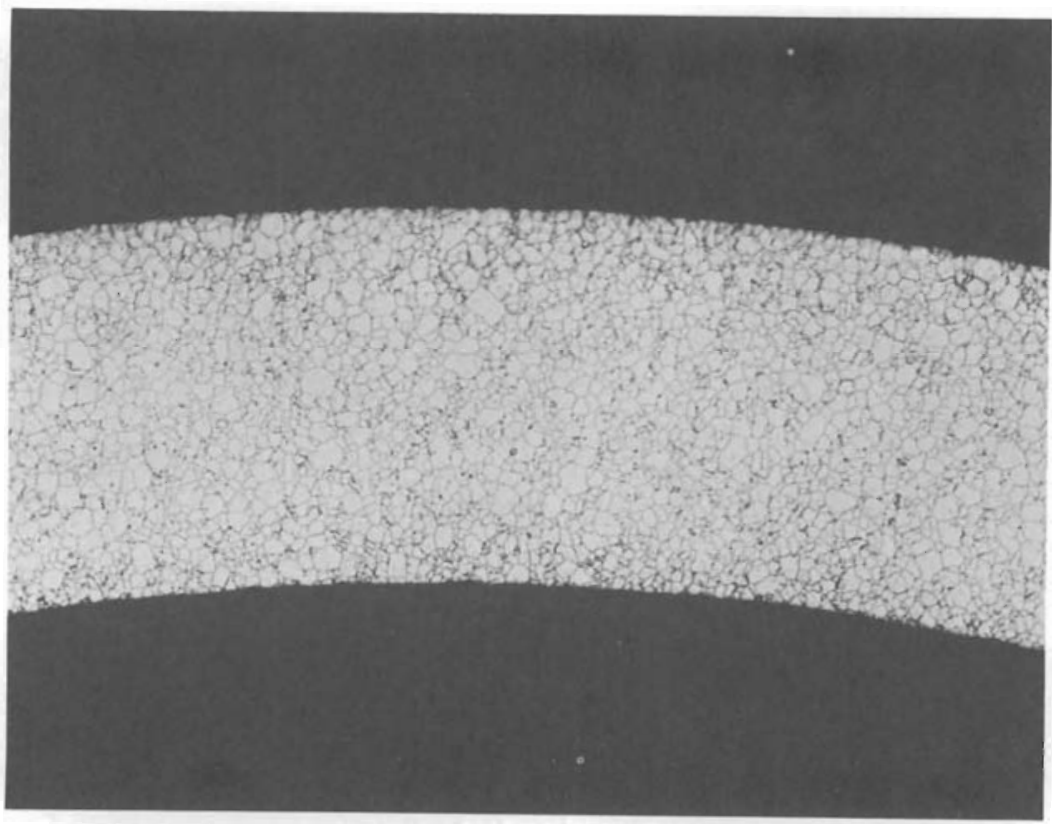

Neg 4961097 A

FIGURE 48. Transverse Tubing Section from Fueled. Region of Fuel Pin 9

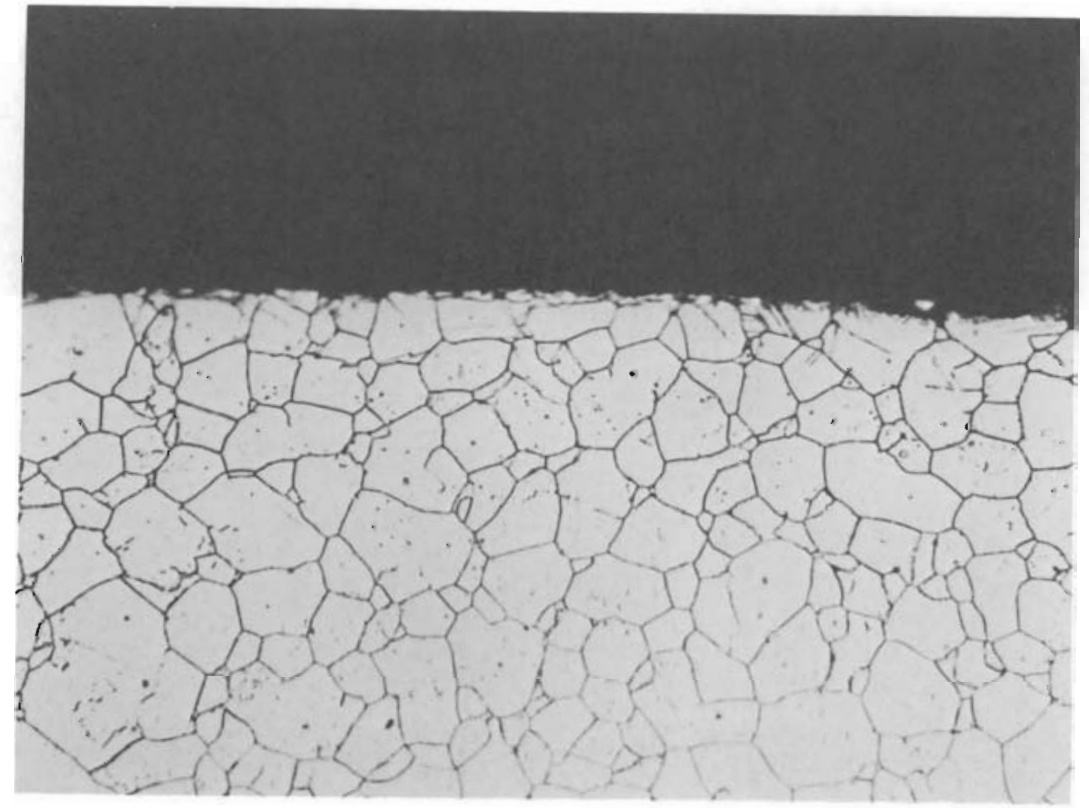

Neg $4691097 B$

$500 \mathrm{X}$

FIGURE 4.9. Enlargement at Tube OD from Fueled Region of Pin 9 
BNWL - 1261

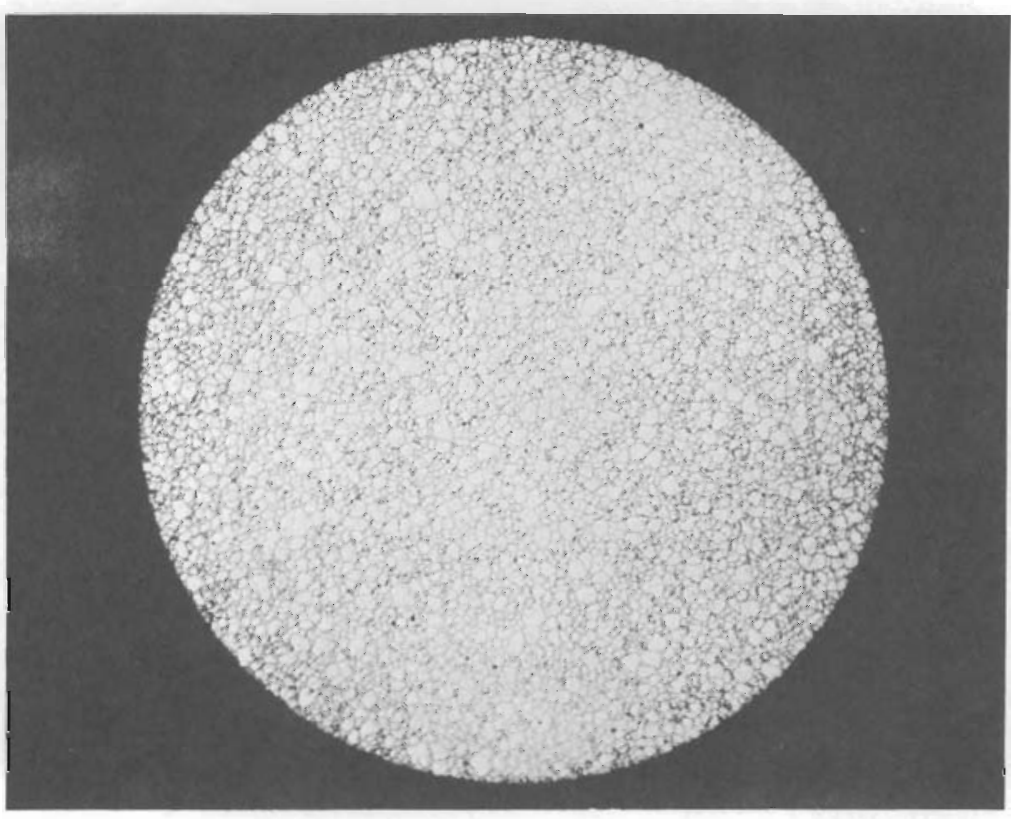

Neg $4691098 \mathrm{~A}$

$100 \mathrm{x}$

FIGURE 50. Transverse Section of Type 304 SS Wire Wrap After Test

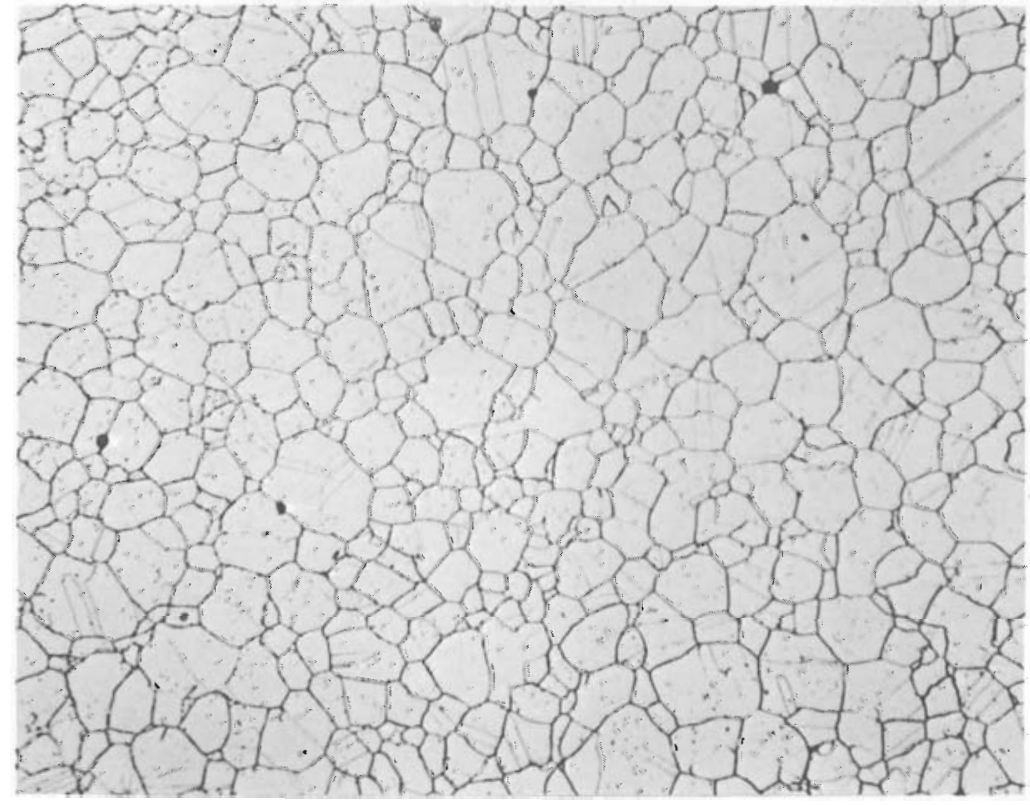

Neg 4691098B

$500 \mathrm{x}$

FIGURE 51. Enlargement of Section of Type 304 SS Wire Wrap After Test 
BNWL - 1261

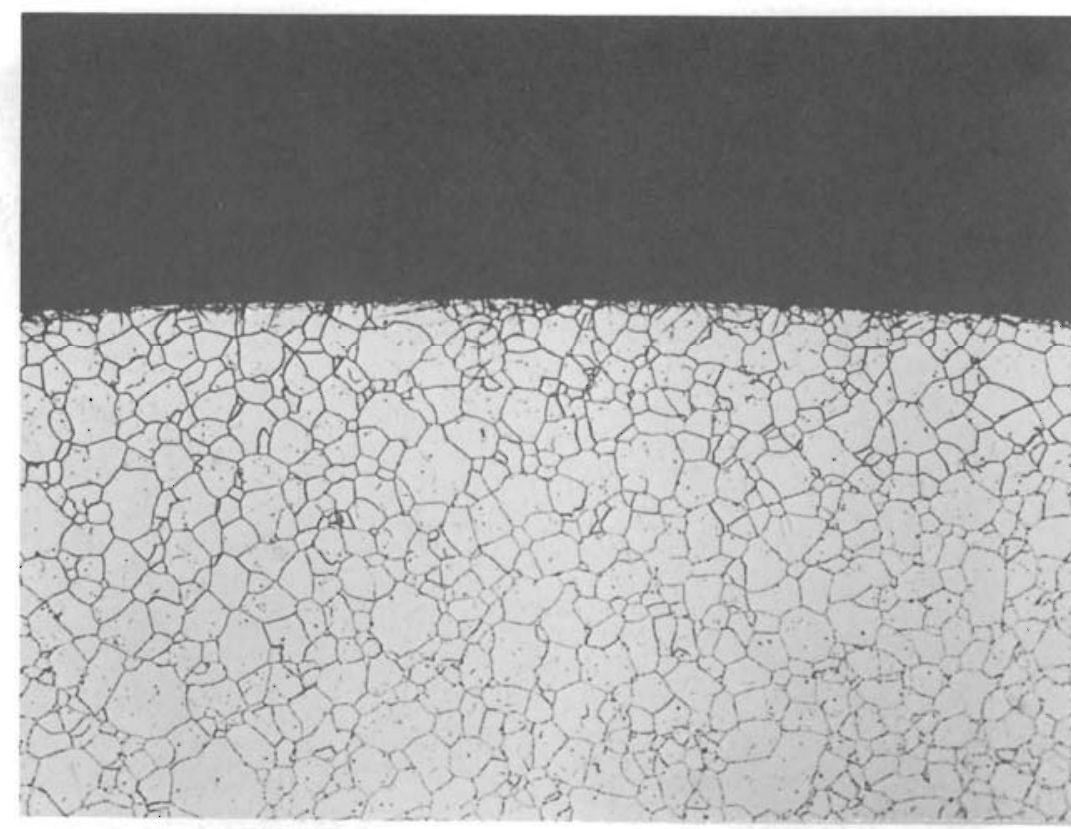

Neg 4691178A

$250 x$

FIGURE 52. Transverse Tubing Section from Pin 51 Fuel Region

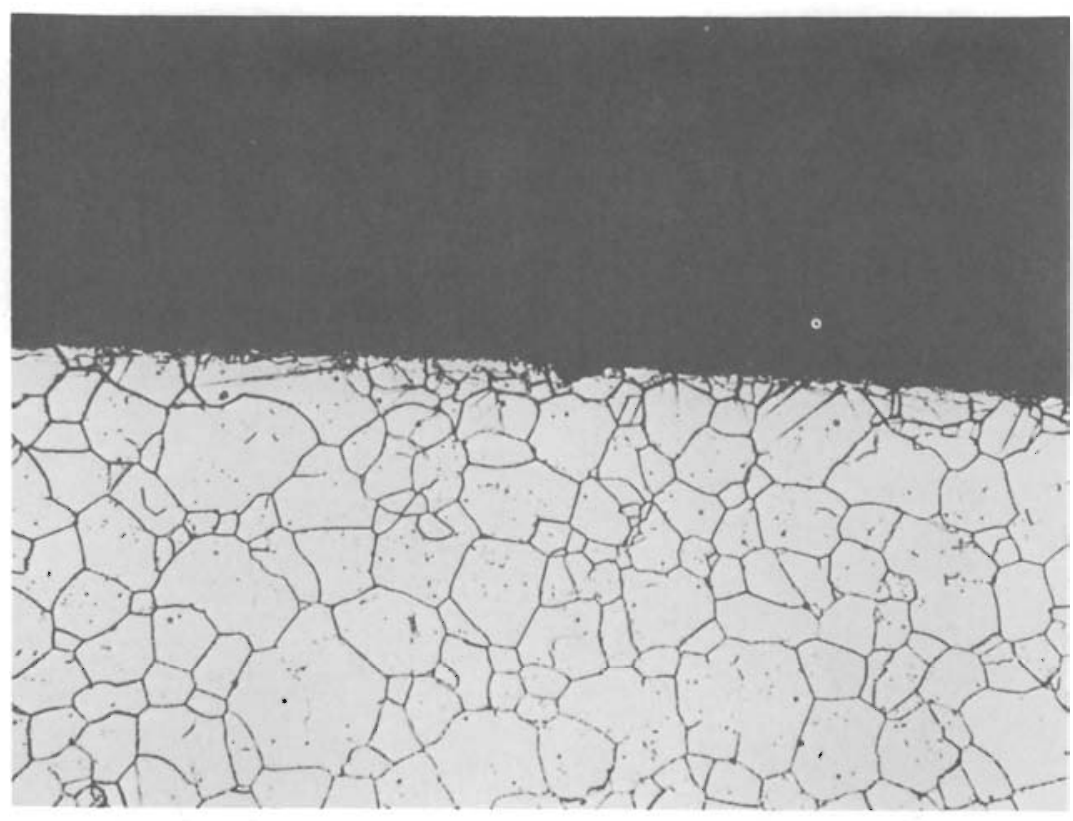

Neg 4691178B

$500 \mathrm{X}$

FIGURE 53. Enlargement of Tube Section from Pin 51 Fuel Region 


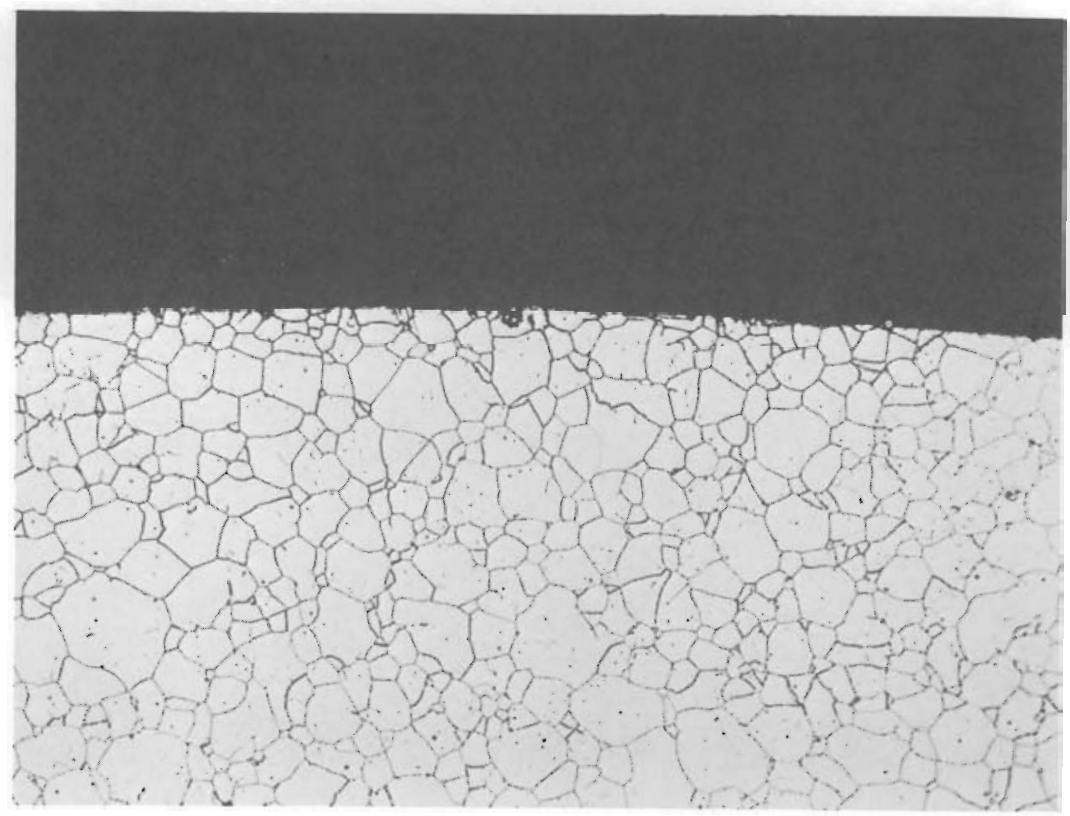

Neg 4691179A

$250 \mathrm{X}$

FIGURE 54. Transverse Tubing section from Pin 51 Plenum Region

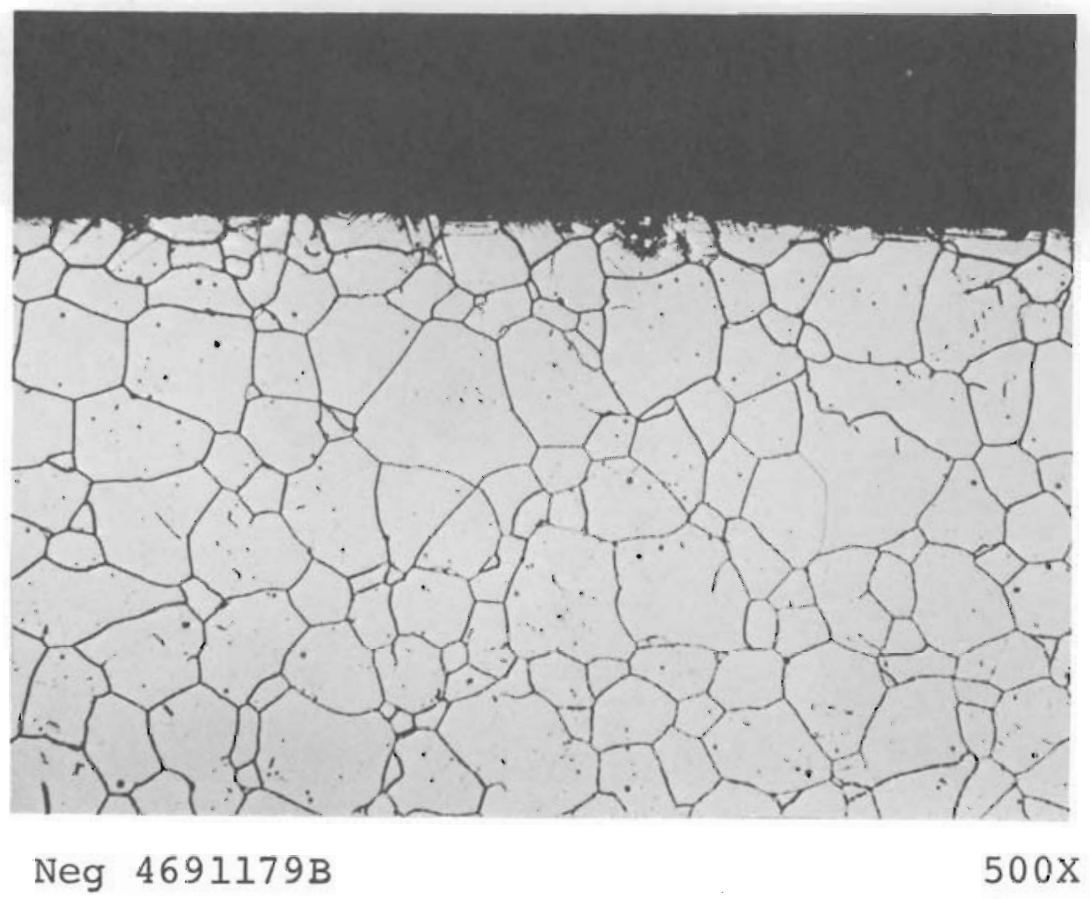

FIGURE 55. Enlargement of Tube Section from Pin 51 Plenum Region 
BNWL - 1261

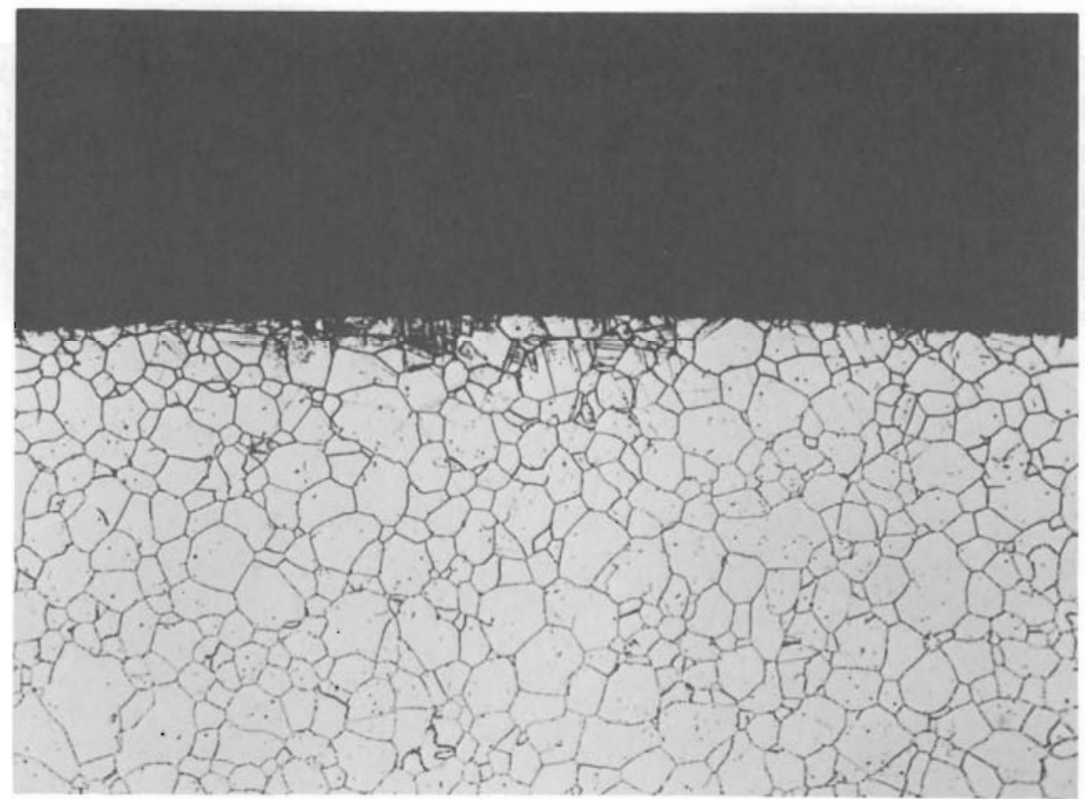

Neg 4691180A

$250 \mathrm{X}$

FIGURE 56. Transverse Tubing section from Pin 110 Fuel Region

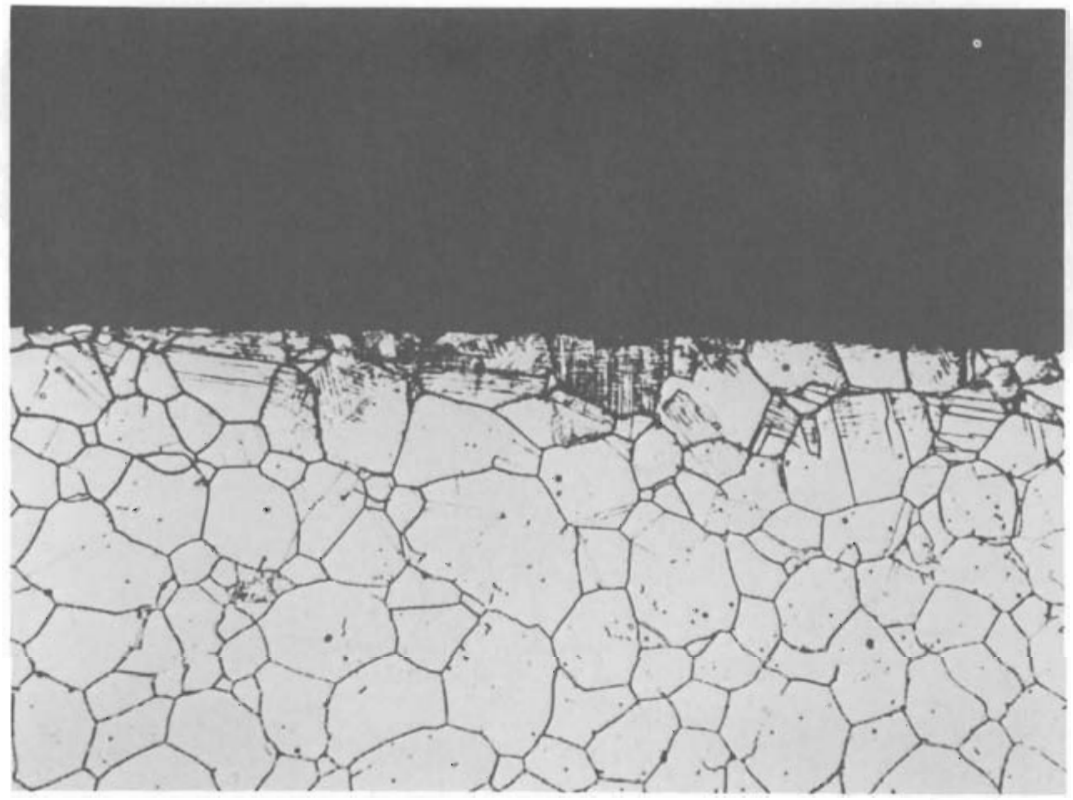

Neg $4691180 B$

$500 \mathrm{X}$

FIGURE 57. Enlargement of Tubing Section from Pin 110 Fuel Region 
BNWL- 1261

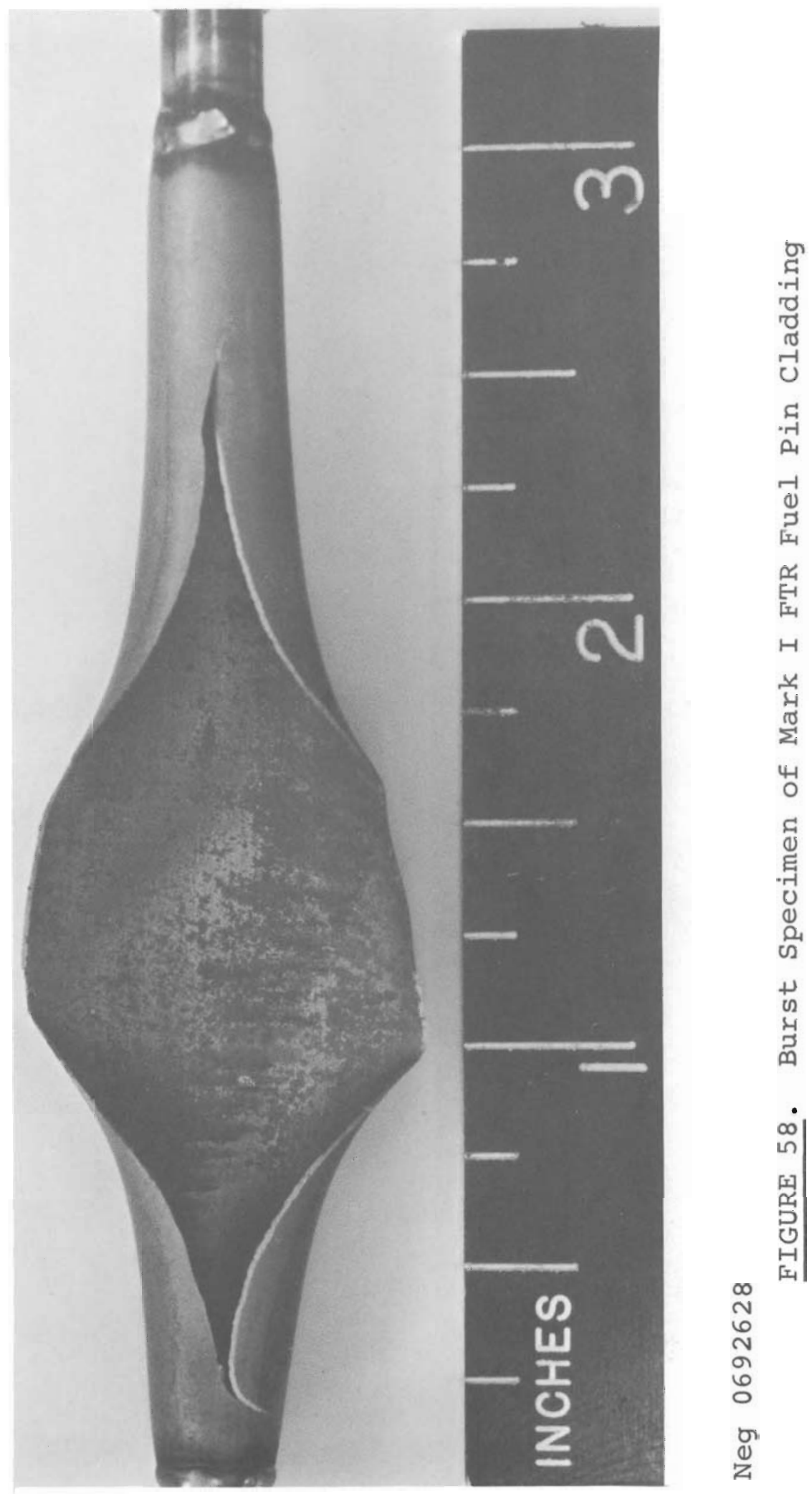




\section{ACKNOWLEDGEMENTS}

The authors wish to acknowledge the efforts of H. G. Powers, G. M. Foster, and M. P. Roper who developed the assembly procedure and equipment and performed the work at PNL. Credit for acquiring pin tubing and assembly flow ducts is largely due to the efforts of R. J. Lobsinger and $R$. Aungst.

The overall effort at Argonne National Laboratory to modify and complete the CCTL was spearheaded by R. A. Jaross, F. A. Smith and R. H. Armstrong. Successful operation of the facility was achieved under the knowledgeable leadership of F. A. Smith and E. Kimont.

L. E. Chulos of BNW extended valuable assistance during the final cleaning operation on the fuel element, while the transportation on the subassembly between sites was expedited by the efforts of D. R. Wilson. 


\section{DISTRIBUTION}

No. of

Copies

OFFSITE

1

AEC Chicago Patent Group

G. H. Lee

AEC Division of Reactor Development and Technology

M. Shaw, Director, RDT

Asst Dir for Nuclear Safety

Analysis \& Evaluation Br, RDT:NS

Environmental \& Sanitary Engrg Br, RDT:NS

Research \& Development Br, RDT:NS

Asst Dir for Plant Engrg, RDT

Facilities $\mathrm{Br}$, RDT:PE

Components $\mathrm{Br}, \mathrm{RDT}: \mathrm{PE}$

Instrumentation $\&$ Control $\mathrm{Br}$, RDT:PE

Liquid Metal Systems Br, RDT:PE

Asst Dir for Program Analysis, RDT

Asst Dir for Project Mgmt, RDT

Liquid Metals Projects Br, RDT:PM

FFTF Project Manager, RDT:PM

Asst Dir for Reactor Engrg, RDT

Control Mechanisms $\mathrm{Br}$, RDT:RE

Core Design $\mathrm{Br}$, RDT:RE

Fuel Engineering $\mathrm{Br}$, RDT:RE

Fuel Handling $\mathrm{Br}$, RDT : RE

Reactor Vesse1s Br, RDT:RE

Asst Dir for Reactor Tech, RDT

Coolant Chemistry $\mathrm{Br}$, RDT:RT

Fuel Recycle Br, RDT:RT

Fuels \& Materials $\mathrm{Br}$, RDT:RT

Reactor Physics Br, RDT:RE

Special Technology Br, RDT:RT

Asst Dir for Engrg Standards, RDT

EBR-II Project Manager, RDT:PM

AEC Division of Technical Information Extension

1 AEC Idaho Operations Office

Nuclear Technology Division

C. W. Bills, Director

1 AEC San Francisco Operations Office

Director, Reactor Division 
No. of

Copies

4

1

7

2

1

1 Combustion Engineering

1000 MWe Follow-On Study

W. P. Staker, Project Manager

1 Combustion Engineering

911 West Main St.

Chattanooga, Tennessee 37401

Mrs. Nel1 Holder, Librarian

AEC Site Representatives

Argonne National Laboratory

General Electric Co.

Westinghouse Electric Corporation

R. A. Jaross

LMFBR Program Office

N. J. Swanson

Atomic Power Development Assoc.

Document Librarian

Atomics Internationa1

FFTF Program Office

Liquid Metal Information Center

A. E. Miller (2)

Babcock \& Wilcox Co.

S. H. Esleeck

G. B. Garton

Bechte1 Corporation

BNW Representative

R. M. Fleischman (ZPPR)

J. J. Teachnor, Project Administrator, FFTF 
No. of

Copies

5

1

1
General Electric Company

Advanced Products Operation

Kar1 Cohen (3)

Nuclear Systems Programs

D. H. Ahmann

(2)

2 Gulf General Atomic Inc. General Atomic Division

D. Coburn

Idaho Nuclear Corporation

J. A. Buckham

Oak Ridge Nationa1 Laboratory

W. O. Harms

Stanford University

Nuclear Division

Division of Mechanical Engrg

R. Sher

1 United Nuclear Corporation

Research and Engineering Center

R. F. DeAngelis

Westinghouse Electric Corporation

Atomic Power Division

Advanced Reactor Systems

D. C. Spencer

ONSI TE - HANFORD

1

Bechtel Corporation

M. O. Rothwell (Richland)

1

Westinghouse Electric Corporation

R. Strzelecki (Richland)

1

AEC Chicago Patent Group

R. K. Sharp 
No. of

Copies

1

RDT Assistant Director

for Pacific Northwest Programs

T. A. Nemzek

2

AEC RDT Site Representatives

P. G. Holsted

2

AEC Richland Operations Office

J. M. Shivley

1

95

Battelle-Northwest
Batte1le Memorial Institute, Columbus

E. R. Astley

A. L. Bement

T. J. Bennett

C. A. Burgess

W. L. Chase

T. T. Claudson

J. C. Cochran

D. L. Condotta

R. L. Dillon

J. F. Erben

E. A. Evans

T. W. Evans

L. M. Finch

J. E. Hanson

P. L. Hofmann

G. A. Last

H. E. Little

W. B. McDona1d

J. S. McMahon

M. K. Millhollen (25)

R. L. Myers (10)

D. J. Oakley

L. A. Pember

R. E. Peterson

H. G. Powers

W. E. Roake

J. M. Seehuus

R. J. Squires

J. W. Thornton

E. T. Weber

J. H. Westsik 
Batte1le-Northwest (contd)
J. Wett
B. Wolfe
Legal - 703 Building
Legal - ROB, 221-A
Technical Information (5)
Technical Publications (2)
FFTF File, 703 Building (10)
FFTF TPO (List "T") 